\title{
Catalysed Hydrothermal Carbonization of Woody Biomass and Recycling of Process Liquid
}

by

Amin Ghaziaskar

\begin{abstract}
A thesis submitted to
the Faculty of Graduate and Postdoctoral Affairs in partial fulfillment of the requirements for the degree of

Master of Applied Science

in

Mechanical Engineering
\end{abstract}

Ottawa-Carleton Institute for Mechanical and Aerospace Engineering

Carleton University

Ottawa, Ontario

(C) 2018, Amin Ghaziaskar 


\begin{abstract}
The research introduces catalysed hydrothermal carbonization (CHTC) as a treatment method for woody biomass to produce solid hydrochar as well as value-added compounds (VACs). The hydrochar had higher heating values (HHV) of $28.3 \mathrm{MJ} / \mathrm{kg}$ and $\mathrm{H} / \mathrm{C}$ and $\mathrm{O} / \mathrm{C}$ ratios similar to coal, when using the liquid:biomass (L:B) ratio of 12:1 for the process. Densified CHTC hydrochar pellets were $97 \%$ durable, and hydrophobic when compared with wood pellets and torrefied wood pellets. CHTC has the potential to produce VACs such as glycolic acid, formic acid, acetic acid, levulinic acid, 5-hydroxymethylfurfural, and furfural, from the process liquid effluent. Recycling the process liquid at $\mathrm{L}: \mathrm{B}$ of 5:1 increased the concentration of the VACs and energy yield of the hydrochar. The production yields of the VACs were dependent upon the L:B ratios, they increased parallel with $\mathrm{L}: \mathrm{B}$ ratios.
\end{abstract}




\section{Preface}

The following thesis is a combination of two separate journal articles. I was fully involved in setting up and conducting the research, obtaining data and analyzing results, as well as preparing and writing the material presented in the co-authored articles integrated into this thesis. 


\section{Acknowledgements}

Glenn A. McRae

Onita D. Basu

Edward P. Lai

Alexis Mackintosh

Maia P. Gill

Kafeel Kamal

Tony O’Neil

Geoff Seater

Marie Tudoret

Guy Tourigny

Margaret A. Knowling

Neelesh Bhadwal

Airex Energy 


\section{Table of Contents}

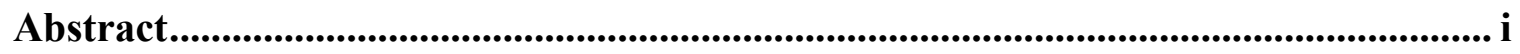

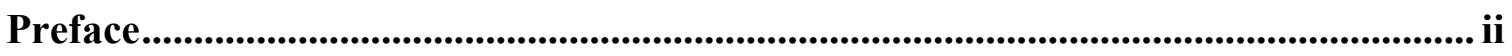

Acknowledgements ........................................................................................................ iii

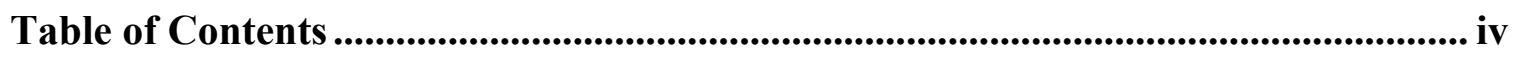

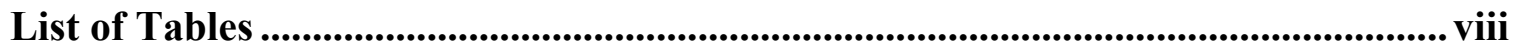

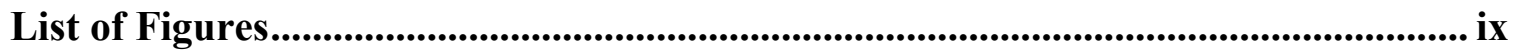

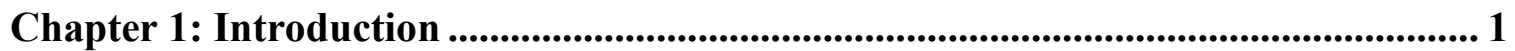

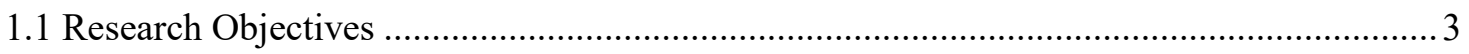

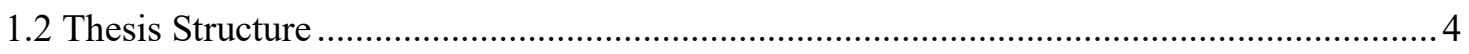

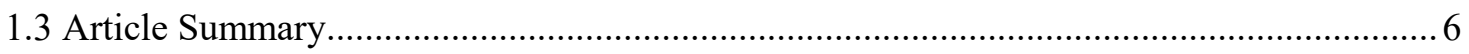

Chapter 2: Literature Review ........................................................................... 8

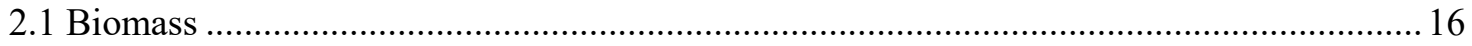

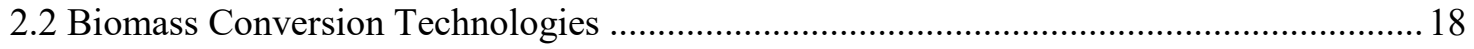

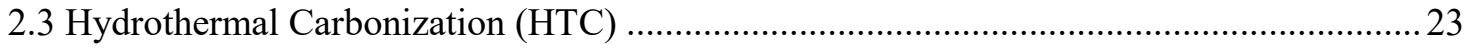

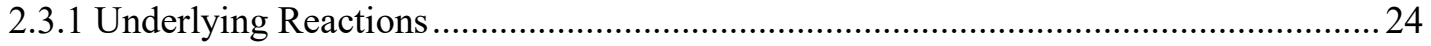

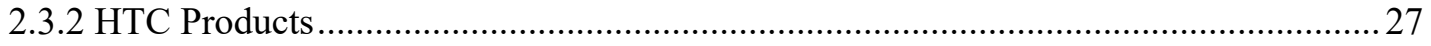

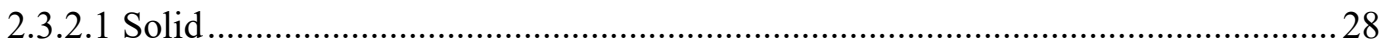

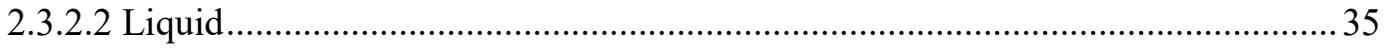

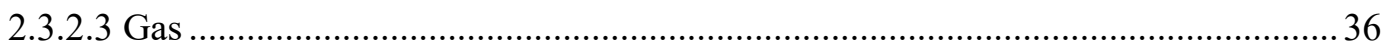

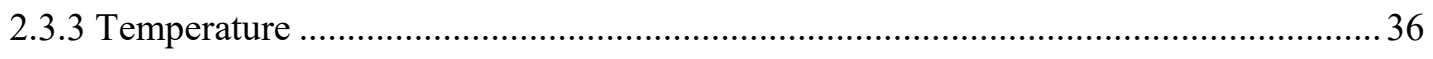

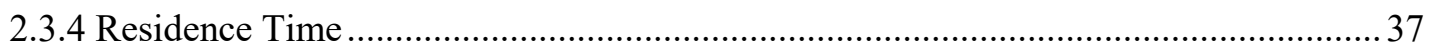

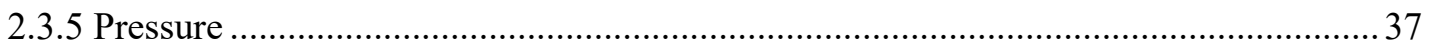




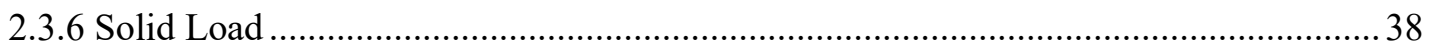

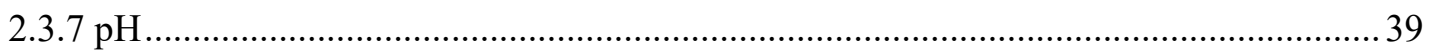

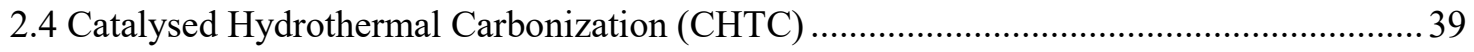

\section{Chapter 3: Catalysed Hydrothermal Carbonization with Process Liquid Recycling}

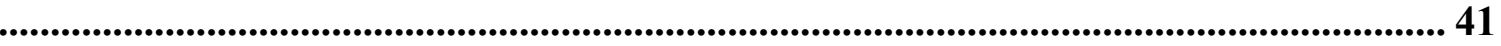

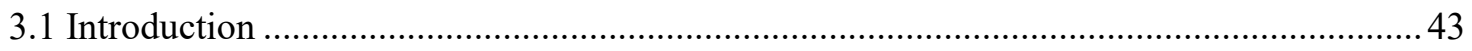

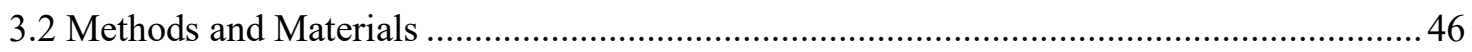

3.2.1 Catalysed Hydrothermal Carbonization (CHTC) …................................................ 46

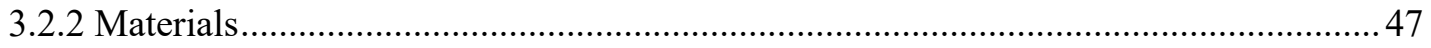

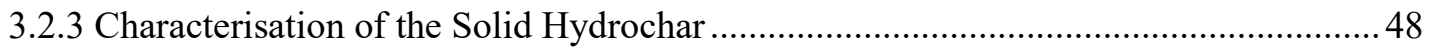

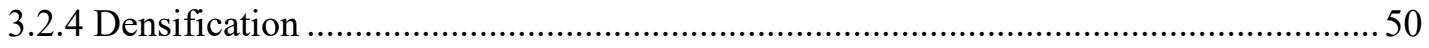

3.2.5 Mechanical Strength of Hydrochar Pellets...............................................................5 50

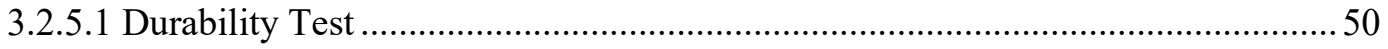

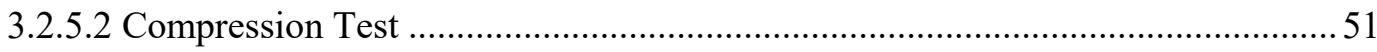

3.2.5.3 Electrochemical water ingress (EWI) test.........................................................52

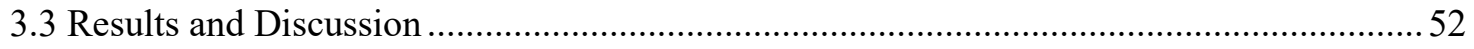

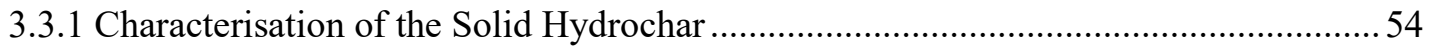

3.3.1.1 Influence of Process Liquid Recycling on Atomic Ratios $(\mathrm{H} / \mathrm{C}-\mathrm{O} / \mathrm{C})$ of the

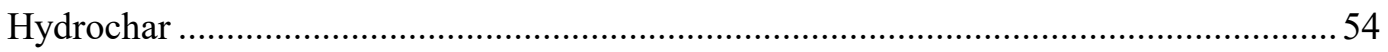

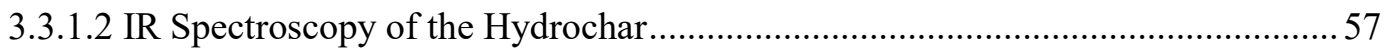

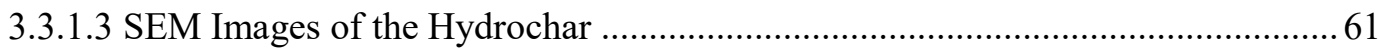

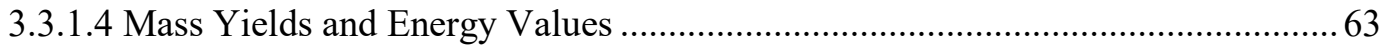

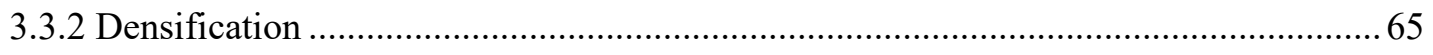

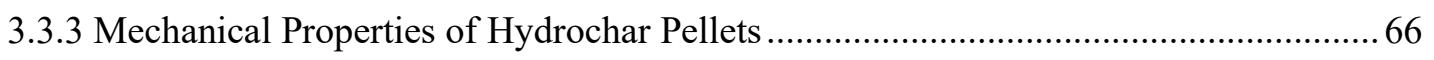

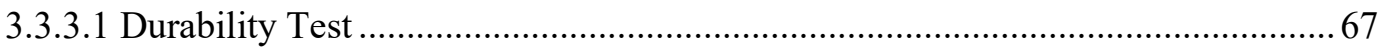




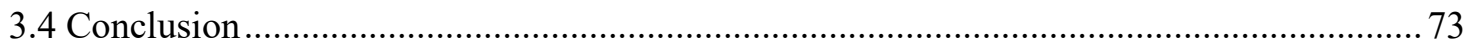

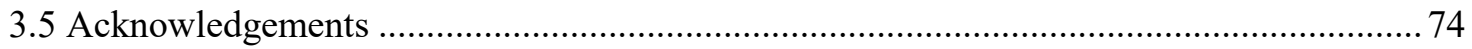

Chapter 4: Production of Organic Compounds through Recycling the Process Liquid of Catalysed Hydrothermal Carbonization ............................................................. 75

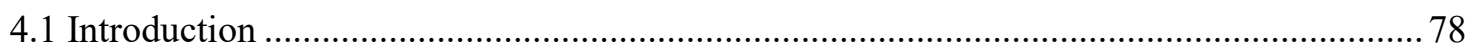

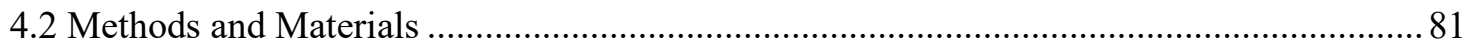

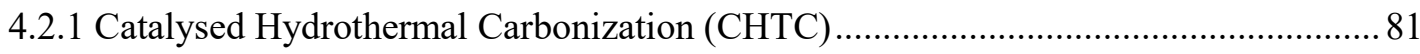

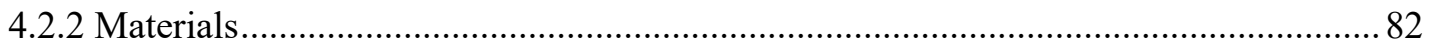

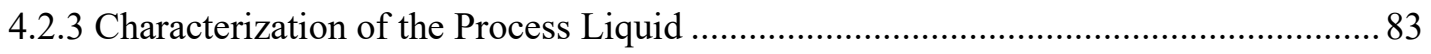

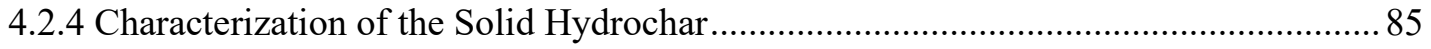

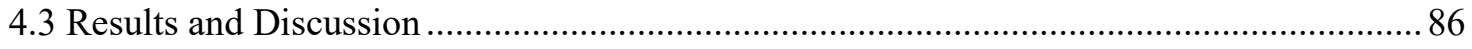

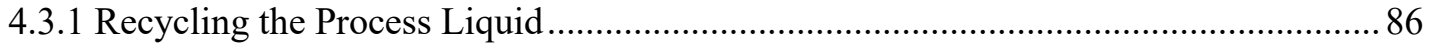

4.3.2 Effects of L:B Ratio on the VAC Concentrations and Hydrochar ............................. 93

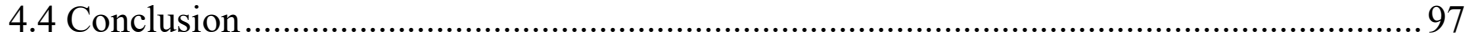

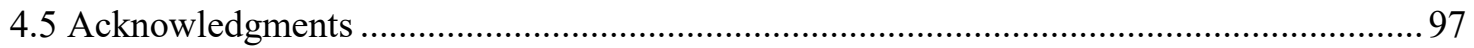

Chapter 5: Challenges and the Future .......................................................................... 98

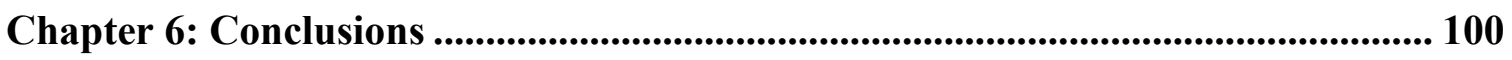

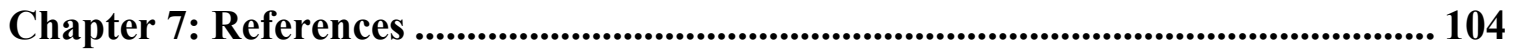

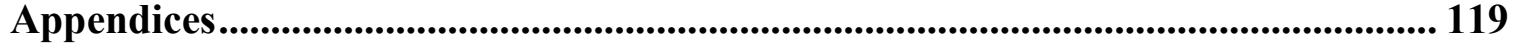

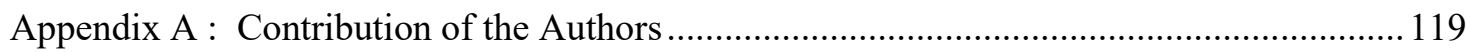

Appendix B : Hydrothermal Carbonization of Woody Biomass ........................................ 121

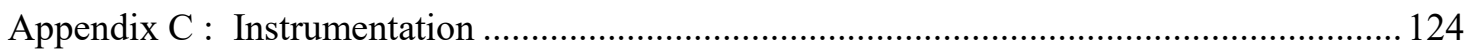

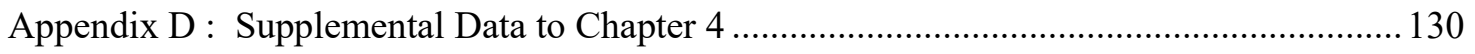




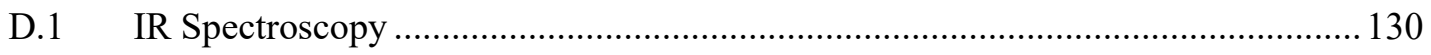

D.2 SEM Images of the Hydrochar and the Biomass ................................................ 134

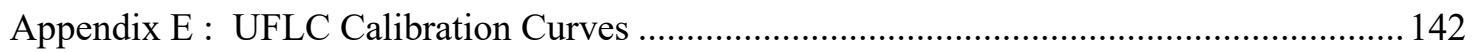




\section{List of Tables}

Table 2-1: Functional groups found in the biomass with their corresponding wavenumber.

Data gathered by Reza et al. [55]. 30

Table 3-1 Elemental composition (on dry basis, \% mass) of the biomass and hydrochar, energy content, energy densification ratio, and energy yield, (uncertainties in measurements are in units of least significant figures unless otherwise noted). ${ }^{1}$ 56

Table 3-2 Durability of the hydrochar pellets with pressure. Durability estimates were similar for pellets made with pressures $\geq 135 \mathrm{MPa}$, but dropped by $\approx 2 \%$ when the pressure was reduced to $70 \mathrm{MPa}$. 68

Table 3-3: Compressive strength of densified hydrochar pellets with densification pressure. The densification pressure was found to affect the compressive strength of the pellets while recycling the process liquid did not.

Table 4-1 Higher heating value (HHV) and compositional analysis of the woody biomass on a dry basis. 83

Table 4-2 Mass yield, HHV, energy densification ratio, and compositional analysis (weight percentages on dry basis) of the hydrochar after recycling the process liquid 15 times with

$\mathrm{L}: \mathrm{B}$ ratio of $5: 1$ 90

Table 4-3 Compositional analysis (dry basis weight percentages) of the hydrochar made with different L:B ratios through CHTC process. 95 


\section{List of Figures}

Figure 2-1: Fast carbon cycle in between land, atmosphere and the ocean. The values are in gigatons of carbon per year. Yellow coloured numbers show neutral fluxes of carbon, while white coloured numbers show the stored carbon. The red coloured numbers show human contributions to the cycle every year [13] .................................................... 9

Figure 2-2: Total anthropogenic GHG emissions (GtCO2eq / yr) by economic sectors in 2010, which totals to $49 \mathrm{GtCO}_{2} \mathrm{eq} / \mathrm{yr}$. AFOLU includes land-based $\mathrm{CO} 2$ emissions from

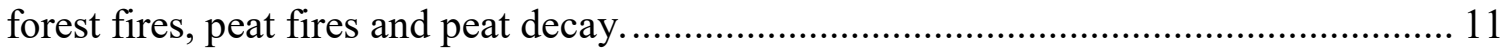

Figure 2-3: Global energy-related $\mathrm{CO}_{2}$ emissions [16]. The data from international energy agency (IEA), shown in the figure, include all the energy-related $\mathrm{CO}_{2}$ emissions from the

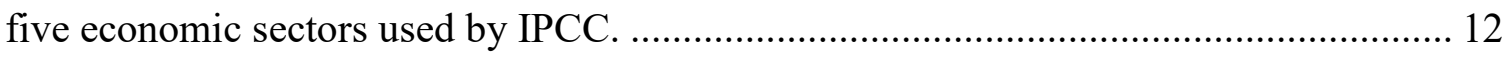

Figure 2-4: Different biomass conversion technologies, specifically thermochemical conversions. The processes are connected to the product forms each produce. Carbonization, liquefaction, and gasification can be both thermal and hydrothermal. .... 19

Figure 2-5: Different hydrothermal processes separated according to their required temperature range on a water phase diagram. The major products of each process are written in parentheses. The figure is an adaptation from the work of Kambo et al. [42]. 22 Figure 2-6: Products of hydrothermal carbonization (HTC) separated according to their phases (i.e., gas, liquid, hydrochar solid) [1] ........................................................... 23

Figure 2-7: Hydrolysis of cellulose into oligosaccharides and glucose components [49].

Figure 2-8: Chemical pathways for biomass components after decomposition [50]...... 27 
Figure 2-9: Products and possible applications of HTC [53]. 28

Figure 2-10: Infrared spectra of initial biomass and final hydrochar after treatment at 240 ${ }^{\circ} \mathrm{C}$. 29

Figure 2-11: Van Krevelen diagram of HTC hydrochar produced with different conditions and from different biomass types [42]. 31

Figure 3-1: Percentage ratio of make-up catalyst solution (Catalyst) to recovered process liquid (Process liquid) used in 15 recycle experiments (stacked columns), circles show pH of the liquid biomass mixture prior to start of the process (initial $\mathrm{pH}$ ), and diamonds show $\mathrm{pH}$ of the process liquid after CHTC (final $\mathrm{pH}$ ). 53 Figure 3-2: Van Krevelen diagram showing atomic ratios of the feedstock biomass and the hydrochar samples. The dehydration and decarboxylation reactions are enhanced by the catalyst producing $\mathrm{CHTC}$ hydrochar with $\mathrm{H} / \mathrm{C}$ and $\mathrm{O} / \mathrm{C}$ ratios that fall in the region where lignite and coal overlap. The $\mathrm{H} / \mathrm{C}$ and $\mathrm{O} / \mathrm{C}$ ratios of the hydrochar do not vary significantly with recycling. The hydrochar produced without catalyst (HTC), but otherwise identical processing conditions, falls within the lignite region of the diagram, shown by the blue square. 57

Figure 3-3: IR spectra of raw biomass, Fresh, and R15. The spectra of the hydrochars were similar, but different when compared with the spectra of the feedstock biomass. 60 Figure 3-4: SEM images: (a, b) feedstock biomass showing fibrous structure; $(c, d)$ spherical structure of the hydrochar from fresh catalyst solution (Fresh); (e, f) porous structure of the hydrochar R1; (g, h) R15 showing spherical and porous structure. The 
images of the hydrochar were indistinguishable, but different from the feedstock biomass.

Figure 3-5: Higher Heating Value (HHV), mass and energy yield of the hydrochar samples. The mass yield increased by 2.7 percentage points for R1 compared with the initial process, which was done using only the catalyst solution as the starting liquid phase (Fresh). Energy yield increased from $64 \%$ (Fresh) to an average of $(68.6 \pm 1) \%$ for R1 to R15. The HHV is essentially unchanged for all the recycles.

Figure 3-6: Average density and energy density of pellets made at four different pressures. The density did not change after increasing the compression from $135 \mathrm{MPa}$ to $155 \mathrm{MPa}$. The energy density reached $30 \mathrm{GJ} / \mathrm{m}^{3}$ at a density of $1070 \pm 30 \mathrm{~kg} / \mathrm{m}^{3}$. 66

Figure 3-7: Current through an electrochemical cell with pellet electrodes made of hydrochar, wood, and torrefied wood. The wood disintegrated after a few minutes. Torrefied wood increased $42 \%$ in mass after $24 \mathrm{~h}$ in the electrolyte. The small currents observed for hydrochar pellets suggests much less water ingress. 72

Figure 3-8: Pictures of the pellets used in the EWI tests when they were first immersed in the electrolyte (time $=0)$ and later at the times indicated. The hydrochar pellets showed no visible indications of breakdown products in the electrolyte, they maintained their shape and passed low currents throughout the tests, as shown in Figure 3-7.

Figure 4-1: (a) VAC concentrations and (b) HHV, mass yield, and energy yield of the hydrochar produced after recycling the CHTC process liquid, at 5:1 L:B ratio. 87 Figure 4-2: The sum of AA, GA, and LA concentrations, represented as data and the fitted model 89 
Figure 4-3: (a) Concentration of VACs in the process liquid after using different L:B ratios with CHTC and (b) production yield of the VACs with respect to dry weight of the biomass

used. . 94 


\section{Chapter 1: Introduction}

Biomass is a renewable source of energy, which can supplement or at best replace the fossil fuels such as coal. However, this task can be challenging depending on the properties of the biomass e.g., moisture content, energy value, uniformity, biological conditions.

Different treatment methods and processes are currently being used to convert biomass into a more stable source of energy to prevent further decomposition of the biomass, which results in the release of green house gases (GHGs) such as carbon dioxide $\left(\mathrm{CO}_{2}\right)$ and methane $\left(\mathrm{CH}_{4}\right)$ into the atmosphere. Hydrothermal carbonization (HTC), as one of the methods that convert biomass into a more energy dense fuel (i.e., hydrochar) has recently been getting attention from researchers, environmentalists, and the industries that use coal as their source of energy. This process uses water to breakdown the chemical structure of the biomass through hydrolysis; therefore, it can treat the biomass that is already wet and can decompose into GHGs.

HTC has the potential to produce a wide range of products in the form of gas, liquid, and solid. Although the main product of the process is recognized as hydrochar in the form of a solid, the output gases and the process liquid can be used to maximize its productivity. The gases produced throughout the 
process include $\mathrm{H}_{2}, \mathrm{CO}_{2}$, and $\mathrm{CH}_{4}$, while the process liquid carries various valuable organic compounds such as furfural, 5-hydroxymethylfurfural, and levulinic acid. These compounds can potentially be harvested in order to add value to the process.

Several operating conditions of the HTC process, such as temperature, time, and liquid:biomass ratio, have been found to affect the production yields and characteristics of the hydrochar, gases, and other organic compounds in the liquid [1]. The addition of acidic and basic compounds to the process liquid ( $\mathrm{pH}$ adjustment) has been shown to improve the quality of the hydrochar, e.g., higher heating value (HHV) and increased carbon content [1]-[3].

Catalysed hydrothermal carbonization (CHTC) of biomass is similar to HTC except for the use of an acidic catalyst, which is added to the process liquid [4]. This process can potentially produce a hydrochar with increased HHVs and concentrations of organic compounds in the process liquid after biomass treatment compared with HTC.

One of the challenges in operating the HTC and CHTC processes is the use of water, which can negatively affect the sustainability of the process. To overcome this challenge, recycling the process liquid has been performed for the HTC process [5]. Recycling the process liquid increases the mass yield, 
improves the HHV of the hydrochar, and changes the concentrations of organic compounds in the process liquid [5]-[8].

Consideration of operating time and temperature of CHTC is also at great importance; however, studying the possibilities of recycling of process liquid and changing the volume of the liquid used for the process can be more advantageous. The main portion of the CHTC system, which requires the most heat for temperature increase, has been identified to be water. Increasing the

temperature from approximately $24{ }^{\circ} \mathrm{C}$ to boiling temperatures of $100{ }^{\circ} \mathrm{C}$ is also more energy intensive compared with keeping the operation near temperatures of $200-300{ }^{\circ} \mathrm{C}$. Lowering the overall volume of the liquid used in the process and hot recycling of process liquid can cause tremendous energy savings regardless of what the operating time and temperatures are.

\subsection{Research Objectives}

This thesis mainly studies the effects of recycling the proprietary catalyst used for the CHTC process on a wide range of parameters such as the mass yield, energy content, elemental composition, compressibility of the hydrochar, water absorptivity of the pellets made from the hydrochar, and composition of the process liquid (effluent). In addition, the liquid:biomass ratio used for CHTC is optimized in order to decrease the amount of energy 
used for the CHTC process while preventing any loss in the quality of the hydrochar.

The objectives of this thesis can be summarized into the following:

I. Study the effects of partial recycling of the CHTC process liquid on the physical characteristics of the hydrochar.

II. Study the effects of full recycling of the CHTC process liquid on the chemical characteristics of the liquid effluent.

III. Study the effects of the liquid:biomass ratio on the hydrochar and process liquid effluent of the CHTC process.

\subsection{Thesis Structure}

Chapter 1: an introduction to the HTC of biomass, CHTC, and defining the objectives of the thesis

Chapter 2: a review on the research done in the field of biomass treatment, specifically HTC

Chapter 3 (Submitted, under revision): introduces CHTC of woody biomass, while focusing on partially recycling the process liquid used for CHTC 
processes. Furthermore, the physical-chemical properties of the hydrochar are presented and discussed.

Chapter 4 (Planned submission): presents full recycling of the CHTC process liquid while studying its effects on the hydrochar and the concentration of some Value-Added Compounds (VACs). Discusses the effects of the liquid:biomass ratio on the concentration of the VACs and the properties of the hydrochar.

Chapter 5: presents challenges to further study of the CHTC process and future work needed to be done.

Chapter 6: summarizes the research work with a focus on the significant conclusions.

Appendix A: presents the contributions of the authors to the articles

Appendix B: presents the results of a set of controlled experiments done to compare the HTC process with the CHTC, which includes the properties of the hydrochar and the process liquid.

Appendix C: presents images of the instruments used throughout this research. 
Appendix D: presents the supplemental data to Chapter 4 .

Appendix E: presents the calibration curves used for determining the chemical concentrations in the process liquid using Ultra Fast Liquid Chromatography (UFLC).

\subsection{Article Summary}

Article 1: Catalysed Hydrothermal Carbonization with Process Liquid Recycling

Authors: Amin Ghaziaskar ${ }^{1}$, Glenn A. McRae ${ }^{1}$, Alexis Mackintosh ${ }^{2}$, Onita D. $\mathrm{Basu}^{3}$

Submitted to: Journal of Energy and Fuels

1Department of Mechanical and Aerospace Engineering, Carleton University, Canada, K1S 5B6

2PCS Technologies Inc., Vancouver, Canada

${ }^{3}$ Department of Civil and Environmental Engineering, Carleton University, Canada, K1S 5B6 
Article 2: Production of Organic Compounds Through Recycling the Process Liquid of Catalysed Hydrothermal Carbonization of Lignocellulosic Biomass

Authors: Amin Ghaziaskar ${ }^{1}$, Glenn A. McRae ${ }^{1}$, Alexis Mackintosh ${ }^{2}$, Edward P.C. Lai ${ }^{3}$, Onita Basu ${ }^{4}$

Planned submission to: Journal of Bioresource Technology

1Department of Mechanical and Aerospace Engineering, Carleton University, Canada, K1S 5B6

${ }^{2}$ PCS Technologies Inc., Vancouver, Canada

${ }^{3}$ Department of Chemistry, Carleton University, Canada, K1S 5B6

${ }^{4}$ Department of Civil and Environmental Engineering, Carleton University, Canada, K1S 5B6 


\section{Chapter 2: Literature Review}

Climate change has significantly impacted our surrounding environment. Glaciers are melting, which has resulted in the rise of sea level. Drought in different parts of the world such as South Africa, the middle east, and USA have been more prevalent [9]. Recent years have been the warmest on record with the years 2016,2015 , and 2017 being the $1^{\text {st }}, 2^{\text {nd }}$, and $3^{\text {rd }}$, respectively, while it is speculated that 2018 will be the $4^{\text {th }}[10] . \quad$ Life- $^{-}$ threatening natural events such as hurricanes and tsunamis have become frequent for regions across the world. The role of human beings in climate change is evident; a group of 1300 independent scientists from all over the world have concluded that there is a $95 \%$ probability that human activities over only the last 50 years have increased the overall temperature of the planet [11]. In context, our industrial activities have increased the atmospheric carbon dioxide levels from 280 parts per million to over 400 parts per million in the last 150 years [11].

Climate change has caused fire seasons in Canada to start earlier, and to last longer. Extreme forest fires have been occurring in Canada in the past few years. On average, Canada faces 7500 fires a year, which on average have burned 2.4 million ha per year, since 1990 [12]. However, 2015, with 7140 fire incidents that burned 3.9 million ha, was the third year in a row with above 
average area burned [12]. Furthermore, large fires with extreme consequences can happen even in years with lower averages of fire occurrences.

Figure 2-1 illustrates the neutral carbon cycle of Earth and the negative impact of human activities on it by using the carbon that has taken millions of years for nature to deposit into reservoirs such as fossil fuels [13].

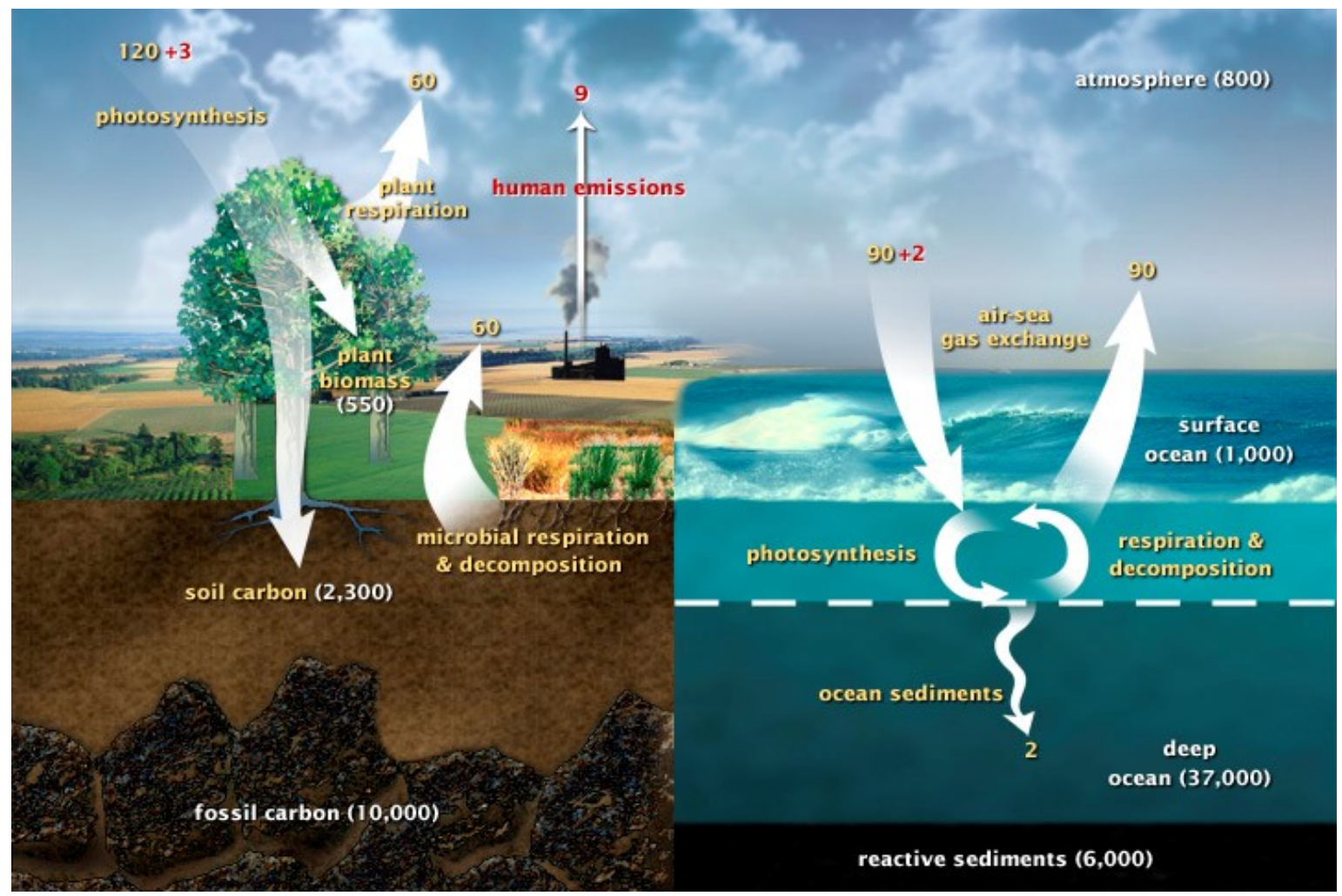

Figure 2-1: Fast carbon cycle in between land, atmosphere and the ocean. The values are in gigatons of carbon per year. Yellow coloured numbers show neutral fluxes of carbon, while white coloured numbers show the stored carbon. The red coloured numbers show human contributions to the cycle every year [13]. 
The flow of carbon within the atmosphere from one reservoir to another is called the carbon cycle. The fluxes within this cycle can be slow (the buildup of sediments in oceans, or formation of fossil fuels) or fast. Human activities contribute to the fast carbon cycle by removing from the vast underground hydrocarbon reserves and adding it to the atmosphere, as shown in Figure 2-1 [13]. Total anthropogenic greenhouse gas (GHG) emissions (e.g., carbon dioxide $\left(\mathrm{CO}_{2}\right)$, methane $\left(\mathrm{CH}_{4}\right)$, nitrous oxide $\left(\mathrm{N}_{2} \mathrm{O}\right)$, perfluorocarbons $(\mathrm{PFCs})$, hydrofluorocarbons (HFCs), sulphur hexafluoride $\left(\mathrm{SF}_{6}\right)$ and nitrogen trifluoride $\left.\left(\mathrm{NF}_{3}\right)\right)$, were rising continually at an average rate of $1.3 \%(0.4$ $\left.\mathrm{GtCO}_{2} \mathrm{eq}\right)$ per year from 1970 to 2000 , which then went up to $2.2 \%\left(1 \mathrm{GtCO}_{2} \mathrm{eq}\right)$ per year for the years 2000 to 2010. The total GHG emissions were measured at $49 \mathrm{GtCO}_{2}$ eq/yr for the years 2000 to 2010 , the highest in human history [14, $15]$.

Human activities which contribute to the production of GHG emissions, separated by economic sector, using the same designation as the intergovernmental panel on climate change (IPCC), are 1-Energy; 2Agriculture, Forestry and Other Land Use (AFOLU); 3-Industry; 4-Transport; and 5-Buildings, which make up, $34.6 \%, 24 \%, 21 \%, 14 \%$, and $6.4 \%$, respectively, of the $49 \mathrm{GtCO}_{2}$ eq/yr [14], as shown in Figure 2-2. Figure 2-3 shows the global energy-related $\mathrm{CO}_{2}$ emissions, which have been rising since 
the year 2000 [16]; therefore, developing proper mitigation plans against further $\mathrm{CO}_{2}$ emissions from this sector is vital.

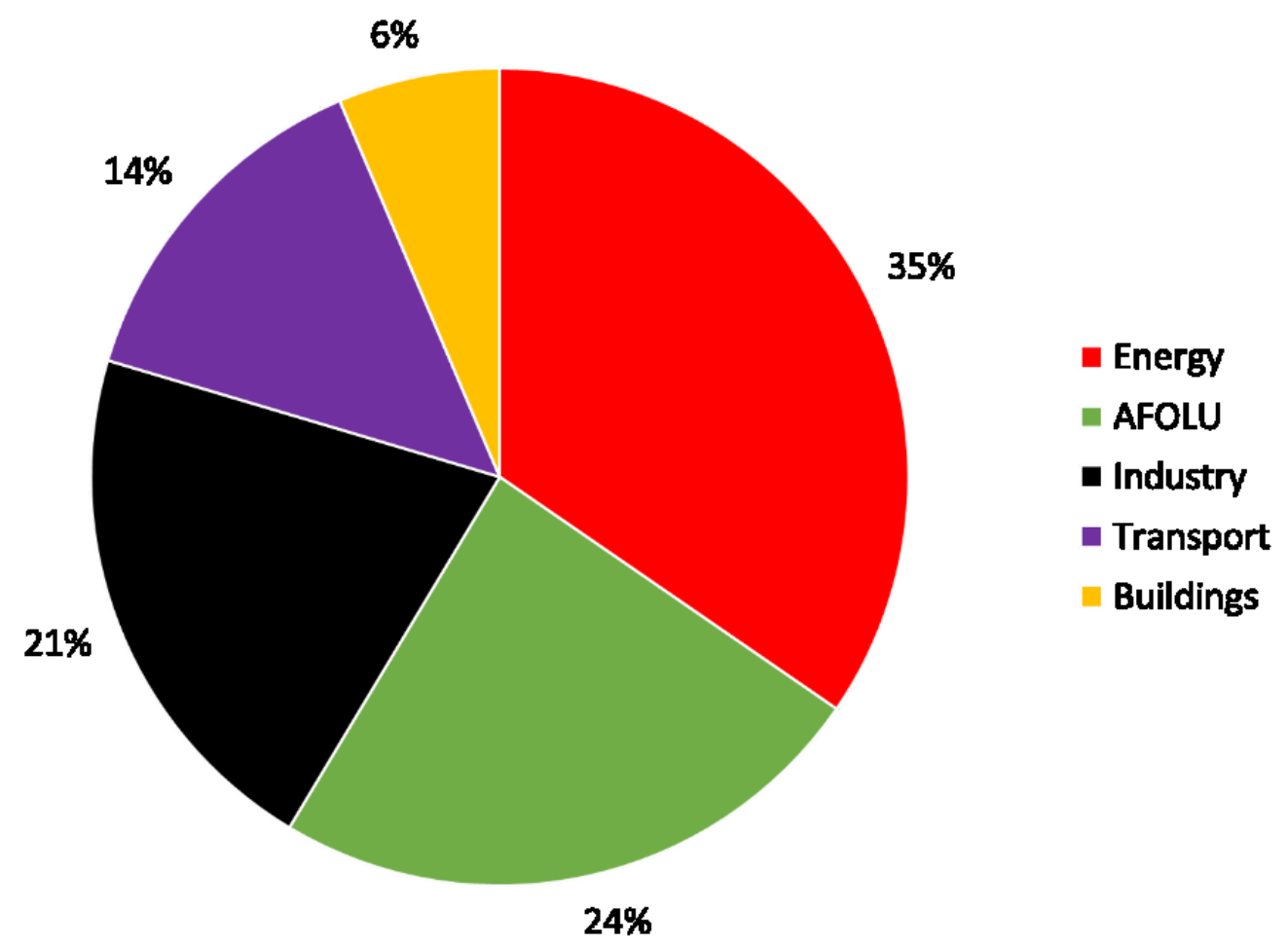

Figure 2-2: Total anthropogenic GHG emissions (GtCO2eq / yr) by economic sectors in 2010, which totals to $49 \mathrm{GtCO}_{2} \mathrm{eq} / \mathrm{yr}$. AFOLU includes land-based $\mathrm{CO} 2$ emissions from forest fires, peat fires and peat decay.

In the last decade, growing energy demands and the increased share of coal in the global fuel mix have caused this increase in GHG emissions [11]. Decarbonizing happens more rapidly in the energy sector compared with the industry sector [14]. 


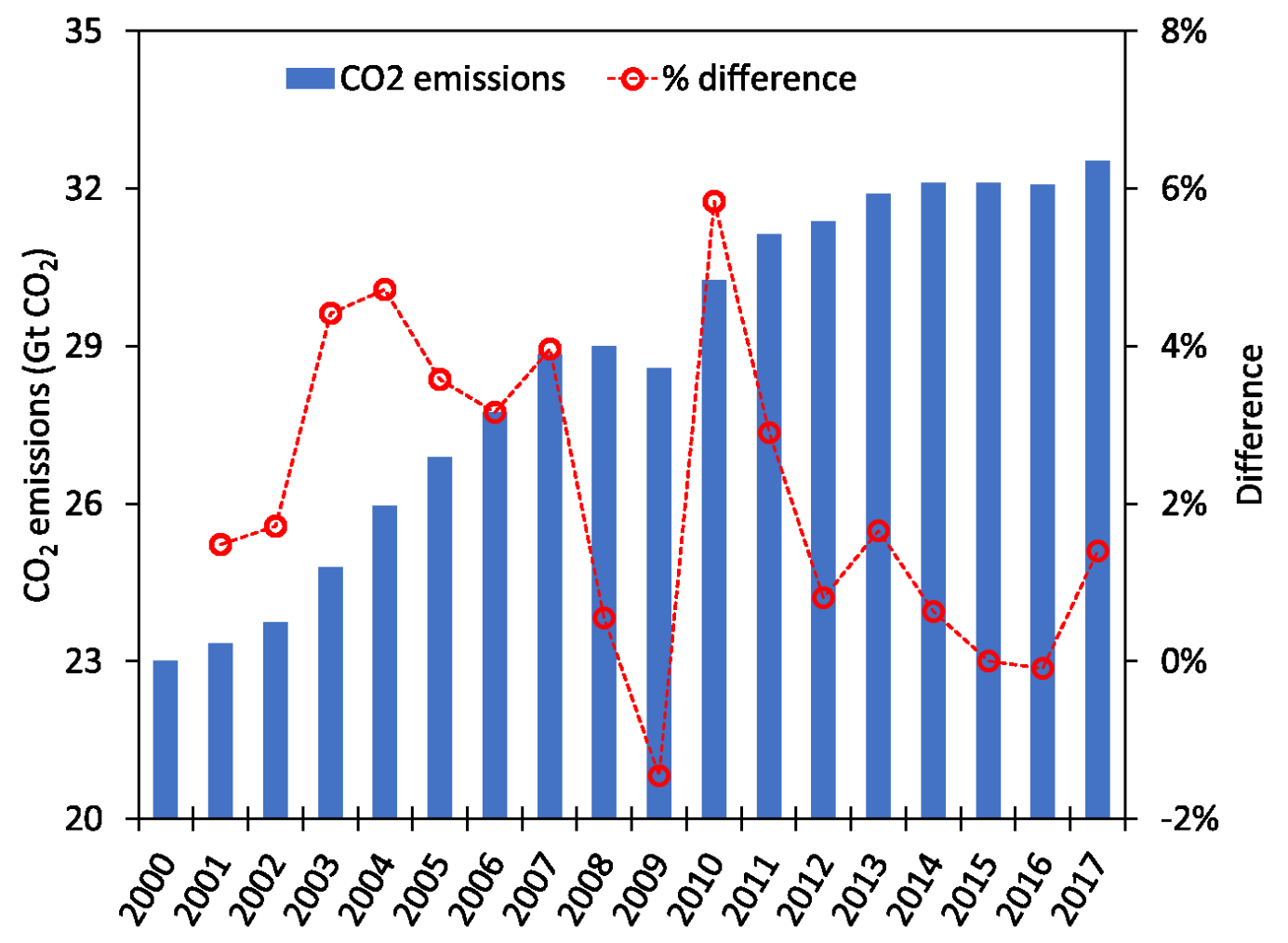

Figure 2-3: Global energy-related $\mathrm{CO}_{2}$ emissions [16]. The data from international energy agency (IEA), shown in the figure, include all the energy-related $\mathrm{CO}_{2}$ emissions from the five economic sectors used by IPCC.

The use of low carbon electricity supply technologies (i.e., renewable energy, nuclear, and carbon capture and storage (CCS)) should increase from the current $30 \%$ (in 2014) share of the energy sector to $80 \%$ by 2050 , and to $100 \%$ by 2100 according to the IPCC mitigation plans developed in 2014 [14]. In addition, according to the international energy agency's (IEA) sustainable development scenario, the global emissions need to peak soon and decline rapidly into 2020, which requires the share of low-carbon energy sources to increase by $1.1 \%$ every year, which is more than five times the growth 
registered in 2017 [16]. Even after meeting the IEA's scenario requirements, the temperature increase has been estimated to be $1.7-1.8^{\circ} \mathrm{C}$ by 2100 , which still depends on the rate of global $\mathrm{CO}_{2}$ emission reductions [17].

The transition from using high carbon energy sources, such as coal and oil, to renewable energy, nuclear, and CCS should be well planned and done wisely. In 2005 , the province of Ontario started to phase out all coal-fired power plants. This effort was based on a cost-benefit analysis, which suggested $\$ 3$ billion annual savings in health care expenses as a result of lowering smogrelated air contaminants [18]. However, McKitrick and Aliakbari found that the effects of closing the power plants resulted in only small improvements in the air quality of some locations in Ontario, while the effects of coal power plants could have been nullified by installing new pollution control systems near the power plants.

Coal held the largest share (38\%) in global power generation in 2017, the same as in 1998, despite the efforts encouraging the shift from coal to other sources of energy [19]. The share of oil and gas was $27 \%$ while the non-fossil fuels had a share of $35 \%$ in the global power generation sector in 2017 [19].

The production of coal in the world was reported at 7.3 billion tonnes in 2017 after peaking at 8.1 billion tonnes in 2013, while it was 6.4 billion tonnes in 2007 [20]. Total coal consumption in China alone reached 3.8 billion tonnes 
in 2017 , more than $60 \%$ of its total energy mix, which is more than half of the coal produced in the world [21]. Canada produced 61 million tonnes (MT) of coal in 2017, out of which 56\% was metallurgical (used for making steel), and $44 \%$ was thermal coal (used for electricity) [20]. Furthermore, $9 \%$ of the energy generated in Canada uses coal, which totalled 34.3 MT in 2016 [20]. Meanwhile, the government of Canada has planned to phase out coal-burning power plants by 2030 , which would eliminate the use of thermal coal but not metallurgical coal.

In Canada, $17.4 \%$ of the total energy supply was renewable in 2016 , 67.5\% (2055 petajoules (PJ)) of which came from moving water; other technologies, such as wind, solar, and biomass were also used [20]. After hydropower, biomass had the biggest cut of the total renewable energies used in Canada at $22.6 \%$ [20].

Canada has vast amounts of biomass in the form of forestry (998 M ha) and standing biomass carbon stock, which has been estimated at 15835 MT with a 5\%-10\% increase every year [22]. The extractable energy from these resources is equal to 566 exajoules (EJ), which is the equivalent of 69 years of Canada's energy demand, currently supplied by fossil fuels. In addition, Canada's annual biomass produced from the forestry and agricultural divisions is about $143 \mathrm{MT} \mathrm{C}$ per year, which is equal to $5.1 \mathrm{EJ}$ (equivalent to $62 \%$ of 
energy derived from fossil fuels per year) [22]. Sixty megaton of this total amount is the annual residual or waste biomass, enough to produce 1.5 EJ of energy every year; however, these resources are widely left untouched to decay over time due to lack of technology and knowledge.

Biomass makes up one-third of the total energy consumption of developing countries in Asia and Africa, mostly because of its availability compared with fossil fuels such as coal and natural gas [23]. In countries such as India, with vast reserves of coal (250 billion tonnes) in only specific regions, the supply of the fuel to the whole country would not be financially or even physically possible, while biomass is more evenly distributed over the country and generally available [23]. It is essential to find, develop, and optimise technologies, which can make use of this vast energy resource on the planet. 


\subsection{Biomass}

"Biomass is the plant material derived from the reaction between $\mathrm{CO}_{2}$ in the air, water, and sunlight via photosynthesis, to produce carbohydrates that form its building blocks" [24].

Biomass has been characterised differently by researchers. However, one method is to put biomass into four different categories [24]:

- Woody plants

- Herbaceous plants/grasses

- Aquatic plants and algae

- Manures

Biomass consists of cellulose, hemicellulose, lignin, and small amounts of extractables [24], [25]. Algal biomass and aquatic plants are mainly made up of lipids, carbohydrates and proteins [26]. Cellulose and hemicellulose, carbohydrates, are the primary load-bearing elements of the plant while lignin, provides stiffness and rigidity [27]. Therefore, trees (lignin content of $20 \%$ to $30 \%$ ) can grow taller before they bend compared with grass (lignin content of less than 20\%) [28]. 
Cellulose has been recognized as the most abundant natural polymer with an estimated annual worldwide production of 1.5 teratonnes and it is considered to be a nearly inexhaustible source of raw biomass material [29]. Cellulose is generally represented by the chemical formula $\left(\mathrm{C}_{6} \mathrm{H}_{10} \mathrm{O}_{5}\right)_{\mathrm{n}}$, which is a long chain of polysaccharides. The average molecular weight of cellulose is around $100,000 \mathrm{~g} / \mathrm{mol}$ [24]. Cellulose is generally the most substantial fraction of biomass, $40-50 \%$ by weight [24].

Hemicellulose forms approximately $20-30 \%$ of the dry weight of many wood species and is an amorphous heteropolysaccharide. The structure of hemicellulose is also highly dependent upon the biomass material [26], [30]. Hemicellulose is almost entirely composed of sugars such as glucose, mannose, xylose, and arabinose and other five-carbon monosaccharides, with an average molecular weight of $<30,000 \mathrm{~g} / \mathrm{mol}[24]$.

Lignin is a natural polymer in which aromatic compounds consist of phenylpropane units, with hydroxyl and methoxyl groups connected mainly through ether bonds [31]. Lignin is an amorphous material, which is hydrophobic and has low solubility in water. Hardwood is made of $18-25 \%$ lignin, while softwood has a higher lignin content of $25-35 \%$ [32]. Lignin is used to help strengthen the structure of the plants [31], [32]. Lignin has 
around 30\% higher energy content (22-29 MJ/kg) compared with cellulose and hemicellulose [33]-[35].

Biomass can be distinguished by its energy, moisture, fixed carbon, volatile matter, ash, and alkali metal contents, as well as its cellulose/lignin ratio [24]. Higher energy contents, lower ash and moisture contents, as well as lower alkali contents, are often preferred for biomass to be used as a fuel source.

\subsection{Biomass Conversion Technologies}

Biomass conversion technologies include thermochemical and biochemical conversions, as shown in Figure 2-4. Thermochemical conversions are not only more rapid than biochemical conversions but they also convert the biomass into a more energy dense fuel by heating it under a pressurized and oxygen deprived enclosure [36]. Biochemical conversions occur naturally through aerobic and anaerobic degradations, fermentation, and enzymatic hydrolysis [26]. Thermochemical conversion can eliminate pathogens and potentially organic contaminants such as pharmaceutically active compounds that might be in the feedstock [37]. Moreover, valuable solid, liquid, and gas products can be produced through thermochemical conversions [37]. 
Thermochemical conversions include gasification, pyrolysis, combustion, and hydrothermal processes, as shown in Figure 2-4.

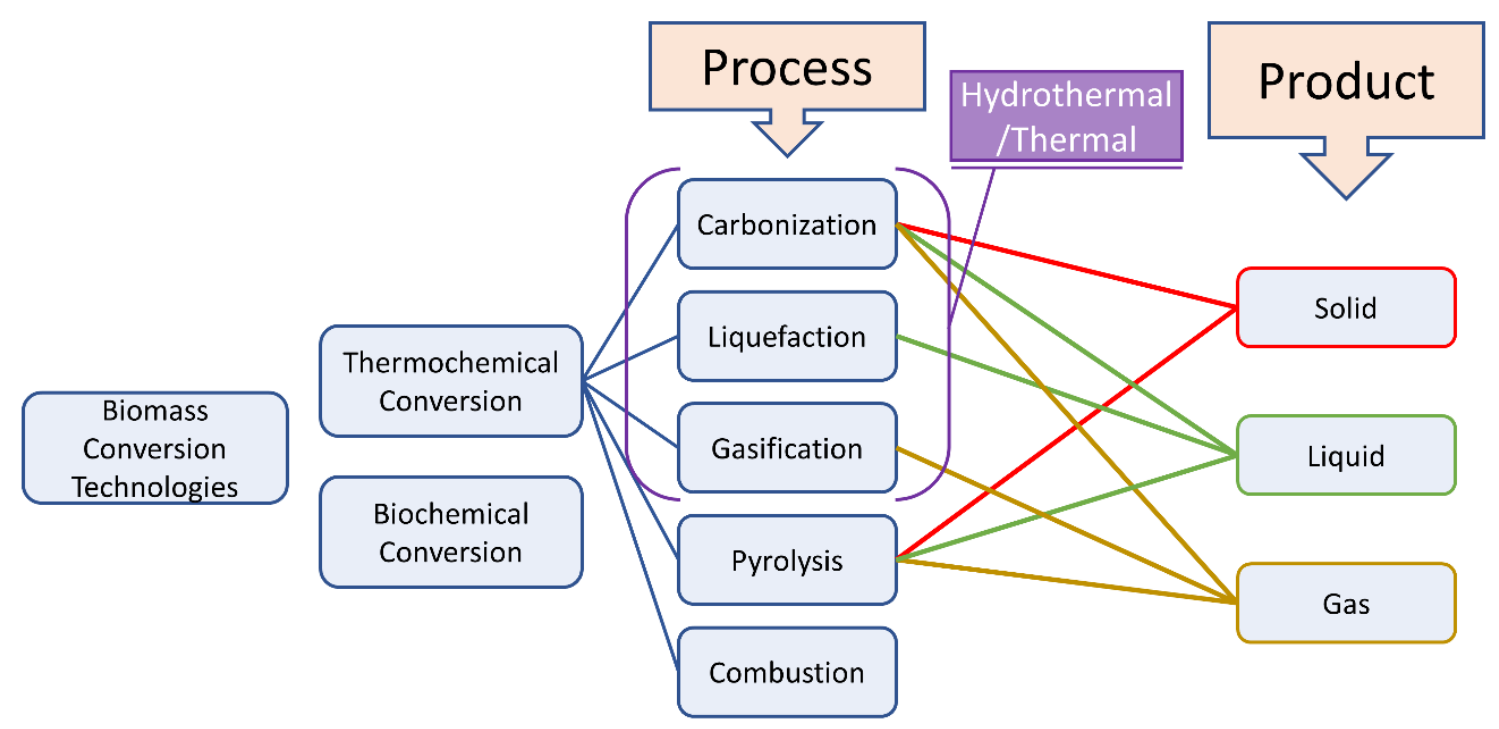

Figure 2-4: Different biomass conversion technologies, specifically thermochemical conversions. The processes are connected to the product forms each produce. Carbonization, liquefaction, and gasification can be both thermal and hydrothermal.

Gasification of biomass occurs by partial oxidation of the carbon in the biomass at high temperature $\left(500-1300{ }^{\circ} \mathrm{C}\right)$ using a controlled amount of oxidant that can be air, pure oxygen, or steam [38]. Depending on the oxidant, the heating value of the produced gas can be $4-7 \mathrm{MJ} / \mathrm{m}^{3}$ (air) or $10-18 \mathrm{MJ} / \mathrm{m}^{3}$ (pure oxygen or steam) [23], [39]. In comparison, the energy value of natural gas on average is $35-39 \mathrm{MJ} / \mathrm{m}^{3}$. Different types of biomass can be converted into syngas through gasification. Syngas, depending on the feedstock, mainly contains hydrogen, carbon monoxide, carbon dioxide, and methane, which can 
be used to generate heat or electricity in an engine or turbine [23]. Gasification can have a few challenging issues, including its impurities such as fly ash particles and tar. Sulphur compounds, hydrogen chloride, alkaline compounds, and ammonia are other possible impurities in syngas, which needs to be purified before it is used [23]. For instance, the condensation of tar can cause clogging or blockage of pipes, filters, or engines [23].

Pyrolysis can be separated into two main stages, solid devolatilization (pyrolysis) and char conversion (combustion and gasification). The yields of pyrolysis products, which are solid char, bio-oil (liquid), and gases such as methane, depend on temperature, pressure, heating rate, and the type of biomass [40], [41]. Pyrolysis can occur within the temperature range 300-600 ${ }^{\circ} \mathrm{C}$ while the operating temperature for pyrolysis on an industrial scale is often more than $450{ }^{\circ} \mathrm{C}$ [38], [41].

Carbonization covers the thermochemical processes, at temperatures of $500-900{ }^{\circ} \mathrm{C}$ in an oxygen-starved environment, by which the carbon content of biomass is increased [38]. The process results in a product, referred to as charcoal. Torrefaction is a similar process to carbonization except that the operating temperatures are at $200-300{ }^{\circ} \mathrm{C}$ while the biomass is without or only little contact with oxygen [38]. The solid char made through torrefaction is often referred to as biochar [42]. 
Combustion of biomass is the process of setting the biomass on fire and making use of the heat, which represents the oldest way of biomass utilized by civilization. The mentioned thermochemical processes face a common challenge that is the need for a dry biomass. Furthermore, these processes cannot eliminate ash and sulphur from the biomass [42].

Hydrothermal processes consist mainly of a wet environment; hence the name hydro, and heat, which can help break down the components of the biomass. Therefore, hydrothermal processes can use feedstock that is already wet. Hydrothermal processes occur in a closed system where a reactor, containing the liquid and feedstock, is heated, causing the pressure to increase. One of the reasons for using water for the process is to use the catalytic behaviours of water at sub and supercritical temperatures [1]. The water can help hydrolyse and break the components of the biomass such as cellulose and hemicellulose. Hydrothermal processes are separated into three different categories depending on the temperature, as shown in Figure 2-5. These processes can eliminate tar, and have higher yields compared with pyrolysis and gasification [36]. Hydrothermal Gasification and Liquefaction occur in supercritical water conditions, as shown in Figure 2-5, whereas hydrothermal carbonization (HTC) operates at temperatures as low as $180{ }^{\circ} \mathrm{C}$ [1], [42]. 


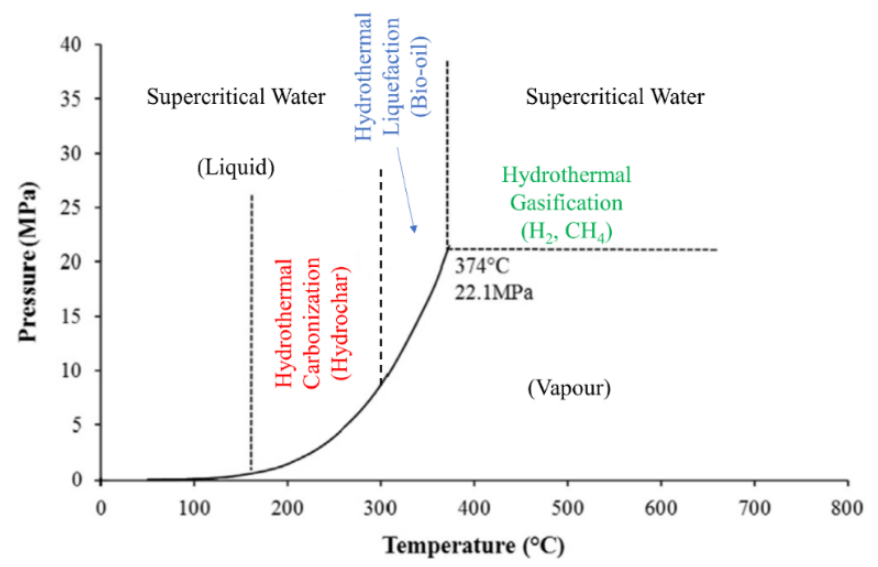

Figure 2-5: Different hydrothermal processes separated according to their required temperature range on a water phase diagram. The major products of each process are written in parentheses. The figure is an adaptation from the work of Kambo et al. [42].

Hydrothermal Gasification (HTG) results in the production of gases such as methane, hydrogen, and carbon dioxide after the feedstock is heated to temperatures above $350{ }^{\circ} \mathrm{C}$ [43]. Hydrothermal Liquefaction (HTL) can convert the biomass into liquid fuels using temperatures of $250-374{ }^{\circ} \mathrm{C}$ and pressures of 4 to $22 \mathrm{MPa}$ [36].

Contrary to HTG and HTL, hydrothermal carbonization (HTC) is a process where the biomass is converted mainly into a solid material, referred to as hydrochar [42]. The process is operated at temperatures above $180{ }^{\circ} \mathrm{C}$ for durations of one to 72 hours under pressure so that the water stays in liquid form [1]. Similar to other hydrothermal processes, HTC can also eliminate the impurities of the biomass (i.e., extractives), lower its ash content, and increase the energy content of the hydrochar product [44], [45]. 


\subsection{Hydrothermal Carbonization (HTC)}

Hydrothermal carbonization (HTC) is one of the hydrothermal processes, which has recently received much attention from industry and researchers [26]. HTC can occur at lower temperatures $(180-300$ $\left.{ }^{\circ} \mathrm{C}\right)$ compared with HTL $\left(300-374{ }^{\circ} \mathrm{C}\right)$ and HTG (which usually occurs at temperatures above $374^{\circ} \mathrm{C}$ ), as shown in Figure 2-5, which leads to lower energy consumption for the conversion of biomass. HTC produces hydrochar, valuable chemicals, and by-product gases [1], as shown in Figure 2-6. The products of HTC are $2-5 \%$ gas, $5-25 \%$ liquid, and $45^{-}$ $70 \%$ solid depending on process conditions, such as temperature, residence time, and solid load [37], [42]. The solid load is also known as the liquid:biomass $(\mathrm{L}: \mathrm{B})$ ratio for the process.

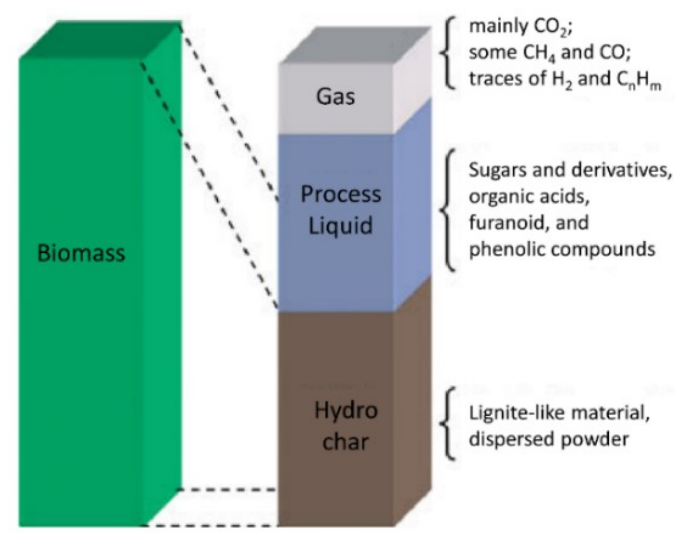

Figure 2-6: Products of hydrothermal carbonization (HTC) separated according to their phases (i.e., gas, liquid, hydrochar solid) [1]. 
The type of feedstock can change the mass yields, process liquid characteristics, and gases produced through the HTC process [1]. Some types of biomass that have been processed with HTC include loblolly pine, tobacco stalks, pine wood, algae, cow manure, paper, corn stalks, and miscanthus [42], [46], [47].

Biomass goes through a series of reactions that cause the concentration of oxygen and hydrogen to drop in the solid fraction while increasing the concentrations of carbon [42]. These chemical reactions release other organic chemicals such as acetic acid, levulinic acid, and 5-hydroxymethylfurfural (HMF), which can be considered as value-added chemical products of the process [5], [8], [45]. The gas is mainly made up of $\mathrm{CO}_{2}, \mathrm{CH}_{4}$, and $\mathrm{H}_{2}$ that can be used as fuel [43].

\subsubsection{Underlying Reactions}

HTC involves a series of reactions that convert different components of the biomass into hydrochar in addition to organic substances dissolved in the liquid and some gas by-products, as shown in Figure 2-6. These reactions 
include hydrolysis, dehydration, decarboxylation, condensation polymerization, and aromatization.

HTC starts with hydrolysis of the biomass components that will result in the production of ether and ester bonds, in the form of oligosaccharides [37], [48]. Hydrolysis of cellulose, breakdown of this compound due to reaction with water, happens when a water molecule splits into two ions of $\mathrm{OH}^{-}$and $\mathrm{H}^{+}$, reacting with cellulose, in order to break down $B 1 \rightarrow 4$ bonds, as shown in Figure 2-7.

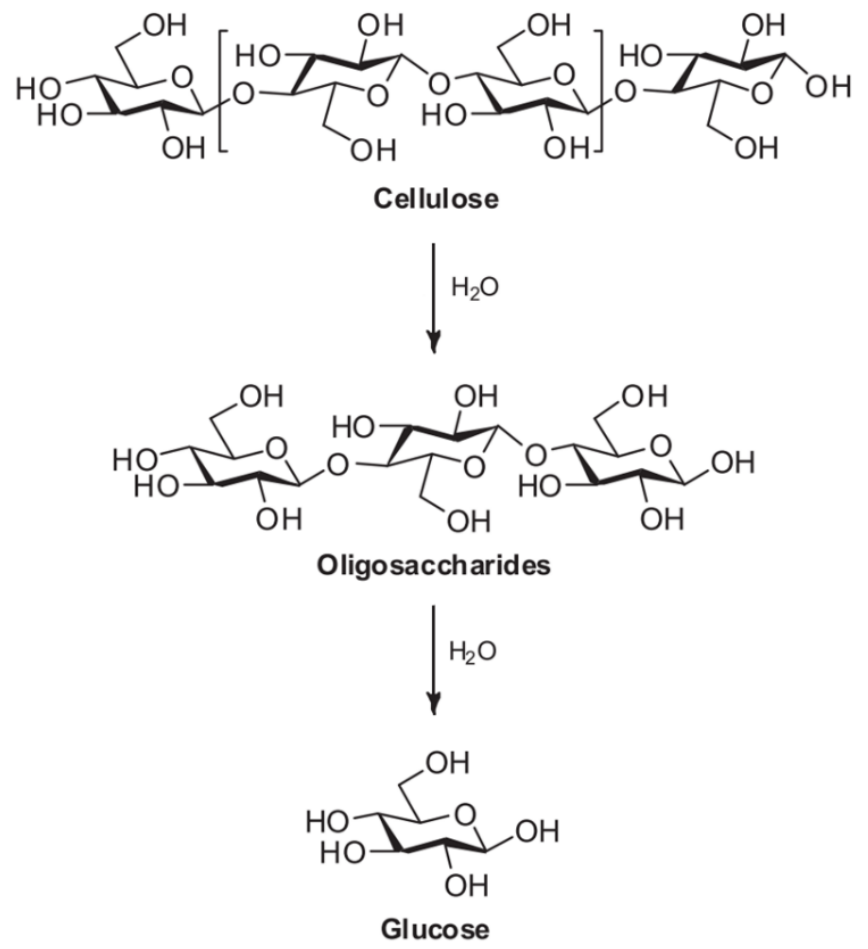

Figure 2-7: Hydrolysis of cellulose into oligosaccharides and glucose components [49]. 
Hydrolysis can eventually result in full decomposition of the physical structure of the biomass into a liquid [37]. Acetic acid and glycolic acid are formed after decomposition of hemicellulose, as summarized in Figure 2-8 [50]. During decomposition of cellulose and hemicellulose intermediate compounds such as 5-hydroxymethylfurfural (HMF), furfural, and phenols are made. These intermediate compounds can further polymerize and condense into solid hydrochar, through which these compounds lose their $\mathrm{OH}^{-}$and $\mathrm{H}^{+}$bonds [1], [37]. Alternatively, the HMF can dehydrate back into levulinic acid and formic acid, hence reducing the yield of the hydrochar [37], [51]. Decarboxylation also occurs during hydrothermal carbonization, through a process which produces $\mathrm{CO}_{2}$. Decarboxylation is when a chemical compound loses a carboxyl group and $\mathrm{CO}_{2}$ is made. Formic acid is one of the compounds that goes through decarboxylation and turns into $\mathrm{CO}_{2}$ and $\mathrm{H}_{2}$ [52]. Dehydration, which is the removal of hydroxyl groups, results in carbonization of the biomass by lowering the atomic ratios, $\mathrm{O} / \mathrm{C}$ and $\mathrm{H} / \mathrm{C}$ [37]. Dehydrated and decarboxylated compounds, such as HMF, will then condense, polymerize, and form hydrochar. The hydrochar polymer chains consist of stable aromatic bonds, which can be considered as a basic building block of the hydrochar [1]. Aromaticity is used to describe a cyclic (ring-shaped), planar (flat) molecule with a ring of resonance bonds that exhibits more stability than other geometric or connective arrangements with the same set of atoms. The liquid contains 
nearly all the fragments from the decomposition of biomass components, which favour the formation of hydrochar [37].

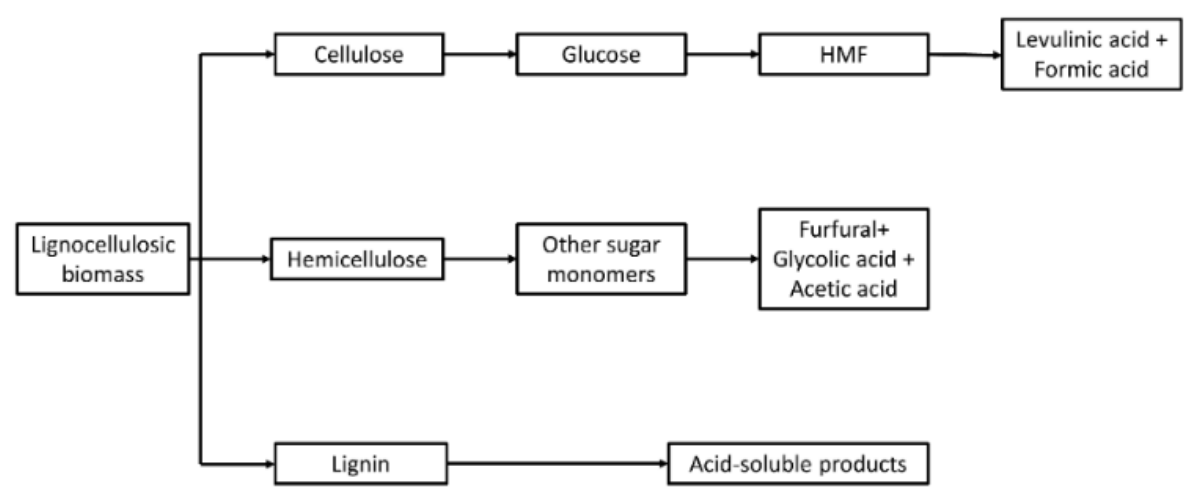

Figure 2-8: Chemical pathways for biomass components after decomposition [50].

\subsubsection{HTC Products}

Figure 2-9 shows different products of the HTC process as well as potential applications of the hydrochar. Although HTC is commonly used to produce an energy-dense solid hydrochar, the process liquid and the by-product gas can potentially be used as a source for value-added products [42]. The liquid contains chemicals, such as glycolic acid, formic acid, acetic acid, levulinic acid, HMF, and furfural, as shown in Figure 2-8. Small amounts of gas can also be extracted and used to generate heat for the process [37]. 


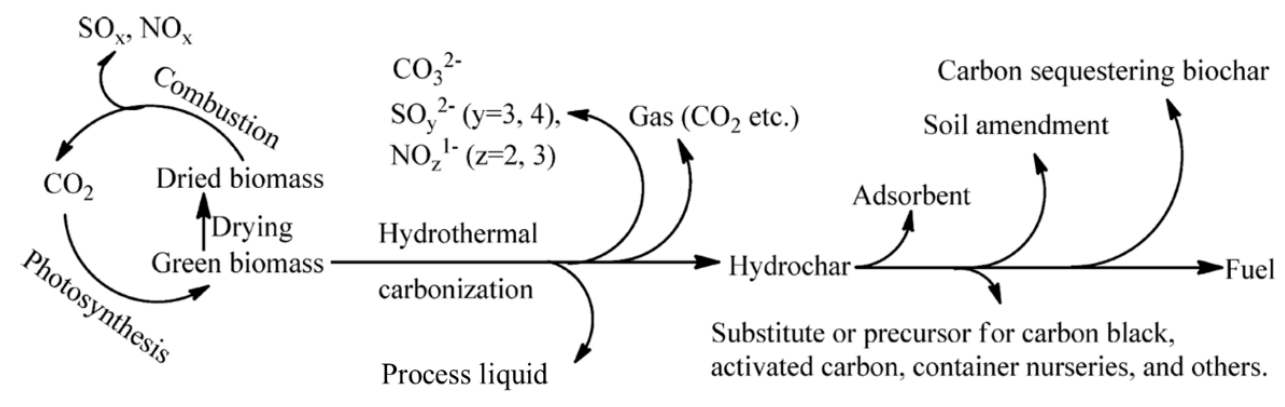

Figure 2-9: Products and possible applications of HTC [53].

\subsubsection{Solid}

Infrared spectroscopy of the hydrochar and the biomass is used to explain the reactions and conversion mechanisms that the biomass goes through during an HTC process [54]. The spectra of the biomass and hydrochar, as shown in Figure 2-10, illustrate the peaks that correspond to a particular type of chemical bond, such as $\mathrm{OH}$ (hydroxyl) bonds at $\approx 3400 \mathrm{~cm}^{-1}$ [55], [56]. IR spectroscopy of hydrochar shows aromatic bonds as well as aliphatic $\left(\mathrm{C}-\mathrm{H}\right.$ at $\left.\approx 2900 \mathrm{~cm}^{-1}\right)$, and ether groups $\left(\mathrm{C}-\mathrm{O}\right.$ at $\left.\approx 1100 \mathrm{~cm}^{-1}\right)$ in the product [53]. Dehydration of the hydrochar causes a reduction in the hydroxyl groups [57]. $\mathrm{C}-\mathrm{O}$ linkages at $1120-1050 \mathrm{~cm}^{-1}$ in the biomass, representing ether bonds, decrease in intensity after the HTC process [53]. 
The peaks at $1600-1700 \mathrm{~cm}^{-1}$ suggest the formation of $\mathrm{C}=\mathrm{O}$ bonds (part of a carboxyl or carbonyl group), which can be formed after dehydration of hydroxyl groups [53], [56].

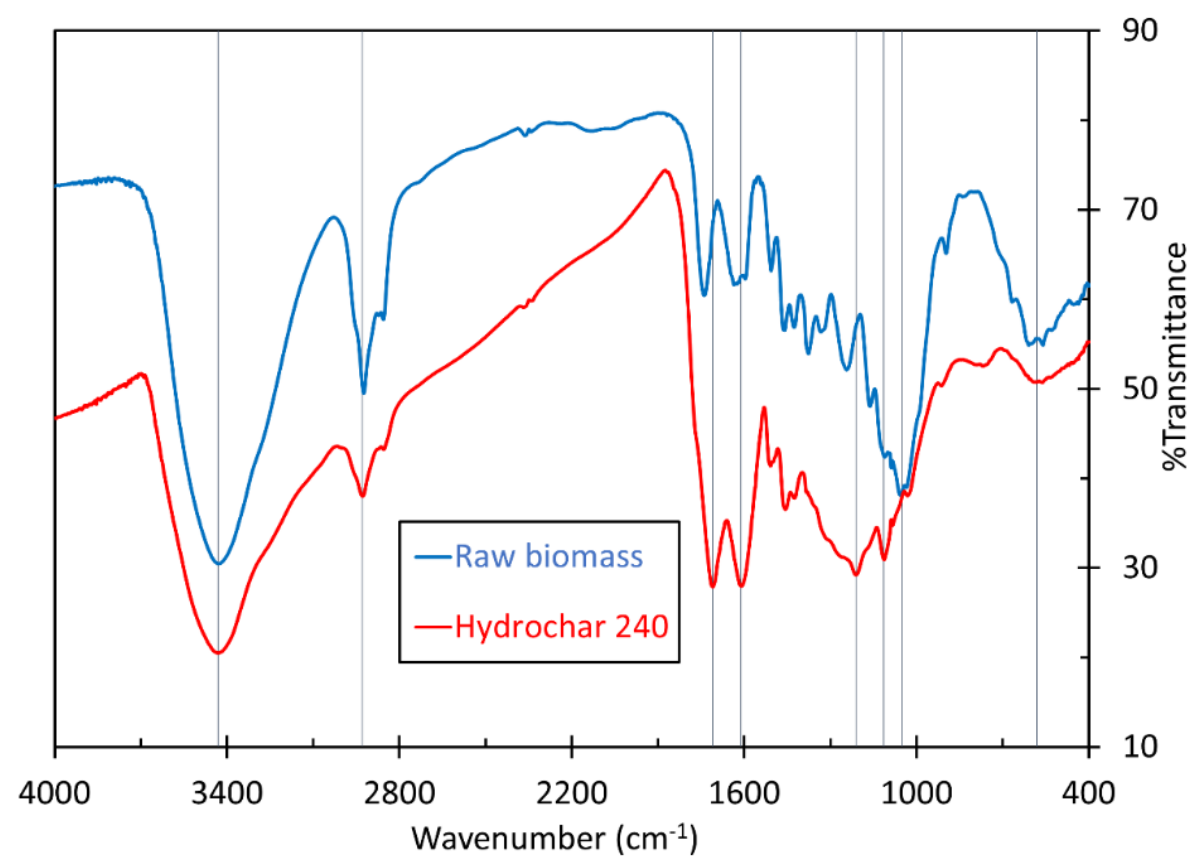

Figure 2-10: Infrared spectra of initial biomass and final hydrochar after treatment at $240{ }^{\circ} \mathrm{C}$. 
Table 2-1 shows different functional groups and their corresponding absorption wavenumbers in IR spectroscopy.

Table 2-1: Functional groups found in the biomass with their corresponding wavenumber. Data gathered by Reza et al. [55].

\begin{tabular}{|c|c|}
\hline Wavenumber $\left(\mathrm{cm}^{-1}\right)$ & Functional groups \\
\hline $3000-3600$ & OH stretching \\
\hline $2860-2970$ & $\mathrm{C}-\mathrm{H}_{\mathrm{n}}$ stretching \\
\hline $\begin{array}{l}1700-1730 \\
1510-1560\end{array}$ & $\mathrm{C}=\mathrm{O}$ stretching \\
\hline 1632 & $\mathrm{C}=\mathrm{C}$ \\
\hline 1613,1450 & $\mathrm{C}=\mathrm{C}$ stretching \\
\hline $1430-1470$ & $\mathrm{O}-\mathrm{CH}_{3}$ \\
\hline $1400-1440$ & $\mathrm{OH}$ bending \\
\hline 1402 & CH bending \\
\hline 1232 & $\mathrm{C}-\mathrm{O}-\mathrm{C}$ stretching \\
\hline 1215 & $\mathrm{C}-\mathrm{O}$ stretching \\
\hline 1170,1082 & $\mathrm{C}-\mathrm{O}-\mathrm{C}$ stretching vibration \\
\hline 1108 & $\mathrm{OH}$ association \\
\hline 1060 & $\mathrm{C}-\mathrm{O}$ stretching and deformation \\
\hline $700-900$ & $\mathrm{C}-\mathrm{H}$ (cellulose, hemicellulose) \\
\hline $400-700$ & $\mathrm{C}-\mathrm{H}$ (hemicellulose) \\
\hline
\end{tabular}


Van Krevelen diagrams can illustrate the change in the elemental composition of the hydrochar compared with the biomass [42]. The diagram is a tool to compare the hydrochar with the different types of solid fuels, such as coal, lignite, and peat. Peat is a brown soil-like material, consisting mainly of partly decomposed vegetable matter, while lignite is a soft brownish coal with traces of plant structure, also referred to as brown coal. Lignite is formed from naturally compressed peat. The hydrogen to carbon (H/C) and oxygen to carbon $(\mathrm{O} / \mathrm{C})$ atomic ratios decrease while the carbon concentration increases to values, that are close to peat, then lignite, then coal, and finally the best carbon solid fuel, anthracite on a Van Krevelen diagram, Figure 2-11.

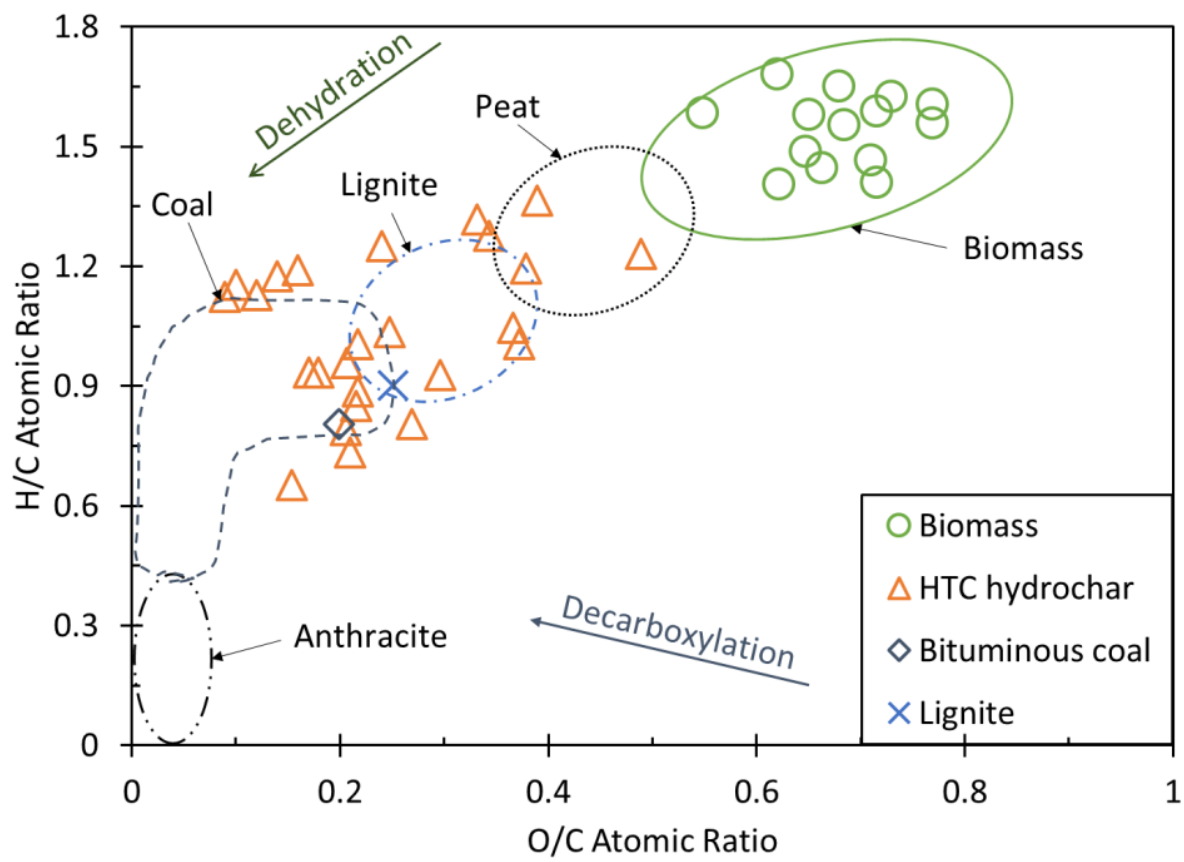

Figure 2-11: Van Krevelen diagram of HTC hydrochar produced with different conditions and from different biomass types [42]. 
Figure 2-11 shows the atomic ratios $(\mathrm{H} / \mathrm{C}$ and $\mathrm{O} / \mathrm{C})$ of different hydrochars that have been produced at temperatures of $175-375{ }^{\circ} \mathrm{C}$, for 30 minutes to 10 hours, from biomass feedstocks such as eucalyptus sawdust, corn stover, birch, and coconut fibre [42]. Elemental analysis of the solid hydrochar has shown an increase in the carbon content of the hydrochar compared with the biomass, which is consistent with the findings of IR spectroscopy, i.e., an increase in carbon-carbon bonds.

The hydrochar samples in Figure 2-11 had higher heating values (HHVs) of $20-36 \mathrm{MJ} / \mathrm{kg}$. The HHV is dependent upon the residence time, temperature, and biomass used for the HTC process. The closer the hydrochar is to the coal and anthracite regions in Figure 2-11, the higher the HHV [37]. HTC causes the release of inorganic minerals (ash) that do not contribute to combustion, such as $\mathrm{Si}, \mathrm{K}, \mathrm{Na}, \mathrm{S}, \mathrm{Cl}, \mathrm{P}, \mathrm{Ca}, \mathrm{Mg}$, and $\mathrm{Fe}$, into the process liquid [25]. This reduction in the ash content, can increase the combustion temperature and reduce fouling (in the form of solid salts, when these minerals are oxidized) [58], [59].

The hydrochar is washed after extraction from the process to remove the organic compounds that might be on its surface. The HHVs of organic chemicals, which are formed during the HTC process, are less than the hydrochar (e.g., HMF has an HHV value of $22 \mathrm{MJ} / \mathrm{kg}$ compared with 24-26 
$\mathrm{MJ} / \mathrm{kg}$ for hydrochar) [42]. Hydrochar is usually densified into pellets or briquettes to simplify storage and transportation [55]. Densification, requires the hydrochar to be heated to its glass transition temperature and compressed into the shape of a pellet [60]. Heating to the hydrochar's glass transition temperature permits enhanced molecular mobility (or plasticity) which permits the hydrochar solid to soft and deform under pressure without chemically decomposing. The glass transition of the hydrochar has been reported to be $140{ }^{\circ} \mathrm{C}$ [61]. Densification conditions (i.e., pressure and temperature) also depend on the shape of the pellets, which can be defined as length to diameter ratio (L/D) for cylindrical pellets [61].

Densified pellets should be durable and hydrophobic [62]. Pellets with higher durability produce less dust when transported. Durability is measured according to ASTM D3402, which consists of rotating the pellets in a tumbler at $24 \mathrm{rpm}$ for 1400 revolutions. The ASTM D3402 is often adjusted for use on a smaller scale in a lab by increasing the rotation speed of the tumbler or the number of revolutions [63]-[65]. The pellet pieces left after the test are passed through a $6.3 \mathrm{~mm}$ mesh and then weighed. The durability of the pellets will then be calculated and represented as a Pellet Durability Index (PDI) or an abrasion index. 
The PDI is calculated as:

$$
\text { PDI }(\%)=\frac{M_{f}}{M_{i}} \times 100,
$$

where $M_{i}$ and $M_{f}$ are the initial and final weight of the pellets. Higher PDI values indicate higher durability.

The abrasion index is calculated as:

$$
\text { Abrasion Index }=\frac{M_{i}-M_{f}}{M_{i}} \times 100,
$$

Higher abrasion index will indicate lower durability. In addition to high durability, the pellets should resist compressive forces caused by stacking piles of pellets during transportation or storage. The compressive strength of the pellets is often measured using a material testing system (MTS) compression test, where a pellet gets crushed using a known force [61].

The hydrochar pellets are favoured when hydrophobic, since water absorption can increase the volume of the pellets to the point where the pellets lose their solid structure. In addition, the heat needed to evaporate the moisture content is considered as wasted energy. Hydrophobicity of the pellets has been measured using the equilibrium moisture content (EMC) method [6], 
[66]. EMC measures the moisture absorbed by the pellet after being exposed to humid environments. In extreme conditions, water will pour directly onto the pellets (e.g. rain), which places the pellets in direct contact with liquid water. One approach to determining the water absorptivity of the densified hydrochar is to measure the weight of the pellet after it has been fully immersed in water. Total immersion of the pellet in water coupled with weight measurements have been previously performed by Pimchuai et al., and Kambo et al. [67], [68]. This approach can also be used to demonstrate the quality of the densification of the hydrochar. Although hydrochar is hydrophobic [6], [69], the densification process can leave empty pores within the densified hydrochar. These pores can be filled with water, which would increase the weight and the volume of the pellet.

\subsubsection{Liquid}

The process liquid contains most of the heat put into the process to increase the temperature. Therefore, hot recycling of the liquid has been suggested to maximize the use of energy and to lessen the need for disposing of the process liquid[5], [45]. It has also been shown that recycling the process liquid can increase the concentrations of organic compounds that can be extracted as VACs [5], [8], [45]. 


\subsubsection{Gas}

The gas produced during HTC mainly consists of $\mathrm{CO}_{2}$; however, $\mathrm{CO}$, $\mathrm{CH}_{4}, \mathrm{H}_{2}$, and $\mathrm{C}_{\mathrm{m}} \mathrm{H}_{\mathrm{n}}$ can also be produced [37], [42]. Decarboxylation is one of the reactions that occur during the hydrothermal process producing $\mathrm{CO}_{2}$ [42], dependent upon the process temperature [43]. Higher temperatures produce more gases; however, the concentration of $\mathrm{CO}$, produced through decarbonylation, decreases as those for $\mathrm{CH}_{4}$ and $\mathrm{H}_{2}$ increase [43].

\subsubsection{Temperature}

Temperature plays a significant role in the production of the hydrochar. The three main components of lignocellulosic biomass (hemicellulose, lignin and cellulose) start to disintegrate and hydrolyze at 180,200 , and $220{ }^{\circ} \mathrm{C}$, respectively [70]. Furthermore, the decomposition temperatures can change depending on the $\mathrm{pH}$ of the process liquid [70]. Elevated temperatures also enhance solvent properties of water enough for even dissolving non-polar compounds. The viscosity of water can change by up to one order of magnitude depending on the temperature (when considering water at $0{ }^{\circ} \mathrm{C}$ versus at 350 ${ }^{\circ} \mathrm{C}$ ), which can then enhance the penetration of water into the pores of biomass and increase its disintegration [1], [71]. 


\subsubsection{Residence Time}

HTC has been reportedly performed in durations ranging from 5 minutes to 1 hour and then to several days [1], [6], [45]. The residence time for HTC has shown to have a positive effect on the mass yield of the hydrochar, which can be explained by further polymerization of already dissolved compounds in the liquid. Long residence times can further disintegrate the biomass and also the hydrochar already formed and put it back into the liquid thereby lowering the mass yield which is not favorable for HTC process. Therefore, optimizing the residence time for desired quality of the hydrochar is imperative [37]. Increasing the operating temperature of the HTC process can shorten the time needed for hydrochar formation [70], while temperatures above $300{ }^{\circ} \mathrm{C}$ can result in liquefaction of the biomass, refer to Figure $2-5$.

\subsubsection{Pressure}

$\mathrm{HTC}$ of biomass is operated at temperatures of $180{ }^{\circ} \mathrm{C}$ and above, under pressure in a closed environment. The pressure can be slightly higher than the saturation vapour pressure of water due to the production of gases such as $\mathrm{CO}_{2}$ and $\mathrm{H}_{2}$ [1], [72]. Some authors have reported that increasing the pressure at the operating temperature can increase the carbon content of the hydrochar while Funke and Ziegler concluded that the small reported differences cannot 
justify the increased carbon content to be caused only by the extra pressure [1]. Addition of $\mathrm{LiCl}$ to the process liquid has been found to decrease the operating pressure of HTC, which can minimize the capital costs required to build the reactor needed for the process [73].

\subsubsection{Solid Load}

The solid load, also referred to as liquid:biomass (L:B) ratio represents the amount of liquid used for the HTC process with respect to the solid biomass. The biomass is mixed into the process liquid (the medium in which the chemical reactions take place). The process liquid (i.e., water) behaves as both a reactant and a solvent. Increasing the L:B ratio (solid load) has been suggested to have an adverse effect on the mass yield of the process [74], [75]. Higher amounts of liquid (i.e., higher L:B ratios) cause higher entropy, which will result in chemical reactions to be driven towards where the entropy is larger, therefore higher concentrations of the chemical compounds can be found in the liquid, produced due to further disintegration of the biomass [76]. These compounds stay in the process liquid rather than polymerizing into hydrochar, which would cause the mass yield to decrease. Optimizing the solid load can increase the mass yield and the concentration of VACs in the process liquid [76]. 


\subsection{7 pH}

Production of different organic acids during the HTC process has been reported to cause the $\mathrm{pH}$ to decrease afterwards [45]. Lower $\mathrm{pH}$ has been suggested to increase the rate of hydrolysis, which facilitates the decomposition of the biomass components [2], [73], [77]. The pH also affects the elemental composition of the hydrochar (i.e., $\mathrm{C}, \mathrm{O}$, and $\mathrm{H}$ concentrations). Higher $\mathrm{pH}$ values are associated with $\mathrm{H} / \mathrm{C}$ atomic ratios similar to that for bituminous coal, while lower $\mathrm{pH}$ values result in reduced O/C ratios [1], [77]. Overall, using weak acids in HTC can improve the rate of reactions in the process, which results in faster production of and higher HHVs for the hydrochar [70], [78]. Ghanim et al. found sulphuric acid increased the mass yield to $\approx 38 \%$ and the HHV to $\approx 23.8 \mathrm{MJ} / \mathrm{kg}$, with $\mathrm{pH}$ of 2 for the process liquid prior to HTC of poultry litter, compared with $27 \%$ and $21.9 \mathrm{MJ} / \mathrm{kg}$, respectively with an initial $\mathrm{pH}$ of $\approx 7$ [77]. Meanwhile, alkaline conditions have been shown to reduce the heavy metal concentration of sewage sludge after the HTC process [3].

\subsection{Catalysed Hydrothermal Carbonization (CHTC)}

Catalysed hydrothermal carbonization (CHTC) is similar to HTC in nature with a main difference that CHTC uses an acidic catalyst with pKa in 
the range of 1.5-3.8 [4]. The lower $\mathrm{pH}$ enhances the decomposition of the biomass components. Hence, hydrochar can be produced at lower temperatures and shorter times [70]. The process can also be used to produce, potentially, higher concentrations of organic compounds such as HMF, levulinic acid, and formic acid [4]. 


\section{Chapter 3: Catalysed Hydrothermal Carbonization with Process}

\section{Liquid Recycling}

(Submitted and under revision)

Amin Ghaziaskar ${ }^{1+}$, Glenn A. McRae ${ }^{1++}$, Alexis Mackintosh ${ }^{2}$, Onita D. Basu $3^{*}$

${ }^{1}$ Department of Mechanical and Aerospace Engineering, Carleton University, Canada, K1S 5B6

+amin.ghaziaskar@carleton.ca, ${ }_{++}^{++}$glenn.mcrae@carleton.ca

${ }^{2}$ PCS Technologies Inc., Vancouver, Canada

alexis@pcsbiofuels.com

3 Department of Civil and Environmental Engineering, Carleton University, Canada, K1S 5B6

onita.basu@carleton.ca

\section{Abstract}

Catalysed Hydrothermal Carbonization (CHTC) was used to produce hydrochar biofuel from wood chips at $240{ }^{\circ} \mathrm{C}$ in one-hour batches that included recycling of the process liquid. Infrared spectra showed changes in the chemical structure consistent with dehydration and decarboxylation. The

*Onita.Basu@carleton.ca, Tel: 613-520-2600, 1125 Colonel By Drive, Ottawa, ON, Canada K1S 5B6 
CHTC hydrochar had Higher Heating Values (HHV) of $28.3 \mathrm{MJ} / \mathrm{kg}$, energy yields of $64 \%$, and $\mathrm{H} / \mathrm{C}$ and $\mathrm{O} / \mathrm{C}$ ratios similar to coal. The same process without the catalyst (HTC) produced a hydrochar with $\mathrm{HHV}$ of $27 \mathrm{MJ} / \mathrm{kg}$, energy yield of 57\%, and $\mathrm{H} / \mathrm{C}$ and $\mathrm{O} / \mathrm{C}$ ratios similar to lignite. Partial recycling of the CHTC process liquid resulted in a $5 \%$ increase in the energy yield; elemental composition, HHV, and scanning electron microscopic images of the CHTC hydrochar for different recycles were indistinguishable. Densified CHTC hydrochar pellets were $97 \%$ durable, and hydrophobic when compared with wood pellets and torrefied wood pellets, which was shown by water ingress measurements using an electrochemical cell with pellet electrodes. The CHTC process with recycling has the potential to provide a green hydrochar biofuel with excellent handling, storage and transportation properties that could be a suitable direct replacement for coal.

\section{Keywords:}

Catalysed Hydrothermal Carbonization, Biomass, Hydrochar, Process liquid, Recycling

\section{Declaration of interest:}

Alexis Mackintosh (co-author) holds patents on acid-catalysed hydrothermal processes. 


\subsection{Introduction}

Renewable fuels are being developed to supplement or replace coal to mitigate climate change. Coal currently is used for $38 \%$ of global power generation [79]. Replacing coal with solid biofuels would lower fossil carbondioxide emissions.

Hydrothermal carbonization (HTC) is a process to produce a solid carbon-neutral fuel called hydrochar, or biofuel. HTC hydrochar is deemed carbon-neutral because the $\mathrm{CO}_{2}$ produced when it is burned is classified as part of the natural or renewable carbon cycle [80]. Compared with coal, hydrochar made from typical sources of biomass has low sulfur [81], which reduces the formation of sulfur oxides and lessens acid rain impacts when burned for power generation.

HTC makes hydrochar by the reaction of biomass in aqueous solution at 180-300 ${ }^{\circ} \mathrm{C}$. The process typically requires 1-72 h [1]; although shorter times have been reported [45], [82]. Furthermore, because HTC is an aqueous process, it is well suited to handling biomass with high moisture and may decrease some process steps during production (i.e. drying). 
The HTC process is a complex series of reactions including hydrolysis, dehydration, decarbonylation, decarboxylation, polymerization, and recondensation [81]. These reactions will result in the production of gases, liquid, and carbonaceous solid. The gas produced through HTC is mainly made up of $\mathrm{CO}_{2}$, due to decarboxylation reactions [61]. The liquid of the HTC process contains organic acids and intermediate compounds produced by degradation of cellulose and lignin [5], [45]. The main components of the lignocellulosic biomass (i.e., cellulose, hemicellulose, and lignin) react by hydrolysis forming fragments such as glucose and fructose, which then further dehydrate into intermediate compounds such as 5-hydroxymethylfurfural (HMF), furfural, phenol, and monomeric sugars. The process reactions also produce organic acids such as acetic acid, levulinic acid, and formic acid. These intermediate compounds polymerize via acid-catalysed condensation into the hydrochar [1], [48]. The carbonaceous solid (hydrochar) can have similar energy density as coal. The organic acids produced during the process may also provide additional commercial revenue if harvested.

The kinetics of the CHTC process is first order with an Arrhenius activation energy of $152 \mathrm{~kJ} / \mathrm{mole}$ associated with hydration of $B(1 \rightarrow 4)$ ether bonds between glucose molecules in cellulose [83], [84]. To make hydrochar in a reasonable time requires heat to bring the process liquid to the reaction temperature. Hot recycling of the process liquid reduces energy costs by lessening the heat required to raise subsequent batches to the reaction 
temperature. Recycling also lessens the burden of waste management by reducing the volume of process liquid to be treated to remove organic substances. Additionally, the process liquid has shown catalytic properties that increase dehydration reactions [5], and lower $\mathrm{pH}$ of the process liquid has been found to improve properties of the hydrochar, including higher energy density [2], [3], [73], [77], [85].

During the HTC process, the $\mathrm{pH}$ is lowered by the production of organic acids, which enhance acid-catalysed condensation and dehydration reactions and hydrochar production. These benefits of low $\mathrm{pH}$ accrue over time as the process proceeds. These benefits might be realized sooner if low $\mathrm{pH}$ was established at the start of the process rather than waiting for it to occur from in-situ production of organic acids. The purpose of this study is to investigate the benefits to the HTC process of controlling the $\mathrm{pH}$ to low values from the start.

This study introduces Catalysed Hydrothermal Carbonization (CHTC) in which a catalyst is added to the HTC process [4]. The catalyst is designed to promote low $\mathrm{pH}$ reactions. This study presents the effects of the catalyst on the HTC process, and results of low initial $\mathrm{pH}$ during recycling of the process liquid. Chemical, physical, and mechanical characteristics of the hydrochar reported include elemental composition, high heating value (HHV), mass yield, 
surface properties, chemical bonds, compressibility, durability, and water absorptivity.

\subsection{Methods and Materials}

\subsubsection{Catalysed Hydrothermal Carbonization (CHTC)}

CHTC experiments were conducted in $300 \mathrm{~mL}$ Parr bench-top reactors (Parr Instrument Company, Moline). Approximately $10 \mathrm{~g}$ of woody biomass was mixed into $120 \mathrm{~mL}$ of water and catalyst (liquid to biomass ratio of $12: 1$ ) in a glass liner placed inside a reactor. The reactor was heated at $7{ }^{\circ} \mathrm{C} / \mathrm{min}$ using a Parr rigid heating mantle (Parr Instrument Company, Moline) to 240 $\pm 2.2{ }^{\circ} \mathrm{C}$ where it was held one hour. The temperature was measured using a type $\mathrm{J}$ thermocouple. The pressure was monitored using an analogue transducer. After the process, the reactor air-cooled to room temperature and gaseous products were vented in a fume hood to atmosphere.

The hydrochar was separated from the process liquid by vacuum filtration with $0.45 \mu \mathrm{m}$ filter paper. Approximately $80 \%$ of the process liquid was recovered after filtration. The $\mathrm{pH}$ of the process liquid was measured with an ORION STAR A326 pH meter from Thermo Scientific (Dreieich, Germany). 
The solid hydrochar was washed with $300 \mathrm{~mL}$ of distilled water and then dried at $105{ }^{\circ} \mathrm{C}$ for $24 \mathrm{~h}$.

Recycling of the process liquid was conducted 15 times. Fresh catalyst was added to recycled process liquid to makeup the reaction volume to $120 \mathrm{~mL}$ and the initial $\mathrm{pH}$ 2.4. The hydrochar produced from the first process is labelled "Fresh", and the hydrochar samples from subsequent recycling experiments are labelled sequentially R1-R15.

The same process was done but without the catalyst and without recycling. The process, in this case, is simply labelled hydrothermal carbonization, or HTC.

\subsubsection{Materials}

The feedstock biomass was wooden stir sticks (white pine and birch, 1 $\mathrm{mm}$ thick) that were ground to lengths $10 \mathrm{~mm}$ to $30 \mathrm{~mm}$, and widths $\approx 2 \mathrm{~mm}$, and then stored in a closed container until processing. The moisture content of 
the sticks was $4.5 \%$. Torrefied wood and wood pellets were supplied by Airex Energy (Laval, Québec, Canada).

\subsubsection{Characterisation of the Solid Hydrochar}

Mass yield was determined from the ratio of the masses of the hydrochar and the feedstock, both on a dry mass basis.

The HHV of the feedstock and hydrochar was estimated in $\mathrm{MJ} / \mathrm{kg}$ using the unified correlation developed by Channiwala and Parikh [86]:

$$
\mathrm{HHV}=0.3491 C+1.1783 H+0.1005 S-0.1034 O-0.0151 N-0.0211 A,
$$

where $C, H, S, O, N$, and $A$ represent carbon, hydrogen, sulphur, oxygen, nitrogen, and ash contents of the hydrochar, respectively, in mass percentages on a dry basis.

The energy-densification ratio was calculated by dividing the HHV of the hydrochar by the HHV of the biomass feedstock:

$$
\text { Energy densification ratio }=\frac{\text { HHV of the hydrochar }}{\text { HHV of the biomass }}
$$


Energy yield was calculated as a product of the mass yield and the energy densification ratio.

Moisture analysis was performed following ISO 18134 using a LECO TGA 701 instrument (LECO Corporation, St. Joseph, MI). The carbon, nitrogen, and hydrogen contents were determined with an Elementar Vario Macro Cube (Elementar Analysensysteme GmbH, Langenselbold, Germany) using ASTM D5373-16. Total sulfur was measured using an Elementar Trace SN cube (Elementar Analysensysteme GmbH, Langenselbold, Germany) according to ASTM 5453. The oxygen content was calculated by mass difference $(\mathrm{O} \%=100-(\mathrm{C} \%+\mathrm{H} \%+\mathrm{N} \%)-\mathrm{ash} \%)$. Ash content was measured using a Mettler TGA/DSC1 using ASTM E1131-08. The elemental analyses mentioned above for the feedstock biomass and hydrochar samples were done by CanmetENERGY - Natural Resources Canada, Ottawa, ON. Infrared (IR) spectra of hydrochar-KBr pellets, made from $10 \mathrm{mg}$ of hydrochar mixed with $300 \mathrm{mg}$ of $\mathrm{KBr}$ at room temperature, were measured with an $\mathrm{ABB}$ Bomem MB100 (ABB Bomem, Quebec, Canada).

The morphology and surfaces of the hydrochar were observed with a JEOL JSM-7500F (JEOL, Japan) Field Emission Scanning Electron 
Microscope (SEM). Samples were dispersed on a conductive carbon pad and coated with Au to a thickness of $5 \mathrm{~nm}$.

\subsubsection{Densification}

The hydrochar was densified using a single-pellet press with a diameter of $8.5 \mathrm{~mm}$. The hydrochar was in the press for $10 \mathrm{~min}$ at $140{ }^{\circ} \mathrm{C}$ prior to pressing to ensure temperature uniformity. Pellets were made with pressures of $70 \mathrm{MPa}, 95 \mathrm{MPa}, 135 \mathrm{MPa}$ and $155 \mathrm{MPa}$ held for 30 seconds. The pellets were pushed out of the press and left to air-cool to room temperature. All the pellets had a diameter of $8.50 \pm 0.05 \mathrm{~mm}$ measured with a caliper. The lengthto-diameter ratios (L/D) of the pellets ranged from 1.1 to 2.2. Pellet masses ranged from $0.5 \mathrm{~g}$ to $1.3 \mathrm{~g}$. Mass density was calculated by dividing the mass by the volume of the pellets. The energy density $\left(\mathrm{MJ} / \mathrm{m}^{3}\right)$ was calculated by multiplying the mass density $\left(\mathrm{kg} / \mathrm{m}^{3}\right)$ and HHV $(\mathrm{MJ} / \mathrm{kg})$.

\subsubsection{Mechanical Strength of Hydrochar Pellets}

\subsubsection{Durability Test}

The durability of hydrochar pellets was quantified with the pellet durability index (\% PDI) using ASTM D3402, Standard Test Method for Tumbler Test for Coke. This method consists of tumbling pellets in a can and 
measuring the mass loss of the pellets. The metal tumbler had length $230 \mathrm{~mm}$, width $210 \mathrm{~mm}$, and depth $90 \mathrm{~mm}$. Two pellets from each recycle experiment were tumbled for $10 \mathrm{~min}$ at $54 \mathrm{rpm}$ with 600 wooden dowels $(\mathrm{L} / \mathrm{D}=2)$. The pellets were screened using a $2.38 \mathrm{~mm}$ sieve. The PDI was calculated using:

$$
\text { PDI }(\%)=\frac{M_{f}}{M_{i}} \times 100,
$$

where $M_{i}$ and $M_{f}$ are the initial and final masses of the pellets. Results of the current version of the method were compared with reported PDI values for torrefied wood pellets from Airex Energy (Québec, Canada) and found to agree within error of the value advertised by the producer $(\geq 96 \%)$, which provides confidence in the current numbers.

\subsubsection{Compression Test}

The compression strength of the pellets was determined using an Instron 5582 testing machine (Instron, Norwood, MA). The pellets were placed vertically on a cylindrical rod and compressed at a rate of $0.2 \mathrm{~mm} / \mathrm{min}$. The force of compression and the displacement were recorded. The maximum force a pellet could withstand before cracking or breaking was used to calculate the maximum compressive strength of the pellet: i.e., by dividing the maximum force by the surface area of the cross-section of the pellet. 


\subsubsection{Electrochemical water ingress (EWI) test}

Water absorption of the densified hydrochar pellets was determined by mass gain and electric current measurements. Hydrochar pellets were partially immersed to a depth of $6 \mathrm{~mm}$ in electrolyte along with a carbon electrode that served to create an electrochemical cell. A Solartron Electrochemical Interface SI1287 (Solartron Analytical, UK) was used to generate a potential difference of $0.5 \mathrm{~V}$ and the current passing through the cell and pellet was measured for 24 hours. The voltage was chosen to prevent electrolysis of the liquid. The electrolyte was deionized water with $10 \mathrm{~g} / \mathrm{L}$ of $\mathrm{NaCl}$. Each pellet was weighed before and after the test with a Sartorius BP 2215 analytical balance with a precision of $0.1 \mathrm{mg}$. The water uptake was calculated:

$$
\text { water uptake }(\%)=\frac{m_{f}-m_{i}}{m_{i}} \times 100 \% \text {, }
$$

where $m_{i}$ was the initial mass of the pellet and $m_{f}$ the final mass of the pellet.

\subsection{Results and Discussion}

The first 'Fresh' processing was done with pure catalyst solution. The $\mathrm{pH}$ of the recovered process liquid for subsequent recycle experiments was between 2.65 and 2.8, as shown in Figure 3-1. Make-up catalyst solution was used to standardize the initial $\mathrm{pH}$ of the recycled process liquid at $2.40 \pm 0.07$ : 
$\approx 40 \%$ by volume was recycled process liquid and the rest was fresh make-up catalyst solution. The higher $\mathrm{pH}$ of the process liquid effluent at the end of each recycle, $\approx 2.7$, is consistent with dilution caused by the water produced from dehydration reactions.

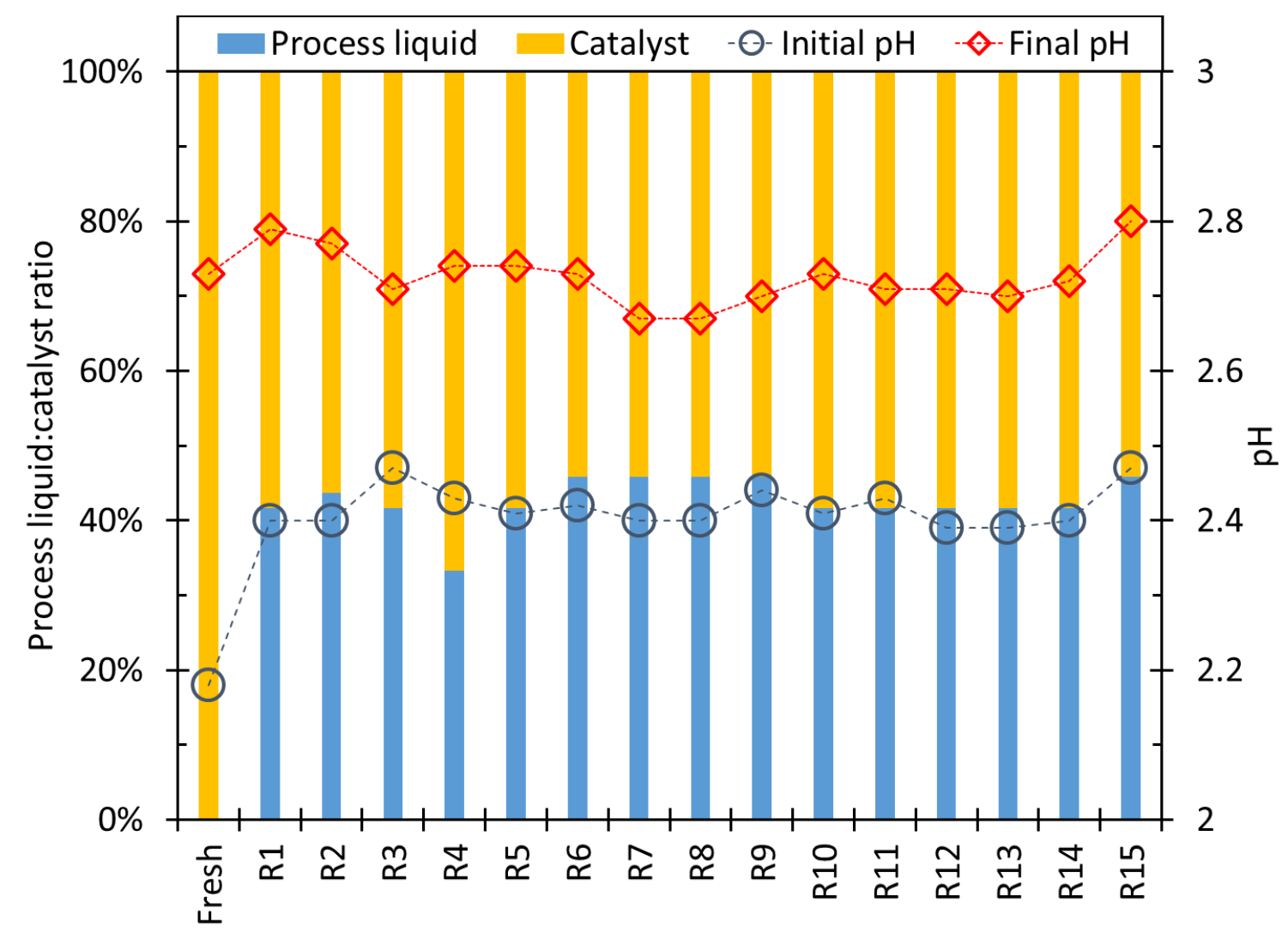

Figure 3-1: Percentage ratio of make-up catalyst solution (Catalyst) to recovered process liquid (Process liquid) used in 15 recycle experiments (stacked columns), circles show pH of the liquid biomass mixture prior to start of the process (initial $\mathrm{pH}$ ), and diamonds show $\mathrm{pH}$ of the process liquid after CHTC (final pH). 


\subsubsection{Characterisation of the Solid Hydrochar}

\subsubsection{Influence of Process Liquid Recycling on Atomic Ratios (H/C-O/C) of the Hydrochar}

The goal of the CHTC process was to produce hydrochar that can be used as a one-for-one replacement for coal, but better than coal because it will have low sulfur and low ash. The similarity of the hydrochar and coal can be illustrated with a Van Krevelen diagram and the hydrogen to carbon (H/C) and oxygen to carbon (O/C) atomic ratios, Figure 3-2. Arrows in Figure 3-2 show the effects of dehydration and decarboxylation reactions, which occur with other reactions during the hydrothermal carbonization process.

Figure 3-2 shows that the ratios of H/C and O/C for the biomass (1.44, 0.66, respectively) are larger than the same ratios for the CHTC hydrochar (0.79, 0.25, respectively). The CHTC hydrochar falls into the range of values associated with coal. By contrast, the HTC process, which was done without catalyst, but otherwise identical conditions, produced hydrochar with $\mathrm{H} / \mathrm{C}$ and $\mathrm{O} / \mathrm{C}$ ratios 0.89 and 0.29 , respectively, that are more like lignin, as shown by the blue square in Figure 3-2. Similar ratios reported for hydrochar produced from HTC using as feedstock biomass poplar wood (Stemann et al., 2013) [5] and paper (Weiner et al., 2014) [8], processed at $220{ }^{\circ} \mathrm{C}$ and $200{ }^{\circ} \mathrm{C}$, respectively, and loblolly pine (Hoekman et al., 2013) [87] and tobacco stalks 
(Cai et al., 2016) [88] which were both treated at $240{ }^{\circ} \mathrm{C}$ are also illustrated in Figure $3-2$. The $\mathrm{O} / \mathrm{C}$ and $\mathrm{H} / \mathrm{C}$ ratios of the hydrochar from $\mathrm{HTC}$ are positioned in ranges associated with lignite (at best) and peat (at worst). The current results showing lower $\mathrm{O} / \mathrm{C}$ and $\mathrm{H} / \mathrm{C}$ ratios for the CHTC hydrochar compared with the HTC hydrochar suggest that the catalyst enhances dehydration and decarboxylation, which is seen by the farther movement to the left and down from the initial biomass region in Figure 3-2.

Elemental compositions of the feedstock biomass and hydrochar produced from the partial recycle experiments can be found in Table 3-1 as mass percentages. The carbon contents of the biomass were increased from $\approx 50 \%$ to $71.5 \%$ in the hydrochar while the concentration of the oxygen reduced from $43.9 \%$ to $23.7 \%$. The amounts of carbon, hydrogen, nitrogen, and oxygen in the CHTC hydrochar did not vary significantly over the 15 recycles, Table $3-1$.

After the CHTC process, the ash content in the hydrochar is half the value in the biomass feedstock; $0.54 \%$ compared with $1.1 \%$. This decrease in ash is expected because the ash is composed mainly of inorganic cations that naturally partition to the process liquid. Mixed results have been reported regarding ash content and accumulation within recycled processes [5], [7], [45]. 
Table 3-1 Elemental composition (on dry basis, \% mass) of the biomass and hydrochar, energy content, energy densification ratio, and energy yield, (uncertainties in measurements are in units of least significant figures unless otherwise noted). ${ }^{1}$

\begin{tabular}{|c|c|c|c|c|c|c|c|c|c|c|}
\hline & $\begin{array}{l}\text { Raw } \\
\text { biomas }\end{array}$ & $\begin{array}{l}\mathrm{HT} \\
\mathrm{C}\end{array}$ & $\begin{array}{c}\text { Fres } \\
\text { h }\end{array}$ & R1 & R3 & $\mathrm{R} 4$ & R8 & R12 & R13 & $\mathrm{R} 15$ \\
\hline & $\mathbf{s}$ & & & & & & & & & \\
\hline \multirow[t]{2}{*}{ C (\%) } & 49.9 & 68.2 & 71.4 & 71 & 71. & 71. & 71 & 71.2 & 71.4 & 71.1 \\
\hline & & & & & 5 & 4 & & & & \\
\hline \multirow[t]{2}{*}{$\mathrm{H}(\%)$} & 5.98 & 5.06 & 4.71 & 4.9 & 4.9 & 4.9 & 4.9 & 4.87 & 4.73 & 4.88 \\
\hline & & & & 8 & 0 & 0 & 0 & & & \\
\hline \multirow[t]{2}{*}{$\mathrm{N}(\%)$} & 0.21 & 0.16 & 0.20 & 0.2 & 0.2 & 0.2 & 0.1 & 0.21 & 0.16 & 0.20 \\
\hline & & & & 2 & 1 & 0 & 8 & & & \\
\hline \multirow[t]{2}{*}{ O (\%) } & 43.9 & 26.6 & 23.7 & 24. & 23. & 23. & 25. & 23.7 & 23.7 & 23.8 \\
\hline & & & & 8 & 4 & 5 & 1 & & & \\
\hline HHV & 19.9 & 27.0 & 28.0 & 28. & 28. & 28. & 28. & 28.1 & 28.1 & 28.1 \\
\hline (MJ/kg & \pm 0.3 & \pm 0.4 & \pm 0.4 & 2 & 3 & 3 & 1 & \pm 0.4 & \pm 0.4 & \pm 0.4 \\
\hline \multirow[t]{2}{*}{)} & & & & \pm 0 & \pm 0 & \pm 0 & \pm 1 & & & \\
\hline & & & & 9 & 4 & 4 & & & & \\
\hline \multirow[t]{2}{*}{$\mathrm{EDR}^{2}$} & 1 & 1.36 & 1.41 & 1.4 & 1.4 & 1.4 & 1.4 & 1.41 & 1.41 & 1.41 \\
\hline & & & & 1 & 2 & 2 & 1 & & & \\
\hline $\begin{array}{l}\mathrm{EY}^{3} \\
(\%)\end{array}$ & & 57 & 64 & 68 & 69 & 67 & 68 & 66 & 68 & 69 \\
\hline \multicolumn{11}{|c|}{${ }^{1}$ Sulfur was less than $0.01 \%$ for all hydrochar samples } \\
\hline \multicolumn{11}{|c|}{2 Energy densification ratio } \\
\hline 3 Energy & & & & & & & & & & \\
\hline
\end{tabular}




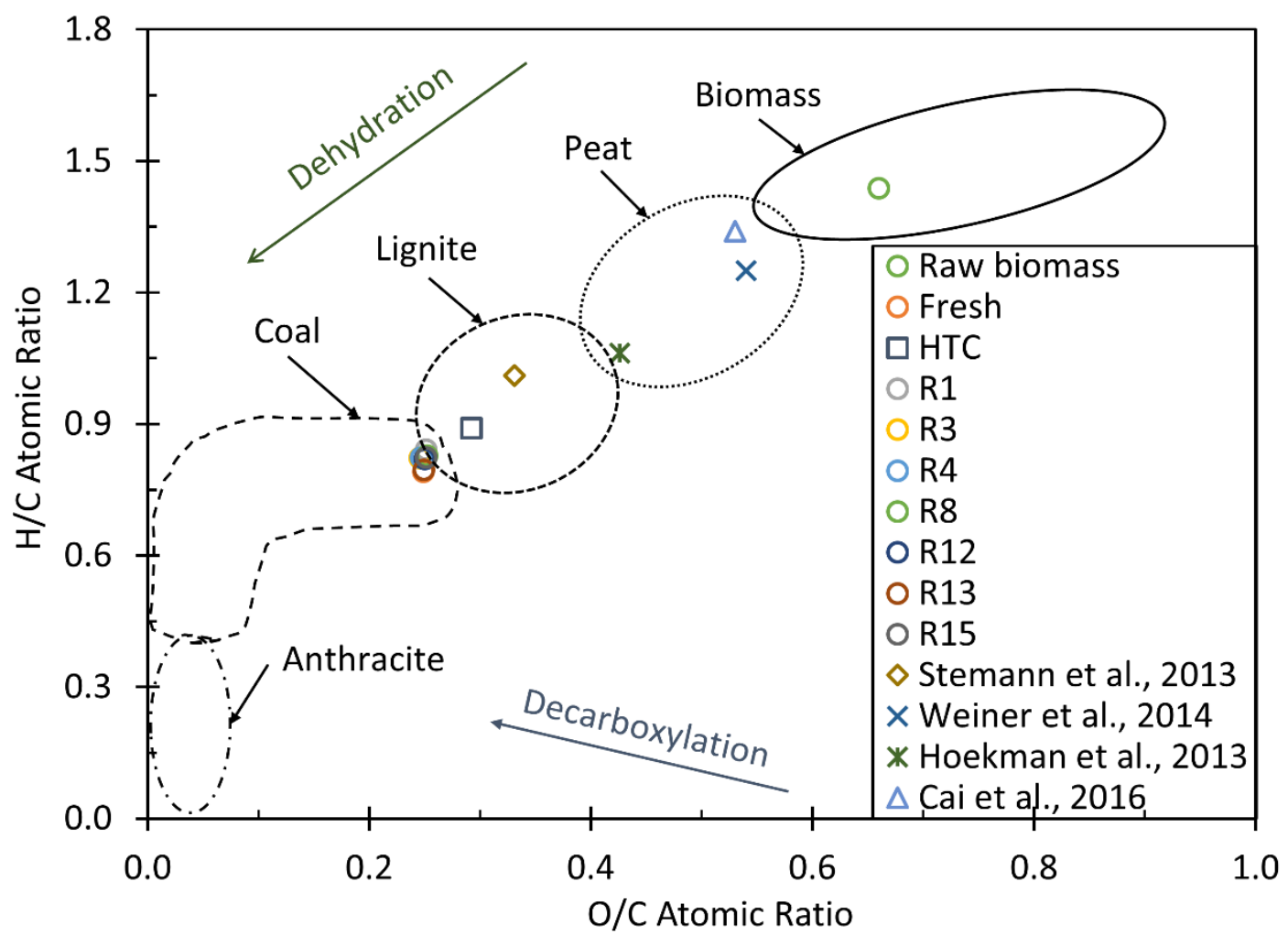

Figure 3-2: Van Krevelen diagram showing atomic ratios of the feedstock biomass and the hydrochar samples. The dehydration and decarboxylation reactions are enhanced by the catalyst producing CHTC hydrochar with $\mathrm{H} / \mathrm{C}$ and $\mathrm{O} / \mathrm{C}$ ratios that fall in the region where lignite and coal overlap. The $\mathrm{H} / \mathrm{C}$ and $\mathrm{O} / \mathrm{C}$ ratios of the hydrochar do not vary significantly with recycling. The hydrochar produced without catalyst (HTC), but otherwise identical processing conditions, falls within the lignite region of the diagram, shown by the blue square.

\subsubsection{IR Spectroscopy of the Hydrochar}

Infrared spectra can be used to track changes in bonding that occur during the CHTC process. Figure 3-3 shows IR spectra of the feedstock 
biomass, the hydrochar processed using only the catalyst solution (Fresh), and the hydrochar after 15 partial recycles (R15), and HTC hydrochar produced in this study (HTC). Chemical bonds found in woody biomass include $-\mathrm{OH}, \mathrm{C}-$ $\mathrm{H}$, and $\mathrm{C}-\mathrm{O}$, which are absorbed at $\sim 3400,2900$, and $1100 \mathrm{~cm}^{-1}$, respectively [56].

The intensity of the hydroxyl group peak, at $3400 \mathrm{~cm}^{-1}$, decreased after CHTC of the woody biomass, which suggests a decrease in the number of $\mathrm{OH}$ bonds consistent with the enhanced dehydration inferred from the lower $\mathrm{O} / \mathrm{C}$ and $\mathrm{H} / \mathrm{C}$ ratios shown in Figure 3-2. Reduction of the number of hydroxyl bonds is beneficial because it leads to an increase in hydrophobicity of the hydrochar [57], which is desired when outside storage of hydrochar might be subject to weather including rain. The intensity of the hydroxyl peak also decreased following the HTC process of woody biomass, but not as much as it did for CHTC. These results are consistent with lower $\mathrm{O} / \mathrm{C}$ and $\mathrm{H} / \mathrm{C}$ ratios for CHTC hydrochar compared with HTC hydrochar shown in Figure 3-2. In addition, the $\mathrm{C}-\mathrm{H}$ bonds (found in aliphatic groups) at $\sim 2900 \mathrm{~cm}^{-1}$ [89] reduced in intensity after CHTC, which is also consistent with dehydration of the feedstock biomass. The intensity of $\mathrm{C}-\mathrm{O}$ bonds at $\sim 1060 \mathrm{~cm}^{-1}$ found in cellulose and hemicellulose in the form of alcohol, [53] were greatly reduced after processing. However, the peak at $1200 \mathrm{~cm}^{-1}$, which also represents $\mathrm{C}-\mathrm{O}$ bonds, in the form of ether, was intensified in the hydrochar, showing the 
transition occurring from alcohols into stronger ether bonds through CHTC process.

The IR spectra also suggests that the CHTC process makes new chemical bonds such as $\mathrm{C}=\mathrm{O}, \mathrm{C}=\mathrm{C}, \mathrm{C}-\mathrm{O}$ found at $\sim 1700,1600$, and $1200 \mathrm{~cm}^{-1}$, respectively. The $\mathrm{C}=\mathrm{O}$ bonds can be found in the form of a carboxyl and/or a carbonyl group [53], while $\mathrm{C}=\mathrm{C}$ bonds in polymeric chains of the hydrochar. Evidence of $\mathrm{C} \_\mathrm{O}$ bonds, which can also be found in lignin [44], increased after CHTC.

Figure 3-3 shows that the chemical features inferred from the IR spectra of the hydrochar samples (Fresh, and R15 are shown for comparison) were relatively similar, but different from those in the raw biomass feedstock, which suggests that chemical features of the hydrochar produced from recycling the CHTC process liquid did not change appreciably. 


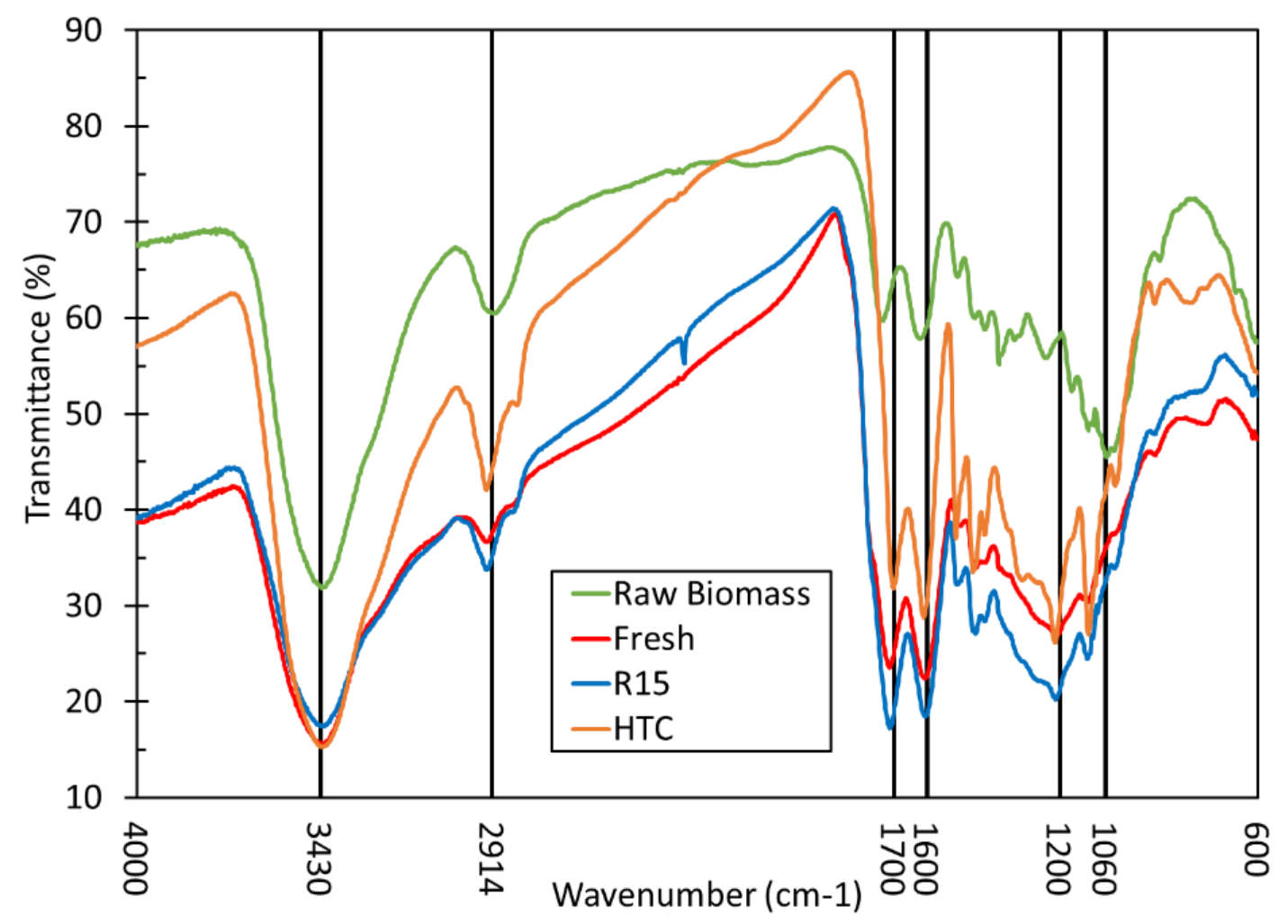

Figure 3-3: IR spectra of raw biomass, Fresh, and R15. The spectra of the hydrochars were similar, but different when compared with the spectra of the feedstock biomass. 


\subsubsection{SEM Images of the Hydrochar}

SEM images are shown in Figure $3-4$ for the woody biomass, and hydrochar produced from the Fresh catalyst solution, the $\mathrm{R} 1$ recycle, and $\mathrm{R} 15$ recycle. Figure 3-4a and $\mathrm{b}$ show fibrous structure in the feedstock biomass. After CHTC process, this fibrous structure disappears and is replaced with a spherical and porous hydrochar product. Figure $3-4 \mathrm{c}, \mathrm{d}$, e, and h show the hydrochar composed of spheres suggesting condensation about nucleation sites. Figure $3-4 \mathrm{~g}$ and $\mathrm{f}$ show the porous structure of the hydrochar. The images

of the hydrochar were indistinguishable regardless of recycling, which further supports the consistency of the hydrochar produced from recycling the process liquid. The porosity of the hydrochar is attributed to vaporization of volatile components [90]. 


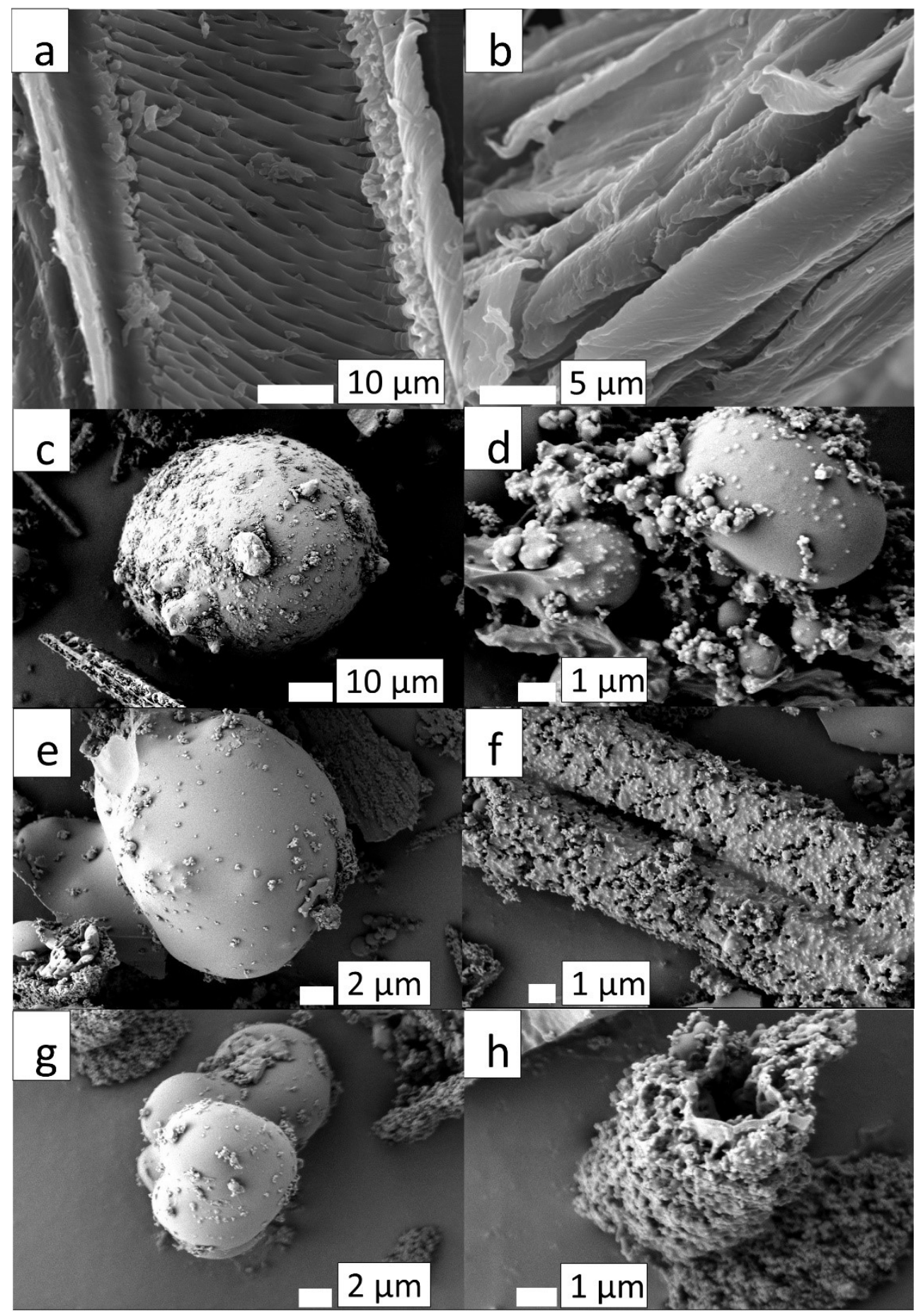

Figure 3-4: SEM images: (a, b) feedstock biomass showing fibrous structure; (c, d) spherical structure of the hydrochar from fresh catalyst solution (Fresh); (e, f) porous structure of the hydrochar R1; (g, h) R15 showing spherical and porous structure. The images of the hydrochar were indistinguishable, but different from the feedstock biomass. 


\subsubsection{Mass Yields and Energy Values}

The mass yields for the recycled samples are shown in Figure 3-5. The mass yield of hydrochar produced with Fresh catalyst solution was $45 \%$, but for subsequent recycling, the mass yield was greater and constant at $(48.3 \pm$ $0.3) \%(95 \%$ confidence).

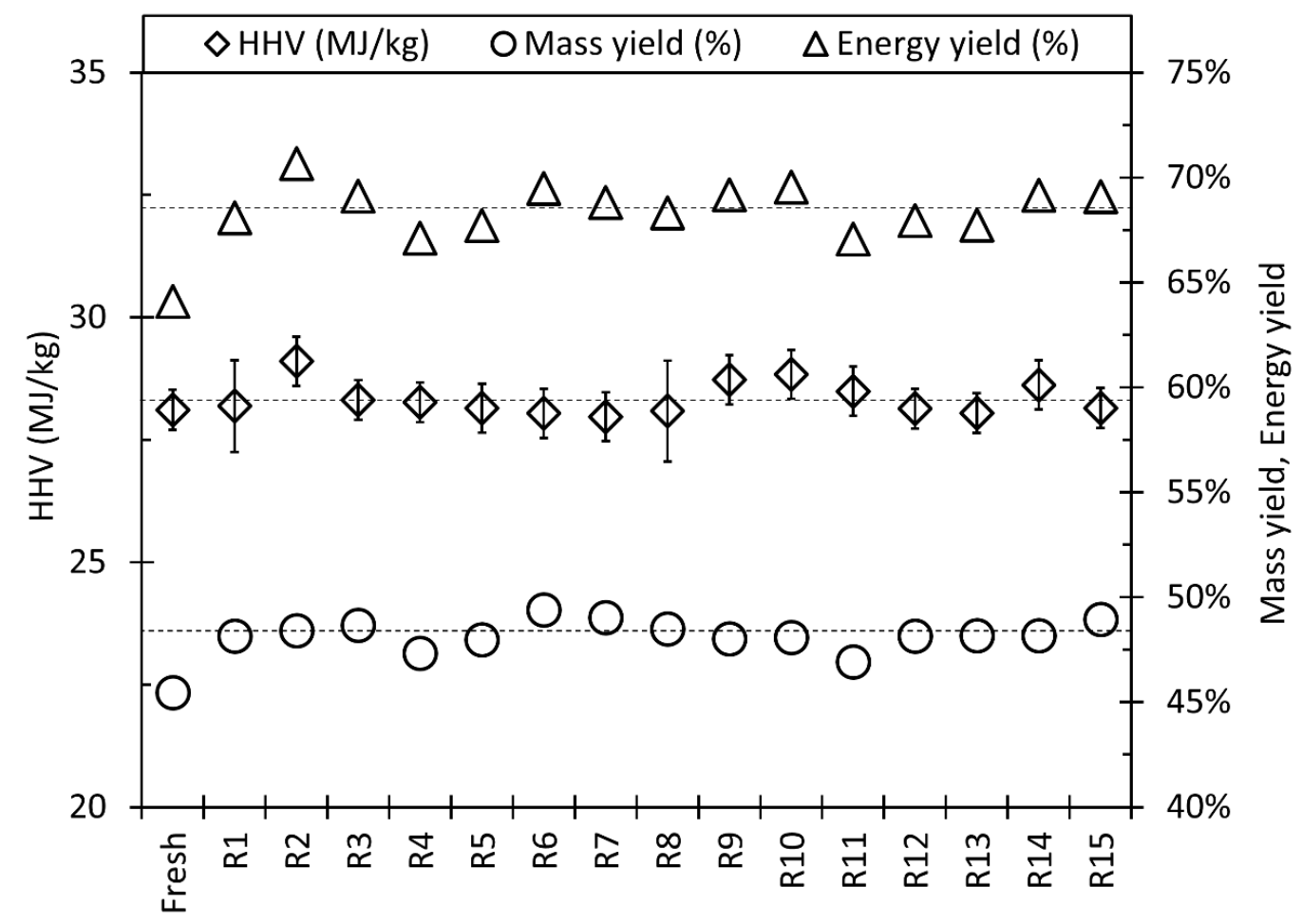

Figure 3-5: Higher Heating Value (HHV), mass and energy yield of the hydrochar samples. The mass yield increased by 2.7 percentage points for $\mathbf{R} 1$ compared with the initial process, which was done using only the catalyst solution as the starting liquid phase (Fresh). Energy yield increased from $64 \%$ (Fresh) to an average of $(68.6 \pm 1) \%$ for R1 to R15. The HHV is essentially unchanged for all the recycles. 
Hemicellulose and cellulose decompose hydrothermally at a useful rate at $180{ }^{\circ} \mathrm{C}$ and $220^{\circ} \mathrm{C}$, respectively [1], into sugar monomers such as glucose, fructose, and xylose that further degrade into intermediates such as formic acid, acetic acid, levulinic acid, and HMF [48]; lignin decomposes around $200{ }^{\circ} \mathrm{C}$ into aromatic alcohols. These intermediate compounds condense and polymerize into hydrochar. The mass yield from the initial process with fresh catalyst was $45.5 \%$. The mass yield increased to $(48.3 \pm 0.3) \%$ for recycles $\mathrm{R} 1$ R15. This increase is attributed to the hydrochar produced from the intermediate compounds already in the process liquid from previous recycles. Similar increases are seen for the energy yield: Pearson correlation coefficient of $0.96, p=0.0002$, for the energy yield and the volume of effluent added from the previous processes.

The CHTC hydrochar made using only Fresh catalyst solution had an energy content of $28.1 \pm 0.4 \mathrm{MJ} / \mathrm{kg}$, which is an increase of $40 \%$ compared with the HHV value of the feedstock biomass, $19.9 \pm 0.3 \mathrm{MJ} / \mathrm{kg}$. The increased HHV is attributed to the reduction of low-energy bonds from catalysed degradation of the biomass cellulose, hemicellulose, and lignin, and formation of highenergy bonds from polymerization of HMF into hydrochar. The HHV for CHTC hydrochar using recycled process liquid was the same, $28.3 \pm 0.3 \mathrm{MJ} / \mathrm{kg}$, independent of recycling, as shown in Figure 3-5. The energy yield, equal to 
the product of the mass yield and HHV, was likewise independent of recycling, Figure 3-5.

The determined values of HHV, mass yield and energy yield of CHTC hydrochar were all greater than the values obtained for HTC hydrochar. The HHV values were $28.1 \pm 0.4 \mathrm{MJ} / \mathrm{kg}$ for the $\mathrm{CHTC}$ compared with $27.0 \pm 0.4$ MJ/kg for HTC hydrochar - similar HTC studies with similar woody biomass feedstocks found $(24-26.7) \mathrm{MJ} / \mathrm{kg}$ [6], [45], [87]. The mass yield of the CHTC hydrochar was $45 \%$ compared with $42.3 \%$ for HTC. The overall performance of the processes can be characterized with the energy yield, which was $64 \%$ for CHTC and 57\% for HTC. By these metrics, the CHTC process is superior to the uncatalysed HTC process.

\subsubsection{Densification}

The pressure required to make pellets of woody biomass and hydrochar depends on material properties, temperature, moisture content, and particle size [91]. The hydrochar was pelletized at $140{ }^{\circ} \mathrm{C}$, where the hydrochar particles are expected to go through their glass transition [61], for the pressures shown in Figure 3-6. At the glass temperature, the hydrochar particles soften into a viscous state allowing flow into voids when pressure is applied. At higher pressures the density of pellets was increased from $830 \pm$ 
$50 \mathrm{~kg} / \mathrm{m}^{3}$ at $70 \mathrm{MPa}$ to $1050 \pm 60 \mathrm{~kg} / \mathrm{m}^{3}$ at $135 \mathrm{MPa}$, and $1070 \pm 30 \mathrm{~kg} / \mathrm{m}^{3}$ at 155 MPa. The density of the pellets was not found to vary with the number of times the process liquid was recycled.

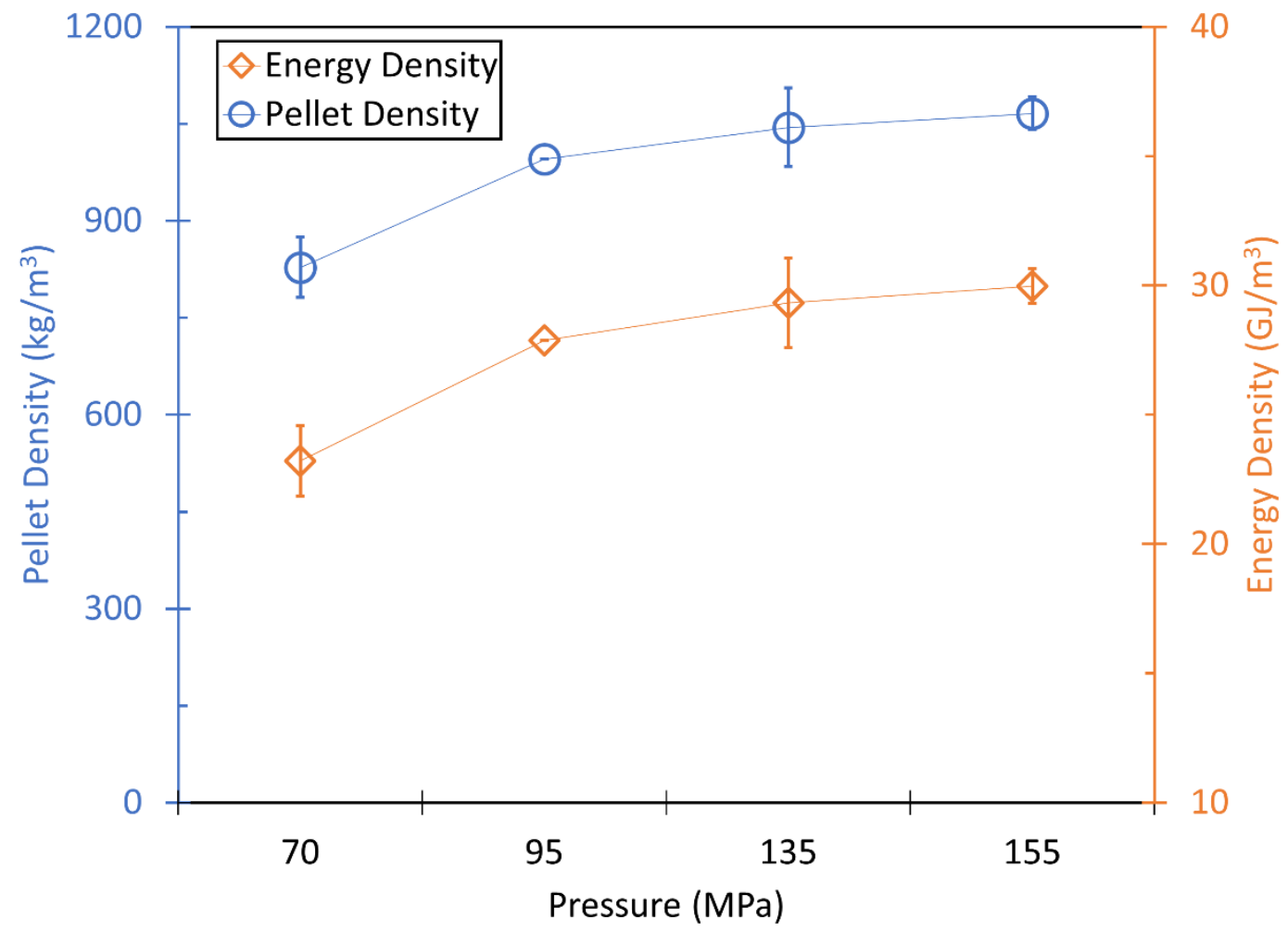

Figure 3-6: Average density and energy density of pellets made at four different pressures. The density did not change after increasing the compression from $135 \mathrm{MPa}$ to $155 \mathrm{MPa}$. The energy density reached $30 \mathrm{GJ} / \mathrm{m}^{3}$ at a density of $1070 \pm 30 \mathrm{~kg} / \mathrm{m}^{3}$.

\subsubsection{Mechanical Properties of Hydrochar Pellets}

Densified hydrochar pellets were subjected to durability, compression, and water absorptivity tests to investigate their behaviour under extreme 
service conditions. The hydrochar will likely be transported in large containers where pellets will be stacked in piles, so pellets must have good compression strength, and should be non-friable to avoid dust and potential breathing and explosion hazards. These pellets should also withstand high humidity including rain and water immersion.

\subsubsection{Durability Test}

Pellets made from feedstock biomass, and hydrochar from recycle R1, R4, R6, R11, R13, and R15 were tested for durability, Table 3-2. The durability of the hydrochar pellets were within a range of $96 \%$ to $97.1 \%$, independent of recycling the process liquid, except R11, which had durability of $94.5 \%$. The lower durability of R11 was likely because of lower densification pressure. 
Table 3-2 Durability of the hydrochar pellets with pressure. Durability estimates were similar for pellets made with pressures $\geq 135 \mathrm{MPa}$, but dropped by $\approx 2 \%$ when the pressure was reduced to 70 MPa.

\section{Densification pressure}

(MPa)

\begin{tabular}{ccc}
\hline \multirow{2}{*}{155} & $\mathrm{R} 4$ & $96.7 \%$ \\
\cline { 2 - 3 } & $\mathrm{R} 15$ & $96.2 \%$ \\
\hline & $\mathrm{R} 1$ & $97.1 \%$ \\
\hline & $\mathrm{R} 6$ & $96.0 \%$ \\
\hline 70 & $\mathrm{R} 13$ & $96.5 \%$ \\
\hline
\end{tabular}

Sample

Durability 
and compressive strengths were $\leq 14 \mathrm{MPa}$. Higher compressive strengths of $100 \mathrm{MPa}$ for HTC hydrochar pelletized at $550 \mathrm{MPa}$ have been reported [61]. Table 3-3 shows that the compressive strength of the pellets was lower for pellets made with lower densification pressures, which suggests that higher pressures could produce stronger pellets, if required.

Table 3-3: Compressive strength of densified hydrochar pellets with densification pressure. The densification pressure was found to affect the compressive strength of the pellets while recycling the process liquid did not.

\section{Densification pressure (MPa) Sample \\ Maximum Compressive Strength \\ $(\mathrm{MPa})$}

R2 14

135

R10 14

95

R9

9

70

R7

3

\subsubsection{Electrochemical water ingress (EWI) test}

Figure 3-7 shows the time-dependence of electric current passing through an electrochemical cell composed of a sodium chloride solution with one electrode a carbon rod and the other electrode a pellet made of wood, hydrochar, or torrefied wood. Electrolyte ingress or penetration into the pellet 
short-circuits the electrical resistance of the pellet which causes the current in the cell to rise. Thus, current indicates water ingress.

The wood pellet disintegrated after 8 minutes in the electrochemical cell as shown in Figure 3-7 by the vertical 'spike' reaching $16 \mathrm{~mA}$. This disintegration was mainly caused by the hydration forces (repulsive forces acting in between surfaces separated by a thin layer of water) in between the wood particles as a result of water absorption by cellulose, hemicellulose, and lignin [92]. The current returned to zero when the wood pellet disappeared into solution, Figure 3-8. The electrochemical cell with a torrefied-wood-pellet electrode took 24 hours for the current to reach half the value measured through the wood pellet when the wood pellet disintegrated. In contrast to both the wood and the torrefied-wood pellets, the densified hydrochar pellets showed more resistance against water ingress. The current in the electrochemical cell was zero for the 24 hours tests with hydrochar pellets made from pure catalyst solution (Fresh) and recycle R3. Tests with hydrochar pellets from R8 and R14 showed very slight currents, less than $0.4 \mathrm{~mA}$. The hydrochar pellets (i.e., Fresh, R3, R8, and R14) gained 20\% mass after 24 hours, while the volume increased by $5 \%$, which suggests water ingress into $\approx 15 \%$ porosity.

Curiously, the hydrochar pellets absorbed mass, which presumably is because of water ingress, but their resistance did not change, suggesting that 
the water was only absorbed by a part of the pellets. The lack of current increase also suggests reduced capillary motion of the water through the hydrochar pellet, which is consistent with the reduced number of $\mathrm{OH}$ bonds in the hydrochar inferred from the IR spectra, Figure 3-3. These bonds can help elevate water through the porous structure of the pellet. The torrefied wood and wood pellets have relatively more $\mathrm{OH}$ bonds which makes them hydrophilic and prone to water absorption. Another curious feature is that air bubbles are seen in Figure 3-8 on the surface of the hydrochar pellet, which is also consistent with voids in the hydrochar pellets that can be filled with water. Further experiments are needed to quantify water ingress into the pellet and whether it is possible to reduce the number/volume of the voids and pores by changing densification conditions. 


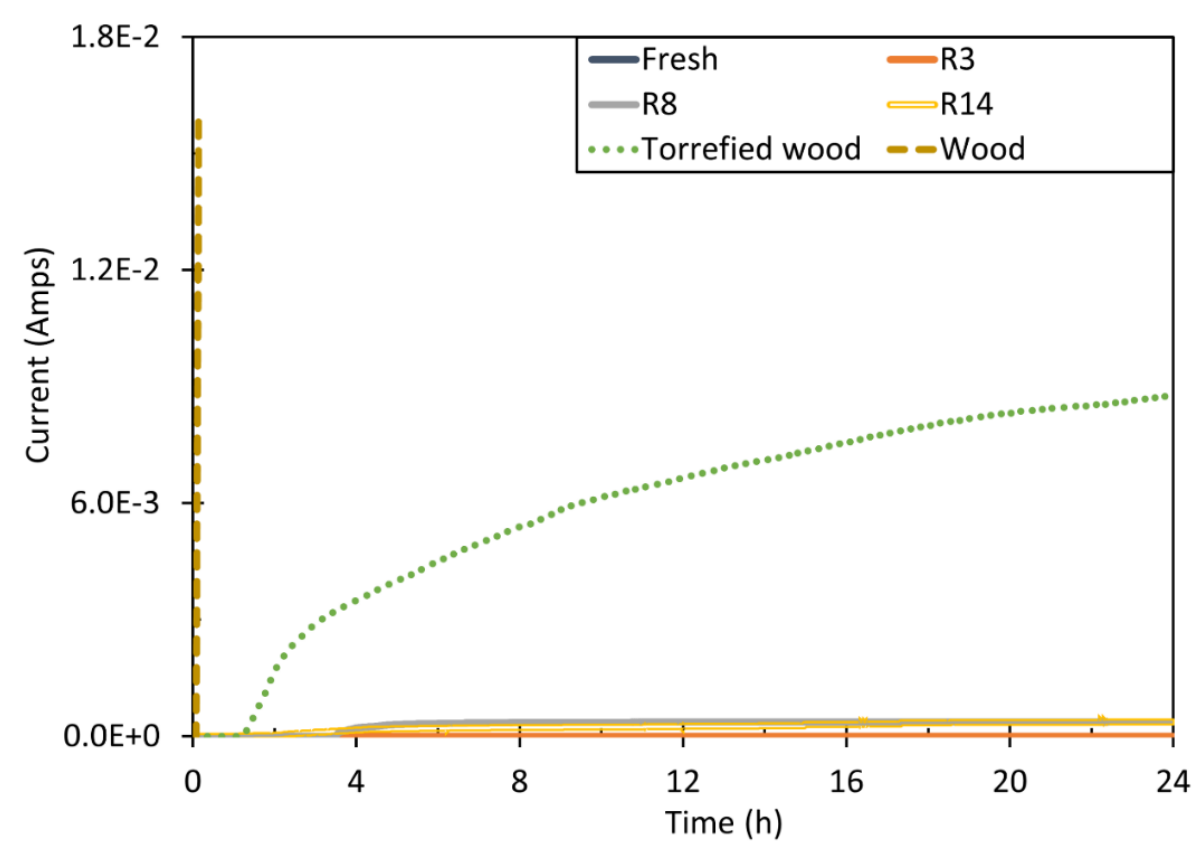

Figure 3-7: Current through an electrochemical cell with pellet electrodes made of hydrochar, wood, and torrefied wood. The wood disintegrated after a few minutes. Torrefied wood increased $42 \%$ in mass after $24 \mathrm{~h}$ in the electrolyte. The small currents observed for hydrochar pellets suggests much less water ingress.

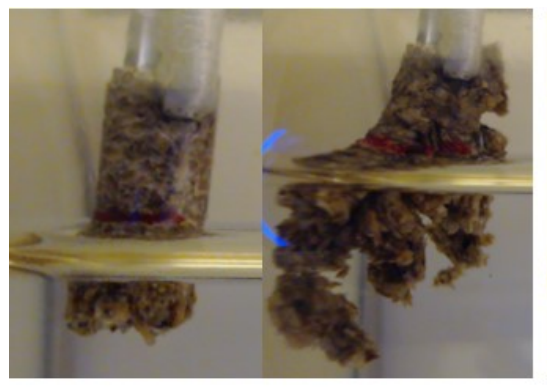

Wood time $=0$

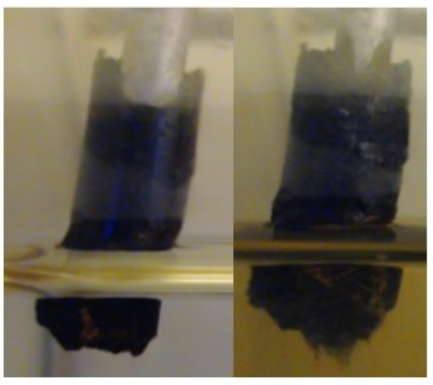

Torrefied Wood Torrefied Wood time $=0$ $24 \mathrm{~h}$

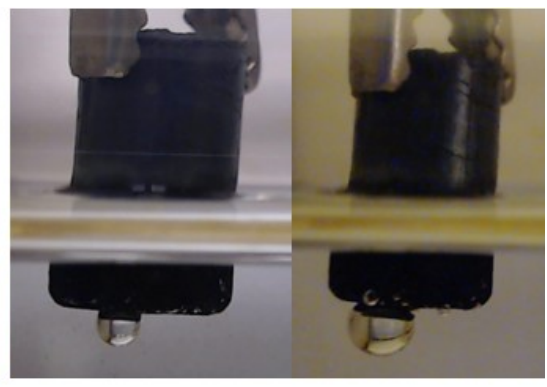

Hydrochar time $=0$
Hydrochar $24 \mathrm{~h}$

Figure 3-8: Pictures of the pellets used in the EWI tests when they were first immersed in the electrolyte (time $=0$ ) and later at the times indicated. The hydrochar pellets showed no visible indications of breakdown products in the electrolyte, they maintained their shape and passed low currents throughout the tests, as shown in Figure 3-9. 


\subsection{Conclusion}

Catalysed Hydrothermal Carbonization (CHTC) of a woody biomass feedstock in a catalysed solution has been shown to produce hydrochar with hydrogen, oxygen and carbon contents that are similar to those of coal. In contrast, the uncatalyzed control (HTC) sample produced a product similar to lignite. The determined values of HHV, mass yield, and energy yield of CHTC hydrochar were all greater than the values obtained for HTC hydrochar: $28.1 \pm 0.4 \mathrm{MJ} / \mathrm{kg}$ for CHTC compared with 27. $0 \pm 0.4 \mathrm{MJ} / \mathrm{kg}$ for HTC; $45 \%$ versus $42.3 \%$ for mass yields; and $64 \%$ versus $57 \%$ for energy yields. The ash in the CHTC hydrochar was reduced to half the value in the feedstock. Infrared spectroscopy showed the CHTC process reduces hydroxyl bonds and creates more carbon-carbon bonds consistent with proposed condensation and polymerization reactions. The hydrochar in SEM images appeared as porous spheres. Process liquid could be recycled with no change in the HHV for the hydrochar, but recycling increased the energy yield by 5\%. Durability, compressive strength, and water absorptivity of the densified hydrochar were not influenced by recycling. Hydrochar pellets were hydrophobic compared with wood pellets and torrefied wood pellets. 


\subsection{Acknowledgements}

The authors would like to thank Professor Edward Lai of the Carleton University and Guy Tourigny of CanmetEnergy for their help and support, Neelesh Bhadwal of the University of Toronto for helpful discussions, and Airex Energy for providing the torrefied pellets and wood pellets. The authors would like to thank the Natural Sciences and Engineering Research Council (NSERC) for helping fund this research. 


\section{Chapter 4: Production of Organic Compounds through Recycling the Process Liquid of Catalysed Hydrothermal Carbonization}

Planned submission.

Amin Ghaziaskar ${ }^{a+}$, Glenn A. McRae ${ }^{a+}$, Alexis Mackintosh ${ }^{b}$, Edward P.C. Laic, Onita Basud ${ }^{\mathrm{d} \dagger}$

a Department of Mechanical and Aerospace Engineering, Carleton University, Canada, K1S 5B6

+amin.ghaziaskar@carleton.ca,

b PCS Technologies Inc., Vancouver, Canada

alexis@pcsbiofuels.com

c Department of Chemistry, Carleton University, Canada, K1S 5B6

edward.lai@carleton.ca

${ }^{d}$ Department of Civil and Environmental Engineering, Carleton University, Canada, K1S 5B6

onita.basu@carleton.ca

† Onita.Basu@carleton.ca, Tel: 613-520-2600, 1125 Colonel By Drive, Ottawa, ON, Canada K1S 5B6 


\section{Abstract}

Catalysed hydrothermal carbonization (CHTC) of lignocellulosic biomass has the potential to produce value-added compounds (VACs) from the liquid effluent in addition to a solid hydrochar product. This research examined the production of glycolic acid, formic acid, acetic acid, levulinic acid, 5-hydroxymethylfurfural, and furfural as potential VACs, in conjunction with properties of the solid hydrochar such as higher heating value (HHV). Recycling the process liquid increased the concentration of VACs and energy yield of the hydrochar while the HHV stayed within the range $27.6 \pm 0.3 \mathrm{MJ} / \mathrm{kg}$. liquid:biomass (L:B) ratio was found to be an effective way to increase the yield of the VACs in both CHTC and HTC processes. The production yield of the VACs and the mass yield of the hydrochar were negatively correlated after changing the L:B ratios of $\mathrm{CHTC}$ and HTC. The research demonstrates the potential to have multiple product streams from the CHTC process. 
Keywords: Catalysed Hydrothermal Carbonization, Process liquid, Valueadded compounds, Recycling, Biomass

\section{Declarations of interest:}

Alexis Mackintosh (co-author) holds the patent on which the basis of this research is conducted.

\section{Graphical abstract}

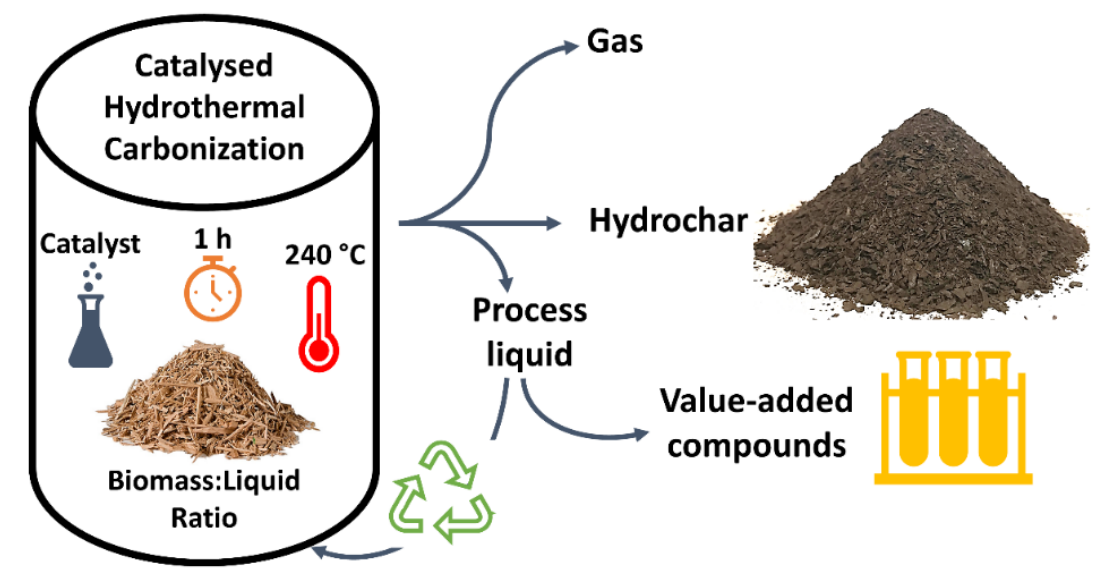

\section{Highlights}

- VACs increased in concentration after recycling the process liquid.

- Higher L:B ratios caused the yield of VACs to increase.

- Energy yield of CHTC increased, $72 \%$ to $80 \%$, after recycling the process liquid.

- Hydrochar had similar FC and VM to bituminous coal. 


\subsection{Introduction}

Climate change is escalating as the use of fossil fuels continues [14]. The contribution of these fuels (e.g., coal and oil) to greenhouse gas (GHG) emissions has surpassed $30 \mathrm{GtCO}_{2}$ eq/yr since 2010 , which makes up over $60 \%$ of the annual anthropogenic GHG emissions into the atmosphere [14]. The increased use of coal compared with other energy sources has reversed the decarbonization of the world's energy supply [14]. Therefore, finding an energy source replacement for coal-burning industries is imperative to reducing the amount of GHG emissions into the atmosphere.

Hydrothermal carbonization (HTC) is a chemical process that produces solid carbonaceous fuel, referred to as hydrochar, from a wide range of renewable biomass (e.g., municipal waste, animal waste, forestry waste, and agricultural waste). HTC involves the heating of the biomass in an aqueous solution under elevated pressures to temperatures of at least $180{ }^{\circ} \mathrm{C}$ for times on the scale of minutes to multiple days. HTC reduces the ash content in the char compared with the biomass, increases surface area, and results in a hydrophobic product that is easy to densify into a pellet when compared with other treatment processes (e.g., torrefaction or pyrolysis) [58], [61]. 
Catalysed hydrothermal carbonization (CHTC) of biomass is similar to HTC but with an added catalyst to increase the rates of reactions occurring throughout the process [4]. The hydrochar can be used as a one-to-one replacement for coal because of its high energy content $(\approx 28 \mathrm{MJ} / \mathrm{kg})$ and similar physical characteristics, but the hydrochar is better than coal because of its lower ash contents $(\approx 1 \%$ compared with $15.5 \%$ for bituminous coal) [93].

CHTC and HTC have the potential to produce various value-added compounds (VACs) from biomass. The major components of lignocellulosic biomass (i.e., cellulose, hemicellulose, and lignin) break into different oligosaccharides, which subsequently hydrolyze into compounds such as glucose/fructose. The sugar monomers can further dehydrate into intermediate compounds (e.g. 5-hydroxymethylfurfural (HMF), furfural (FF), and phenol) [76]. These intermediate compounds are more reactive and can condense into hydrochar [48]. Furthermore, the hydrolysis of the biomass can produce other compounds such as acetic acid (AA), glycolic acid (GA), levulinic acid (LA), and formic acid (FA), which are considered as by-products and cannot turn into hydrochar [94]. Alternatively, the HMF can dehydrate back into LA and FA instead of condensing into hydrochar [95].

LA, HMF, and FF are of the most valuable chemicals that are produced through hydrothermal carbonization of biomass [42]. The hydroxyl and 
aldehyde groups as well as furan rings in $\mathrm{HMF}$ and $\mathrm{FF}$, and carbonyl and carboxy groups in the LA, are convertible to a wide range of chemicals with different industrial applications [96], [97]. FF is recognized as a platform chemical for other furan based chemicals, such as furfuryl alcohol (FFA), tetrahydrofurfuryl alcohol (THFA), and furoic acid, and can be produced commercially for approximately $1100 \$ /$ ton [97], [98]. Industrial production of HMF can be challenging; however, Kazi et al., 2011, suggested the price of 1050 \$/ton, which can be highly dependent on the cost of feedstock. LA sold for 5000$8000 \$ /$ ton in 2013 [96]. Other by-product VACs include GA, which is often used in the production of cosmetics; AA, usually used as a solvent, and FA, used as a pesticide for agricultural crops. Recycling the liquid phase has been reported to increases the concentration of these VACs in the process liquid [5], [45], and can be designed to preserve the energy used in a hydrothermal process if the recycling is done hot.

Changing process variables of HTC (i.e., temperature, residence time, and $\mathrm{L}: \mathrm{B}$ ratio) has been found to affect the physicochemical propertise of the hydrochar [75], [100]. In addition, altering L:B ratio for hydrothermal carbonization of olive stones [76] and glucose [50] changed the concentrations of HMF, FU, and LA in the process liquid. 
This paper examines the effects of recycling and $\mathrm{L}: \mathrm{B}$ ratio on the production of VACs and physicochemical properties of the hydrochar, in an attempt to show the contribution of intermediate compounds, HMF and FF, to hydrochar production, while other organic acids tend to saturate the process liquid. Furthermore, the potential effects of $\mathrm{L}: \mathrm{B}$ ratio on the quality and rapidness of CHTC hydrolysis and dehydration reactions are studied.

\subsection{Methods and Materials}

\subsubsection{Catalysed Hydrothermal Carbonization (CHTC)}

CHTC experiments were conducted in $300 \mathrm{~mL}$ Parr bench-top reactors (Parr Instrument Company, Moline). Approximately $10 \mathrm{~g}$ of woody biomass was mixed into $50 \mathrm{~mL}$ of water and catalyst in a glass liner placed inside the reactor, $\mathrm{L}: \mathrm{B}$ ratio of 5:1. The reactor was heated at $7{ }^{\circ} \mathrm{C} / \mathrm{min}$ using a rigid heating mantle up to $240 \pm 2.2{ }^{\circ} \mathrm{C}$ where it was held constant for one hour. The temperature was measured using a type $\mathrm{J}$ thermocouple and controlled with a proportional-integral-derivative (PID) controller. The pressure was monitored using an analog transducer. After the CHTC process, the reactor was quenched cooled to room temperature and gaseous products were vented into a fume hood.

The hydrochar was separated from the CHTC process liquid by vacuum filtration through $0.45-\mu \mathrm{m}$ filter paper. Approximately $80 \%$ of the process 
liquid was recovered in the filtrate. The $\mathrm{pH}$ of the process liquid was measured with a SP21 portable $\mathrm{pH}$ meter (VWR, USA). The solid hydrochar was washed with $300 \mathrm{~mL}$ of distilled water and then dried at $105{ }^{\circ} \mathrm{C}$ for $24 \mathrm{~h}$.

Recycling of the CHTC process liquid was conducted 15 times. Fresh catalyst (10-13 mL) was added to the process liquid to make up the $50-\mathrm{mL}$ reaction volume. The hydrochar produced from the first recycling process is labeled "fresh", and the hydrochar samples from subsequent recycling processes were labeled R1-R15.

Similar CHTC process was carried out to examine different $\mathrm{L}: \mathrm{B}$ ratios while using the same amount of biomass $(10 \mathrm{~g})$. The volume of the liquid was changed from $50 \mathrm{~mL}$ to 120,100 , and $30 \mathrm{~mL}$ which were referred to as $12: 1$, 10:1, and 3:1, L:B ratios, respectively. The HTC (non-catalysed) experiments were carried out with deionized water without catalyst addition at the same $\mathrm{L}: \mathrm{B}$ ratios as the CHTC process; temperature and time of reaction were conducted under the same conditions.

\subsubsection{Materials}

The feedstock biomass was wooden stir sticks (white pine and birch) that were ground to $2.38 \mathrm{~mm}$ mesh particle size, and then stored in a closed 
container until CHTC processing. The characteristics of the feedstock biomass are summarized in Table 4-1.

Table 4-1 Higher heating value (HHV) and compositional analysis of the woody biomass on a dry basis.

\begin{tabular}{lc}
\hline \multicolumn{2}{c}{ Raw Biomass } \\
\hline HHV (MJ/kg) & $19.6 \pm 0.2$ \\
\hline Total Volatile (\%) & $85.3 \pm 0.2$ \\
\hline Fixed Carbon (\%) & $13.5 \pm 0.1$ \\
\hline Ash (\%) & $1.1 \pm 0.1$ \\
\hline
\end{tabular}

\subsubsection{Characterization of the Process Liquid}

Liquid chromatography was used for quantification of the known compounds existing in the process liquid. All the analyses were done using a Shimadzu Ultra-Fast Liquid Chromatograph (UFLC) (Shimadzu, Japan), equipped with a DGU-20A5 degasser, a SIL-20AHT autosampler and an SPDM20A diode array detector (DAD). An LC-20A equipped with a gradient unit was used to pump the mobile phase through the column. Windows-based Lab Solutions software was used to control the UFLC system and to analyze the chromatograms. 
Phosphoric acid (88\% pure), acetonitrile (HPLC grade), and acetic acid (glacial) were purchased from Fisher Scientific. Furfural (98\% pure) and 5hydroxymethylfurfural (95\% pure) with the brand Alfa Aesar and formic acid (99\% pure) and levulinic acid (98\% pure) with the brand Acros Organics were purchased from Fisher Scientific. Glycolic acid (99\% pure) was purchased from Sigma Aldrich. Glycolic acid, formic acid, acetic acid, levulinic acid, 5hydroxymethylfurfural, and furfural are referred to as GA, FA, AA, LA, HMF, and $\mathrm{FF}$, respectively.

Chromatographic separation was achieved using a $150 \mathrm{~mm} \times 4.6 \mathrm{~mm}$ id, 5- $\mu \mathrm{m}$ particle size Agilent Zorbax Sb-Aq column at $30{ }^{\circ} \mathrm{C}$ with $10 \%$ of acetonitrile and $90 \%$ of $76 \mathrm{mM}$ phosphate buffer $(\mathrm{pH}=2)$ as the mobile phase at a flow rate of $1.0 \mathrm{~mL} / \mathrm{min}$. All the organic compounds were detected at a wavelength of $210 \mathrm{~nm}$ using the $\mathrm{DAD}$ detector.

After determining the concentration of each $\mathrm{VAC}$, the yield was calculated as a ratio of the total mass of the solute in process liquid to the dry mass of the feedstock. Total mass of the solute was calculated as the product of the concentration of the VAC and the liquid volume, which was 30, 50, 100, and $120 \mathrm{~mL}$ for $3: 1,5: 1,10: 1$, and 12:1 L:B ratios, respectively. 


\subsubsection{Characterization of the Solid Hydrochar}

Mass yield was determined as a ratio of the hydrochar dry mass to the feedstock dry mass.

$$
\text { Mass yield }(\%)=\frac{\text { Hydrochar dry mass }}{\text { Feedstock dry mass }} \times 100
$$

The Higher Heating Value (HHV) of the hydrochar samples were measured using the Parr 6200 Isoperibol oxygen bomb calorimeter (Parr Instrument, Moline) according to the American Standard Testing Method (ASTM) D5865. Compositional analysis by thermogravimetry (i.e., moisture content, volatile matter, fixed carbon, and ash) was performed according to ASTM E1131 using a TGA/DSC 1 Thermogravimetric Analyzer \& Differential Scanning Calorimeter (Mettler, USA).

The energy-densification ratio was calculated by dividing the HHV of the hydrochar by the HHV of the biomass feedstock:

$$
\text { Energy densification ratio }=\frac{\text { HHV of the hydrochar }}{\text { HHV of the biomass }}
$$

Energy yield was calculated as a product of the mass yield and the energy densification ratio.

Infrared (IR) spectra of hydrochar (10 mg) mixed with $\mathrm{KBr}(300 \mathrm{mg})$ were measured with an MB100 spectrophotometer (ABB Bomem, Quebec, 
Canada). The morphology and surface of the hydrochar were observed with a Vega-II XMU VPSEM Scanning Electron Microscope (SEM) (Tescan, Czech Republic). Samples were dispersed on a conductive carbon pad and coated with $\mathrm{Au}$ to a thickness of $7 \mathrm{~nm}$.

\subsection{Results and Discussion}

\subsubsection{Recycling the Process Liquid}

During 15 repeated cycles of CHTC (at $240{ }^{\circ} \mathrm{C}$ with L:B ratio of $5: 1$ ), the concentrations of the known VACs in the process liquid were determined. As shown in Figure 4-1, AA was the most abundant VAC; its concentration increased from $25.8 \pm 0.7 \mathrm{~g} / \mathrm{L}$ for the Fresh process liquid to $68.6 \pm 1.9 \mathrm{~g} / \mathrm{L}$ for the last three recycles. The concentrations of GA and LA, similar to AA, increased from $4.2 \pm 0.3 \mathrm{~g} / \mathrm{L}$ (Fresh) to $16.7 \pm 0.5 \mathrm{~g} / \mathrm{L}(\mathrm{R} 15)$ for GA and $10.4 \pm$ $0.1 \mathrm{~g} / \mathrm{L}$ (Fresh) to $16.9 \pm 0.6 \mathrm{~g} / \mathrm{L}$ for LA. Meanwhile, the concentration of HMF, $\mathrm{FF}$, and FA stayed within the ranges $3.9 \pm 0.6 \mathrm{~g} / \mathrm{L}, 5.7 \pm 0.3 \mathrm{~g} / \mathrm{L}$, and $3.4 \pm 0.6$ $\mathrm{g} / \mathrm{L}$, respectively, throughout all recycles. 

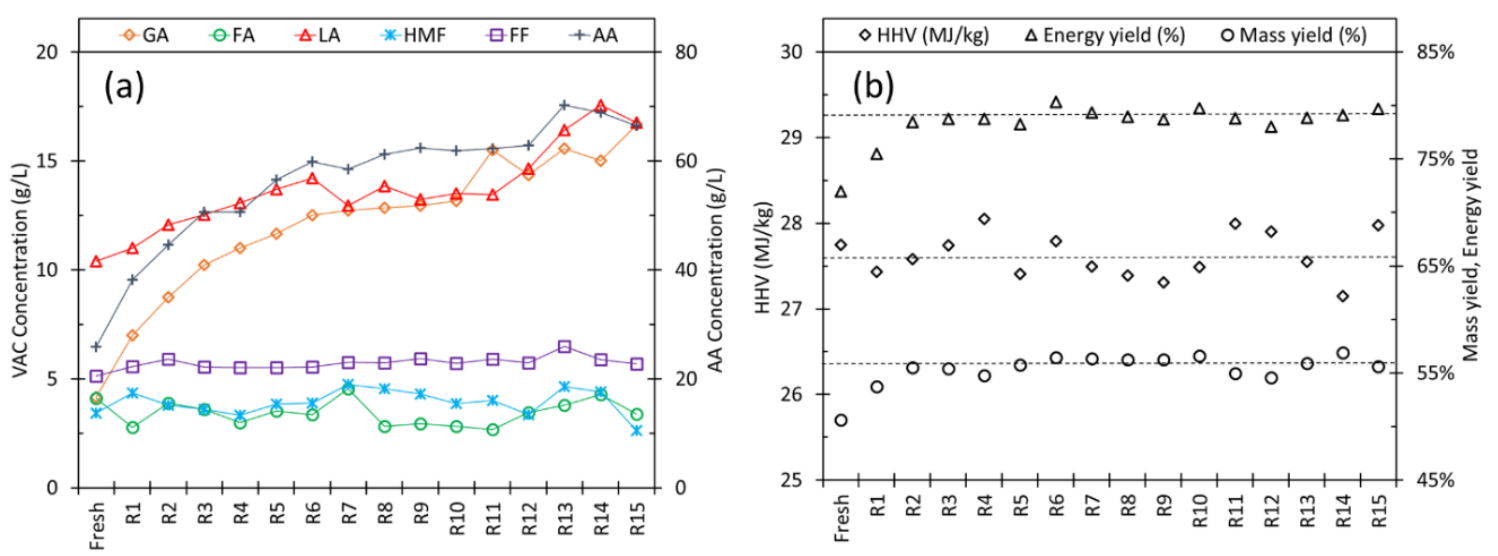

Figure 4-1: (a) VAC concentrations and (b) HHV, mass yield, and energy yield of the hydrochar produced after recycling the CHTC process liquid, at 5:1 L:B ratio.

Figure 4-1a shows two general trends for the concentration of the VACs: the increasing trend of $\mathrm{AA}, \mathrm{GA}$, and $\mathrm{LA}$, and the almost constant concentrations of HMF, FF, and FA. The HMF and FF are known as two of the intermediate compounds, which can be transformed into hydrochar through hydrothermal processes [94]. Near constant concentrations of the two chemical compounds, $\mathrm{HMF}$ and $\mathrm{FF}$, approve their contribution to the process where they are consumed rather than accumulated. Furthermore, the consumption of these compounds was illustrated by the increase seen in the mass yield of the hydrochar, Figure 4-1b, after recycling the process liquid effluent with initial concentrations of HMF and FF. [44], [101].

Chemical compounds such as AA, GA, and LA were suggested to have low or no contribution to the production of hydrochar other than catalysing hydrolysis and dehydration processes [101], [102]. Therefore, the 
concentration of the three VACs (i.e., AA, GA, and LA) was expected to increase as the recycling of the process liquid continues. However, the increase in the concentration of these chemicals in the process liquid slowed down, which hinted approaching a saturation limit for the process liquid. Figure 4-2 shows the accumulated concentrations of the VACs, AA, GA, and LA, which, according to the fitted model, have reached their saturation limits.

FA is not known as a precursor to hydrochar and is unstable at temperatures above $225^{\circ} \mathrm{C}$ [1]; therefore, it goes through fast formation and then decarboxylation reactions at $240{ }^{\circ} \mathrm{C}$ during the CHTC process. The near constant concentration of the FA in the process liquid of the CHTC suggests an equilibrium between the formation and decarboxylation of FA, which ultimately results in the production of $\mathrm{CO}_{2}$, causing the operating pressure of the CHTC to increase [1], [102]. 


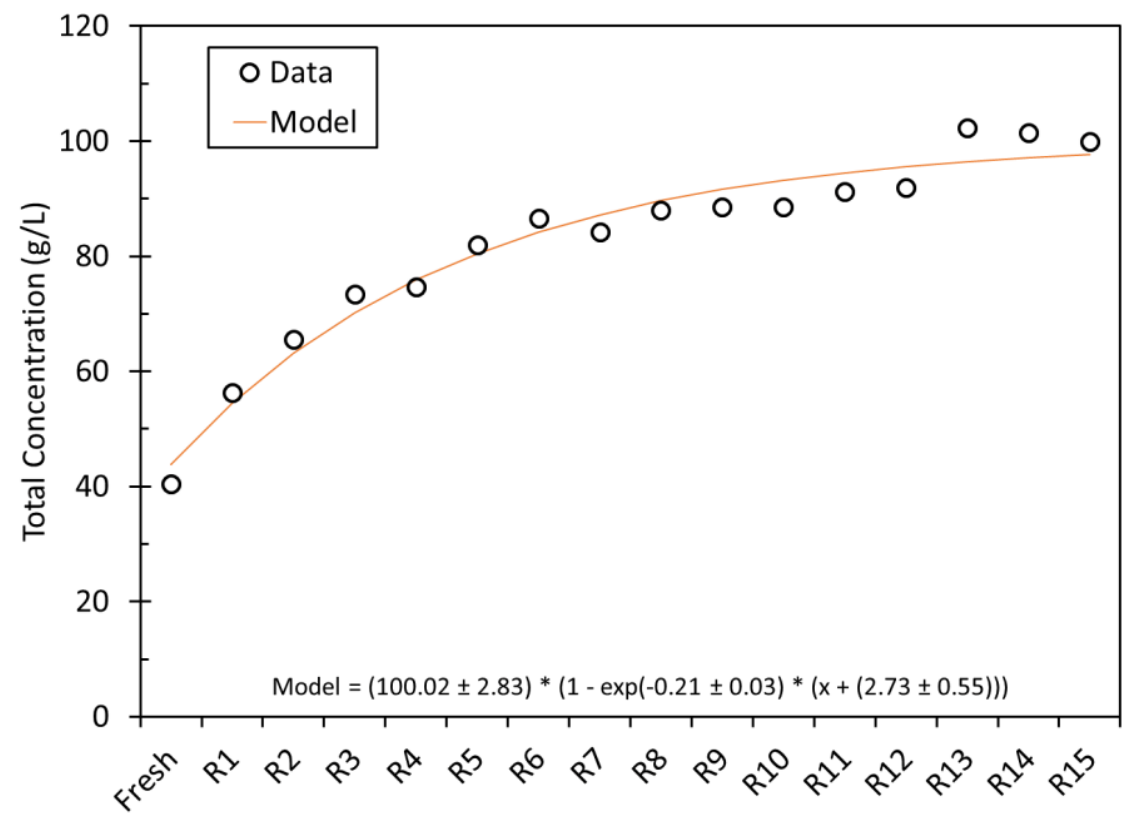

Figure 4-2: The sum of AA, GA, and LA concentrations, represented as data and the fitted model.

As shown in Figure 4-1b, the mass yield increased from 51\% (Fresh) to $55.8 \pm 0.7 \%$ (R2-R15). The HHV of the hydrochar was independent of recycling the process liquid and stayed within the range $27.6 \pm 0.3 \mathrm{MJ} / \mathrm{kg}$, a $41 \%$ increase compared with HHV of the biomass. Furthermore, the mass yield and the HHV of the hydrochar (R2-R15) were negatively correlated with a Pearson correlation coefficient of $-0.78, p=0.00023$, as shown in Figure D-10, where HHV was measured above average $(27.6 \mathrm{MJ} / \mathrm{kg})$ and the mass yield was below its average value (55.8\%). This correlation can suggest that the accumulated VACs in the process liquid can limit the decomposition of cellulose and hemicellulose into smaller monomers, which would result in higher mass yields and lower HHVs compared with the initial cook (Fresh). 
Table 4-2 Mass yield, HHV, energy densification ratio, and compositional analysis (weight percentages on dry basis) of the hydrochar after recycling the process liquid 15 times with L:B ratio of 5:1.

\begin{tabular}{|c|c|c|c|c|c|c|}
\hline & $\begin{array}{c}\text { Mass yield } \\
\text { (\%) }\end{array}$ & $\begin{array}{c}\text { HHV } \\
\text { (MJ/kg) }\end{array}$ & $\mathrm{EDR}^{1}$ & $\begin{array}{l}\text { Volatile Matter } \\
\qquad(\%)\end{array}$ & $\begin{array}{c}\text { Fixed Carbon } \\
\text { (\%) }\end{array}$ & $\begin{array}{l}\text { Ash } \\
\text { (\%) }\end{array}$ \\
\hline Fresh & 50.6 & $27.7 \pm 0.2$ & 1.42 & $50.0 \pm 0.3$ & $48.8 \pm 0.3$ & 0.6 \\
\hline R1 & 53.7 & $27.4 \pm 0.3$ & 1.40 & $52.5 \pm 0.2$ & $46.4 \pm 0.2$ & 0.9 \\
\hline R2 & 55.5 & $27.6 \pm 0.3$ & 1.41 & $52.5 \pm 0.2$ & $46.8 \pm 0.2$ & 0.8 \\
\hline R3 & 55.4 & $27.7 \pm 0.3$ & 1.42 & $53.4 \pm 0.2$ & $46.4 \pm 0.2$ & 1.2 \\
\hline R4 & 54.8 & $28.1 \pm 0.3$ & 1.43 & $54.1 \pm 0.3$ & $46.6 \pm 0.3$ & 0.7 \\
\hline R5 & 55.8 & $27.4 \pm 0.3$ & 1.40 & $53.2 \pm 0.2$ & $46.1 \pm 0.2$ & 0.7 \\
\hline R6 & 56.4 & $27.8 \pm 0.3$ & 1.42 & $54.2 \pm 0.6$ & $46.6 \pm 0.5$ & 0.7 \\
\hline R7 & 56.4 & $27.5 \pm 0.3$ & 1.41 & $53.6 \pm 0.2$ & $45.5 \pm 0.2$ & 0.8 \\
\hline R8 & 56.3 & $27.4 \pm 0.3$ & 1.40 & $54.4 \pm 0.2$ & $45.4 \pm 0.2$ & 0.1 \\
\hline R9 & 56.3 & $27.3 \pm 0.3$ & 1.40 & $53.5 \pm 0.2$ & $45.7 \pm 0.2$ & 0.8 \\
\hline R10 & 56.6 & $27.5 \pm 0.3$ & 1.41 & $52.8 \pm 0.2$ & $46.1 \pm 0.2$ & 0.9 \\
\hline R11 & 54.9 & $28.0 \pm 0.3$ & 1.43 & $52.4 \pm 0.2$ & $46.7 \pm 0.2$ & 1.0 \\
\hline R12 & 54.6 & $27.9 \pm 0.3$ & 1.43 & $52.0 \pm 0.2$ & $46.9 \pm 0.2$ & 1.0 \\
\hline R13 & 55.9 & $27.5 \pm 0.3$ & 1.41 & $53.5 \pm 0.2$ & $45.9 \pm 0.2$ & 0.8 \\
\hline R14 & 56.9 & $27.1 \pm 0.3$ & 1.39 & $53.4 \pm 0.2$ & $46.1 \pm 0.2$ & 0.5 \\
\hline R15 & 55.6 & $28.0 \pm 0.3$ & 1.43 & $51.2 \pm 0.2$ & $47.9 \pm 0.2$ & 0.9 \\
\hline
\end{tabular}

${ }^{1}$ Energy densification ratio 
The potential reduction in the decomposition of the biomass components after recycling the process liquid can be further explained by the decrease in fixed carbon (FC) content and increase in volatile matter (VM) compared with the initial cook (Fresh), as shown in Table 4-2. VM and FC content of the hydrochar slightly changed ( 2 percentage points) after recycling the process liquid while independent of the number of recycles.

The FC content of the feedstock increased from $13.5 \%$ to $48.8 \%$, which is comparable to bituminous coal (approx. $\mathrm{FC}=50.5 \%, \mathrm{VM}=34 \%$, and ash $=$ 15.5\%, mass percentage on a dry basis) [93]. This increase makes the hydrochar a good candidate for combustion instead of high-quality coals (e.g., bituminous coal). VM was reduced from $85.3 \%$ (raw biomass) to values within the range $52.6 \pm 1.1 \%$ for the hydrochar. Higher VM in the hydrochar compared with bituminous coal can suggest easier and faster combustion of the hydrochar while similar FC contents can make the combustion as long-lasting, resulting in high burning temperatures.

The ash content was measured at less than $1.2 \%$ for all the hydrochar samples not resulting in a significant difference in between the biomass and the hydrochar. 
The IR spectra of the hydrochar shows the changes to the chemical structure of the biomass after processing it through CHTC, Figure C-1. The IR spectra of the hydrochar were different from that for the biomass but recycling the process liquid had no appreciable effects on the produced hydrochar. One deviation between the hydrochar and the woody biomass was a lower concentration of hydroxyl $(\mathrm{OH})$ groups at $\sim 3400 \mathrm{~cm}^{-1}$ for the hydrochar. Fewer $\mathrm{OH}$ groups are beneficial to the hydrochar since it results in higher hydrophobicity [7]. The aliphatic group $(\mathrm{C}-\mathrm{H}$ bonds $)$ at $\approx 2900 \mathrm{~cm}^{-1}$ was reduced in intensity for the hydrochars compared with the raw biomass. The $\mathrm{C}=\mathrm{C}$ bonds at $\approx 1600-1710 \mathrm{~cm}^{-1}$ representing lignin, cellulose, and aromatics were more eminent in the hydrochar than in the biomass. The peak at $\approx 1050$ $\mathrm{cm}^{-1}$, associated with $\mathrm{C}-\mathrm{O}$ ether bonds and $\mathrm{O}-\mathrm{H}$ stretching bonds (abundant in woody biomass), had peaks with significantly less intensity in the IR spectra of the hydrochars. The peaks at $\approx 600 \mathrm{~cm}^{-1}$, referring to $\mathrm{C}-\mathrm{H}$ bonds in hemicellulose [44], were weakened after CHTC process. The increase in the carbon-carbon bonds, found within 400-1700 $\mathrm{cm}^{-1}$, was aligned with the increased HHV and FC content of the hydrochar compared with the biomass. 


\subsubsection{Effects of L:B Ratio on the VAC Concentrations and Hydrochar}

Figure 4-3 shows the effects of changing L:B ratio of $\mathrm{CHTC}$ on the concentration and production yields of the VACs. The production yield for all the known VACs, except for the LA, was found to be the highest at 10:1 L:B ratio. The concentration and production yield of LA further increased after increasing the $\mathrm{L}: \mathrm{B}$ ratio to $12: 1$ at $14.2 \mathrm{~g} / \mathrm{L}$ with the yield of $18 \%$. Increased liquid volumes were in favor of LA production, through cellulose hydrolysis and dehydration of HMF.

Biomass components decompose into smaller sugar monomers through hydrolysis, which requires water [1]; therefore, larger volumes of water can potentially increase the rate of hydrolysis in the CHTC. However, large volumes of water require larger amounts of energy to heat the system to desired temperatures $\left(240{ }^{\circ} \mathrm{C}\right.$ for this study). Decreasing the volume of the process liquid can result in faster saturation of the process liquid, which either negatively affects the performance of the process by limiting further decomposition/hydrolysis of the biomass or, according to Le Chatelier's principle, positively affects it by driving the reactions towards the hydrochar formation. 
Higher production yields of the VACs after increasing L:B ratios, Figure 4-3b, were accompanied by lower mass yields of the hydrochar, as mentioned in Table 4-3, suggesting better decomposition of the biomass components into organic acids and intermediates while less condensation and polymerization of the hydrochar. Larger volumes of process liquid require higher quantities of the chemicals for the reactions to be pushed towards the formation of the hydrochar. The sudden increase in the production yield of the LA and the decrease in the mass yield of the hydrochar, for $\mathrm{L}: \mathrm{B}$ ratios of $10: 1$ and $12: 1$, both suggest that the dehydration of HMF into LA and FA was increased rather than the formation of the hydrochar.
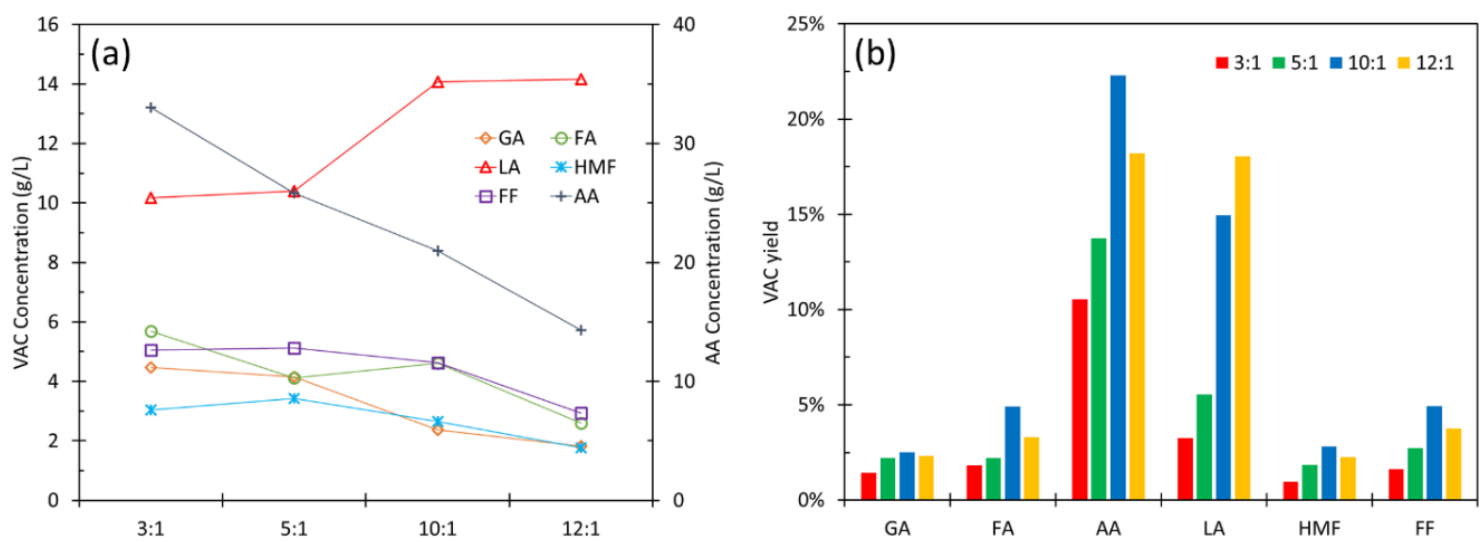

Figure 4-3: (a) Concentration of VACs in the process liquid after using different L:B ratios with CHTC and (b) production yield of the VACs with respect to dry weight of the biomass used.

Meanwhile, changing the L:B ratio was found not to influence the HHV of the hydrochar, Table 4-3. The HHV of the hydrochar stayed within the range $27.7 \pm 0.1 \mathrm{MJ} / \mathrm{kg}$ for all L:B ratios. Furthermore, the energy yield increased 
from $\approx 63 \%$ to $75 \%$ after decreasing the $\mathrm{L}: \mathrm{B}$ ratio from $12: 1$ to $3: 1$. The increase in the energy yield of the hydrochar was mainly due to the $8 \%$ increase seen in the mass yield of the hydrochar, refer to Table 4-3.

Table 4-3 Compositional analysis (dry basis weight percentages) of the hydrochar made with different L:B ratios through CHTC process.

\begin{tabular}{lcccc}
\hline & \multicolumn{4}{c}{ L:B ratio } \\
\cline { 2 - 5 } & $\mathbf{3 : 1}$ & $\mathbf{5 : 1}$ & $\mathbf{1 0 : 1}$ & $\mathbf{1 2 : 1}$ \\
\hline Mass yield (\%) & $52.3 \pm 0.3$ & $50.2 \pm 1.0$ & $44.8 \pm 0.1$ & $44.6 \pm 0.6$ \\
\hline HHV (MJ/kg) & $27.8 \pm 0.2$ & $27.7 \pm 0.2$ & $27.8 \pm 0.1$ & $27.6 \pm 0.1$ \\
\hline Energy yield (\%) & $74.5 \pm 1.0$ & $71.2 \pm 1.9$ & $64.0 \pm 0.1$ & $62.9 \pm 1.0$ \\
\hline Total Volatile (\%) & $52.1 \pm 0.8$ & $50 \pm 0.3$ & $49.5 \pm 0.5$ & $48.9 \pm 0.1$ \\
\hline Fixed Carbon (\%) & $47.3 \pm 1.0$ & $48.8 \pm 0.3$ & $49.6 \pm 0.7$ & $50.3 \pm 0.1$ \\
\hline Ash (\%) & $0.3 \pm 0.2$ & $0.6 \pm 0.1$ & $0.6 \pm 0.1$ & $0.7 \pm 0.0$ \\
\hline
\end{tabular}

The ash content of the hydrochar did not change significantly, which suggests the effects of $\mathrm{L}: \mathrm{B}$ ratio on this factor to be minute. The slight change in FC content and VM of the hydrochar may suggest that using larger process liquid quantities results in an enhancement of the polymerization reactions by producing more intermediate compounds through biomass hydrolysis and other underlying reactions. The formation of the hydrochar can be more rapid at lower L:B ratios when potentially shorter polymer chains are formed, causing the 3\% drop in FC content, as shown in Table 4-3. 
SEM images of the hydrochar, Figure C-3, illustrated the formation of the polymerized particles in the form of microspheres on the leftover structure of the biomass ( potentially the remaining cellulose and lignin [61]). The hydrochar formation on the surface of the biomass can bring some complications to further hydrolyzation of its components; the hydrochar is known to be more hydrophobic than the biomass, which would cause the hydrochar to repel water molecules, thus preventing further water ingress into the biomass. This potential water deficiency can reduce the hydrolysis of the biomass. Lower $\mathrm{L}: \mathrm{B}$ ratios can further elevate this phenomenon; hence, reducing the FC content of the hydrochar, Table 4-3.

The chemical structure of the hydrochar was found not to be affected by changing L:B ratio of the process, Figure $\mathrm{C}-2$. The hydroxyl group $\approx 3400 \mathrm{~cm}^{-}$ 1) reduction in the hydrochar was eminent. The $\mathrm{C}-\mathrm{H}$ bonds at $\approx 600 \mathrm{~cm}^{-1}$ in cellulose and hemicellulose [55], were reduced after CHTC, which would occur as a result of dehydration reactions throughout the process. Furthermore, the C-O-C bonds at $\approx 1200 \mathrm{~cm}^{-1}$ were potentially formed after condensation of the intermediate compounds into the hydrochar. Meanwhile, the C-O-C bonds can be found in the cellulose as 8-1,4-glycosidic bonds, $\approx 1050 \mathrm{~cm}^{-1}$ on the IR spectrum, which break down through hydrolysis [103]. 
Water ingress into biomass is vital for hydrolysis to occur; therefore, higher $\mathrm{L}: \mathrm{B}$ ratios can be preferable. Alternatively, CHTC can utilize lower L:B ratios by using stirring mechanisms for the biomass and process liquid in order to make sure of sufficient water ingression.

\subsection{Conclusion}

Recycling the process liquid of CHTC increased both the concentration of VACs in the liquid and the energy yield of the hydrochar. Further polymerization of the remaining intermediate compounds such as HMF and furfural in the process liquid resulted in an increase in the mass yield of the hydrochar while the HHV stayed within the range $27.6 \pm 0.3 \mathrm{MJ} / \mathrm{kg}$. Higher concentrations of acetic, glycolic, and levulinic acid were suggested to contribute less to the production of the hydrochar. Higher L:B ratios resulted in higher VAC yields and lower mass yields, while the HHV of the hydrochar stayed constant.

\subsection{Acknowledgments}

The authors would like to thank Margaret Anne Knowling of PCS Biofuels Inc. for her help with the compositional analysis and bomb calorimetry of the hydrochar. 


\section{Chapter 5: Challenges and the Future}

Catalysed hydrothermal carbonization (CHTC) was not found to perform significantly better than HTC under the conditions mentioned in this thesis, while lower $\mathrm{pH}$ of the process liquid has been shown to affect the performance of the hydrothermal carbonization processes.

Determining the advantages of the hydrochar made through CHTC over HTC require a more thorough look at the operating conditions of the CHTC process compared with what was used for this study. Similar properties of the hydrochar between the two processes were suspected to be caused by the excess duration of the CHTC process (i.e., 60 minutes). If enough time is given for the biomass to decompose and the hydrochar to polymerize, the use of catalyst can be debatable, while shorter operating durations can potentially better illustrate the advantages of the CHTC over HTC process caused by increasing the rate of hydrolysis of the biomass components and condensation of the hydrochar.

Future work can include a thorough look at the conditions used for the CHTC process (i.e., temperature, time, concentration of the catalyst) while considering different sources of feedstock in addition to the wood chips used for this study. This will allow us to better understand the kinetics of the catalysed 
hydrothermal carbonization (CHTC) of biomass and increase the efficiency of the process by potentially decreasing the operating time and duration of the process.

Economical consideration of the process is also at great importance when the process liquid is recycled. Depending on the design of the reactor (i.e., batch, binary batch, and continuous), recycled temperature, and mass, the recovered energy from recycling varies. An economical simulation of CHTC process should be instigated in the future.

The concentrations of the Valuable Added Compounds (VACs) in the process liquid were also similar in between CHTC and HTC processes, potentially caused by extended operating durations. These VACs have the potential to be extracted from the process liquid of both CHTC and HTC process in order to add value to these processes. Treatment methods and ways to use the process liquid are also tasks worth exploring in the future. 


\section{Chapter 6: Conclusions}

The objectives from the first chapter are listed below with the concluding remarks:

I. Study the effects of partial recycling the CHTC process liquid on the physical characteristics of the hydrochar.

The physical chemical properties of the hydrochar made through Catalysed hydrothermal carbonization (CHTC) of wood chips were determined. The hydrochar was produced by recycling a fraction of the effluent process liquid with the addition of fresh catalyst, and a liquid:biomass (L:B) ratio of 12:1. Recycling the process liquid was done 15 times. The Higher Heating Value (HHV) of the hydrochar samples stayed within the range $28.3 \pm 0.3$ $\mathrm{MJ} / \mathrm{kg}$, while the mass yield increased from $45 \%$ when using fresh catalyst to the range $(48.3 \pm 0.3) \%$ for the recycles $\mathrm{R} 1-\mathrm{R} 15$. The hydrochar was shown to have hydrogen, oxygen and carbon contents that were like those of coal. IR spectroscopy showed the process reduces hydroxyl bonds and creates more carbon-carbon bonds consistent with proposed condensation and polymerization reactions. The hydrochar in SEM images appeared as porous spheres. Process liquid could be recycled with no loss of hydrochar properties. Durability, compressive strength, and water absorptivity of the densified 
hydrochar were not influenced by recycling. Hydrochar pellets were hydrophobic compared with wood pellets and torrefied wood pellets. Water ingress measurements were performed using an electrochemical cell with pellet electrodes. Electrolyte ingress short-circuits the electrical resistance of the pellet, which causes the current in the cell to rise. Thus, current indicates water ingress. The hydrochar showed lower currents, while the current going through the wood pellet and torrefied wood pellet increased, showing less resistance against water ingress. The wood pellet disintegrated after 8 minutes; however, torrefied wood and hydrochar pellets resisted disintegration for longer durations of 24 hours.

II. Study the effects of full recycling of the CHTC process liquid on the chemical characteristics of the liquid effluent.

More than $80 \%$ of the process liquid effluent of CHTC was recycled for 15 times at the L:B ratio of 5:1. The HHV of the hydrochar samples stayed within the range $27.6 \pm 0.3 \mathrm{MJ} / \mathrm{kg}$, while the mass yield increased from $50.6 \%$ for the Fresh process to $55.8 \pm 0.7 \%$ for R2-R15 cooks. Through recycling the process liquid, mass yield and HHV were found to be negatively correlated, which suggested reduced decomposition of the biomass as a result of recycling 
the process liquid. The hydrochar showed similar fixed carbon (FC) contents and volatile matter (VM) compared with bituminous coal.

The concentration of acetic acid, glycolic acid, and levulinic acid saturated after recycling the process liquid. Meanwhile, the concentration of the other valuable added compounds (VACs) i.e., HMF, furfural, and formic acid stayed almost constant. The constant concentration of the formic acid was suggested to have been caused by the formation of $\mathrm{CO}_{2}$ gases throughout the process, while HMF and furfural were considered to be contributing to the production of the hydrochar. Alternatively, the accumulation of acetic acid, glycolic acid, and levulinic acid in the process liquid suggested that these compounds contribute less to the production of the hydrochar compared with the HMF and furfural.

III. Study the effects of L:B ratio on the hydrochar and process liquid effluent of the CHTC process.

$\mathrm{L}: \mathrm{B}$ ratio was shown to change the production yield of the VACs in a CHTC process. The highest VAC production yields were for the $\mathrm{L}: \mathrm{B}$ ratio of 10:1, except for levulinic acid, which had its highest production yield at $\mathrm{L}: \mathrm{B}$ ratio of 12:1. Increasing $\mathrm{L}: \mathrm{B}$ ratio, though helpful for the production of VACs, decreased the mass yield of the hydrochar. Higher L:B ratios helped to better 
decompose the biomass and polymerize the hydrochar, which was suggested by higher concentration of the VACs in the process liquid and the increase in the FC content of the hydrochar, respectively. Alternatively, the HHV of the hydrochar stayed within the range $27.8 \pm 0.1 \mathrm{MJ} / \mathrm{kg}$ for all $\mathrm{L}: \mathrm{B}$ ratios. 


\section{Chapter 7: References}

[1] A. Funke and F. Ziegler, "Hydrothermal carbonization of biomass: A summary and discussion of chemical mechanisms for process engineering," Biofuels, Bioprod. Biorefining, vol. 4, no. 2, pp. 160-177, Mar. 2010.

[2] M. T. Reza, E. Rottler, L. Herklotz, and B. Wirth, "Hydrothermal carbonization (HTC) of wheat straw: Influence of feedwater $\mathrm{pH}$ prepared by acetic acid and potassium hydroxide," Bioresour. Technol., vol. 182, pp. 336-344, 2015.

[3] Y. Zhai et al., "Hydrothermal carbonization of sewage sludge: The effect of feed-water $\mathrm{pH}$ on fate and risk of heavy metals in hydrochars," Bioresour. Technol., vol. 218, pp. 183-188, Oct. 2016.

[4] A. F. Mackintosh, "Preparation of biofuels and other useful products such as 5-(hydroxymethyl)-furfural," US 9,683,328 B2, 20-Jun-2017.

[5] J. Stemann, A. Putschew, and F. Ziegler, "Hydrothermal carbonization: Process water characterization and effects of water recirculation," Bioresour. Technol., vol. 143, pp. 139-146, 2013.

[6] M. H. Uddin, M. T. Reza, J. G. Lynam, and C. J. Coronella, "Effects of water recycling in hydrothermal carbonization of loblolly pine," Environ. Prog: Sustain. Energy, vol. 33, no. 4, pp. 1309-1315, Nov. 2013.

[7] A. Kabadayi Catalkopru, I. C. Kantarli, and J. Yanik, "Effects of spent 
liquor recirculation in hydrothermal carbonization," Bioresour. Technol., vol. 226, pp. 89-93, 2017.

[8] B. Weiner, J. Poerschmann, H. Wedwitschka, R. Koehler, and F.-D. Kopinke, "Influence of Process Water Reuse on the Hydrothermal Carbonization of Paper," ACS Sustain. Chem. Eng., vol. 2, no. 9, pp. 2165-2171, 2014.

[9] R. Damania et al., Uncharted Waters: The New Economics of Water Scarcity and Variability. 2017.

[10] NOAA National Centers for Environmental Information, "State of the Climate: Global Climate Report for August 2018.” [Online]. Available: https://www.ncdc.noaa.gov/sotc/global/201808. [Accessed: 18-Sep-2018].

[11] IPCC, "Climate Change 2014 Synthesis Report Summary Chapter for Policymakers," Ipcc, p. 31, 2014.

[12] Natural Resources Canada, "The State of Canada's Forests: Annual Report 2017,” Ottawa, 2017.

[13] H. Riebeek, "The Carbon Cycle," NASA Earth Observatory, 2011. [Online]. https://earthobservatory.nasa.gov/Features/CarbonCycle. [Accessed: 11Jul-2018].

[14] IPCC, Climate Change 2014: Mitigation of Climate Change. 2014.

[15] F. Neitzert, L. C. Cheng, P. Collas, A. Matin, N. Folliet, and S. McKibbon, "National inventory report 1990-2016: greenhouse gas sources and sinks 
in Canada executive summary," 2018.

[16] International Energy Agency, "Global Energy \& CO2 Status Report," 2018.

[17] International Energy Agency, "World Energy Outlook. Executive Summary,” 2017.

[18] R. McKitrick and E. Aliakbari, "Did the Coal Phase-out Reduce Ontario Air Pollution?," 2017.

[19] BP, "67 th edition Contents is one of the most widely respected," 2018.

[20] Natural Resources Canada, "Energy Facts," 2018. [Online]. Available: https://www.nrcan.gc.ca/energy-facts. [Accessed: 24-Sep-2018].

[21] Y. Qi and J. Lu, "China's coal consumption has peaked," China Daily, 2018. [Online]. Available: https://www.brookings.edu/2018/01/22/chinascoal-consumption-has-peaked/. [Accessed: 24-Sep-2018].

[22] V. R. Surisetty, J. Kozinski, and A. K. Dalai, "Biomass, availability in Canada, and gasification: An overview," Biomass Convers. Biorefinery, vol. 2 , no. 1 , pp. 73-85, 2012.

[23] S. Heidenreich and P. U. Foscolo, "New concepts in biomass gasification," Progress in Energy and Combustion Science, vol. 46. pp. 72-95, 2015.

[24] P. McKendry, "Energy production from biomass (part 1): overview of biomass," Bioresour. Technol., vol. 83, no. 1, pp. 37-46, 2002.

[25] J. Fang, L. Zhan, Y. S. Ok, and B. Gao, "Minireview of potential applications of hydrochar derived from hydrothermal carbonization of 
biomass," J. Ind. Eng. Chem., vol. 57, pp. 15-21, 2018.

[26] K. Tekin, S. Karagöz, and S. Bektaş, "A review of hydrothermal biomass processing," Renew. Sustain. Energy Rev., vol. 40, pp. 673-687, 2014.

[27] P. Basu, "Chapter 2 - Biomass Characteristics," in Biomass Gasification and Pyrolysis, Academic Press, 2010, pp. 27-63.

[28] icfar, "What is Lignin?," Lignoworks, 2016. [Online]. Available: http://www.icfar.ca/lignoworks/content/what-lignin.html. [Accessed: 06Nov-2018].

[29] D. Klemm, B. Heublein, H. P. Fink, and A. Bohn, "Cellulose: Fascinating biopolymer and sustainable raw material," Angew. Chemie - Int. Ed., vol. 44, no. 22, pp. 3358-3393, 2005.

[30] H. V. Scheller and P. Ulvskov, "Hemicelluloses," Annu. Rev. Plant Biol., vol. 61, no. 1, pp. 263-289, 2010.

[31] P. E. Savage, R. B. Levine, and C. M. Huelsman, "Chapter 8 Hydrothermal Processing of Biomass," in Thermochemical Conversion of Biomass to Liquid Fuels and Chemicals, The Royal Society of Chemistry, 2010, pp. 192-221.

[32] R. M. Rowell, "Chapter 3: Cell Wall Chemistry," in Handbook of Wood Chemistry and Wood Composites, 2013.

[33] S. V. Vassilev, D. Baxter, L. K. Andersen, C. G. Vassileva, and T. J. Morgan, "An overview of the organic and inorganic phase composition of 
biomass," Fuel, vol. 94, pp. 1-33, 2012.

[34] A. Demirbas, "Energy Sources, Part A: Recovery, Utilization, and Environmental Effects Higher heating values of lignin types from wood and non-wood lignocellulosic biomasses Higher heating values of lignin types from wood and non-wood lignocellulosic biomasses," 2017.

[35] E. Novaes, M. Kirst, V. Chiang, H. Winter-Sederoff, and R. Sederoff, "Future Perspectives in Plant Biology Lignin and Biomass: A Negative Correlation for Wood Formation and Lignin Content in Trees 1,” 2010.

[36] A. R. K. Gollakota, N. Kishore, and S. Gu, "A review on hydrothermal liquefaction of biomass," Renew. Sustain. Energy Rev., vol. 81, no. June 2017, pp. 1378-1392, 2018.

[37] J. A. Libra et al., "Hydrothermal carbonization of biomass residuals: a comparative review of the chemistry, processes and applications of wet and dry pyrolysis," Biofuels, vol. 2, no. 1, pp. 71-106, 2011.

[38] P. Basu, Biomass gasification, pyrolysis and torrefaction: practical design and theory. Academic press, 2018.

[39] A. Kumar, D. D. Jones, and M. A. Hanna, "Thermochemical biomass gasification: A review of the current status of the technology," Energies, vol. 2, no. 3, pp. 556-581, 2009.

[40] C. Di Blasi, G. Signorelli, C. Di Russo, and G. Rea, "Product distribution from pyrolysis of wood and agricultural residues," Ind. Eng. Chem. Res., 
vol. 38 , no. 6 , pp. 2216-2224, 1999.

[41] S. E. Boslaugh, "Pyrolysis," Encyclopædia Britannica, inc., 2018. [Online]. Available: https://www.britannica.com/science/pyrolysis. [Accessed: 25-Sep-2018].

[42] H. S. Kambo and A. Dutta, "A comparative review of biochar and hydrochar in terms of production, physico-chemical properties and applications," Renew. Sustain. Energy Rev., vol. 45, pp. 359-378, 2015.

[43] A. Kruse, "Hydrothermal biomass gasification," J. Supercrit. Fluids, vol. 47, no. 3, pp. 391-399, 2009.

[44] M. T. Reza, M. H. Uddin, J. G. Lynam, S. K. Hoekman, and C. J. Coronella, "Hydrothermal carbonization of loblolly pine: reaction chemistry and water balance," Biomass Convers. Biorefinery, vol. 4, no. 4, pp. 311-321, 2014.

[45] H. S. Kambo, J. Minaret, and A. Dutta, "Process Water from the Hydrothermal Carbonization of Biomass: A Waste or a Valuable Product?,"Waste Biomass Valor, vol. 9, no. 7, pp. 1181-1189, 2018.

[46] a and C. J. C. M. Toufiq Reza,a,b Ally Freitas,c Xiaokun Yang,a Sage Hiibel,c Hongfei Lin, "Hydrothermal Carbonization (HTC) of Cow Manure: Carbon and Nitrogen Distributions in HTC Products," Environ. Sci. Technol., vol. 33, no. 2, pp. 482-489, 2014.

[47] J. G. Lynam, M. T. Reza, W. Yan, V. R. Vásquez, and C. J. Coronella, "Hydrothermal carbonization of various lignocellulosic biomass," 
Biomass Convers. Biorefinery, vol. 5, no. 2, pp. 173-181, Jun. 2015.

[48] M.-M. Titirici and M. Antonietti, "Chemistry and materials options of sustainable carbon materials made by hydrothermal carbonization," Chem. Soc. Rev., vol. 39, no. 1, pp. 103-116, 2010.

[49] L. Hu, L. Lin, Z. Wu, S. Zhou, and S. Liu, "Chemocatalytic hydrolysis of cellulose into glucose over solid acid catalysts," Appl. Catal. B Environ., vol. 174-175, pp. 225-243, 2015.

[50] B. Girisuta, L. P. B. M. Janssen, and H. J. Heeres, "A Kinetic Study on the Conversion of Glucose to Levulinic Acid," in Chemical Engineering Research and Design, 2006, vol. 84, no. 5, pp. 339-349.

[51] B. F. M. Kuster, "5-Hydroxymethylfurfural (HMF). A Review Focussing on its Manufacture," Starch - Stärke, vol. 42, no. 8, pp. 314-321, Jul. 1990.

[52] J. D. Goddard, Y. Yamaguchi, and H. F. Schaefer, "The decarboxylation and dehydration reactions of monomeric formic acid," J. Chem. Phys., vol. 96, no. 2, pp. 1158-1166, 1992.

[53] S. Kang, X. Li, J. Fan, and J. Chang, "Characterization of hydrochars produced by hydrothermal carbonization of lignin, cellulose, d-xylose, and wood meal," Ind. Eng. Chem. Res., vol. 51, no. 26, pp. 9023-9031, 2012.

[54] M. T. Reza, W. Becker, K. Sachsenheimer, and J. Mumme, "Hydrothermal carbonization (HTC): Near infrared spectroscopy and 
partial least-squares regression for determination of selective components in HTC solid and liquid products derived from maize silage," Bioresour. Technol., vol. 161, pp. 91-101, Jun. 2014.

[55] M. T. Reza, M. H. Uddin, J. G. Lynam, and C. J. Coronella, "Engineered pellets from dry torrefied and HTC biochar blends," Biomass and Bioenergy, vol. 63, pp. 229-238, 2014.

[56] A. B. Fuertes et al., "Chemical and structural properties of carbonaceous products obtained by pyrolysis and hydrothermal carbonisation of corn stover," Aust. J. Soil Res., vol. 48, no. 6-7, pp. 618-626, 2010.

[57] Z. Liu, A. Quek, S. Kent Hoekman, and R. Balasubramanian, "Production of solid biochar fuel from waste biomass by hydrothermal carbonization," Fuel, vol. 103, pp. 943-949, 2013.

[58] M. Mäkelä, A. Fullana, and K. Yoshikawa, "Ash behavior during hydrothermal treatment for solid fuel applications. Part 1: Overview of different feedstock," Energy Convers. Manag., vol. 121, pp. 402-408, Aug. 2016.

[59] S. Jayanti, K. Maheswaran, and V. Saravanan, "Assessment of the effect of high ash content in pulverized coal combustion," Appl. Math. Model., vol. 31, no. 5, pp. 934-953, 2007.

[60] W. Stelte, C. Clemons, J. K. Holm, J. Ahrenfeldt, U. B. Henriksen, and A. R. Sanadi, "Thermal transitions of the amorphous polymers in wheat 
straw," Ind. Crops Prod., vol. 34, no. 1, pp. 1053-1056, 2011.

[61] M. T. Reza, J. G. Lynam, V. R. Vasquez, and C. J. Coronella, "Pelletization of biochar from hydrothermally carbonized wood," Environ. Prog. Sustain. Energy, vol. 31, no. 2, pp. 225-234, Jul. 2012.

[62] M. V. Gil, P. Oulego, M. D. Casal, C. Pevida, J. J. Pis, and F. Rubiera, "Mechanical durability and combustion characteristics of pellets from biomass blends," Bioresour. Technol., vol. 101, no. 22, pp. 8859-8867, 2010.

[63] R. I. Muazu and J. A. Stegemann, "Effects of operating variables on durability of fuel briquettes from rice husks and corn cobs," Fuel Process. Technol., vol. 133, pp. 137-145, 2015.

[64] N. Kaliyan and R. Vance Morey, "Factors affecting strength and durability of densified biomass products," Biomass and Bioenergy, vol. 33, no. 3, pp. 337-359, 2009.

[65] M. Temmerman, F. Rabier, P. D. Jensen, H. Hartmann, and T. Böhm, "Comparative study of durability test methods for pellets and briquettes," Biomass and Bioenergy, 2006.

[66] T. C. Acharjee, C. J. Coronella, and V. R. Vasquez, "Effect of thermal pretreatment on equilibrium moisture content of lignocellulosic biomass," Bioresour. Technol., vol. 102, no. 7, pp. 4849-4854, Apr. 2011.

[67] A. Pimchuai, A. Dutta, and P. Basu, "Torrefaction of agriculture residue to enhance combustible properties," Energy and Fuels, vol. 24, no. 9, pp. 
4638-4645, 2010.

[68] H. S. Kambo and A. Dutta, "Strength, storage, and combustion characteristics of densified lignocellulosic biomass produced via torrefaction and hydrothermal carbonization," Appl. Energy, vol. 135, pp. 182-191, 2014.

[69] T. C. Acharjee, C. J. Coronella, and V. R. Vasquez, "Effect of thermal pretreatment on equilibrium moisture content of lignocellulosic biomass," Bioresour. Technol., vol. 102, no. 7, pp. 4849-4854, 2011.

[70] O. Bobleter, "Hydrothermal degradation of polymers derived from plants," Prog. Polym. Sci., vol. 19, no. 5, pp. 797-841, 1994.

[71] M. Sevilla and A. B. Fuertes, "Chemical and structural properties of carbonaceous products obtained by hydrothermal carbonization of saccharides," Chem. - A Eur. J., vol. 15, no. 16, pp. 4195-4203, 2009.

[72] S. K. Hoekman, A. Broch, and C. Robbins, "Hydrothermal carbonization (HTC) of lignocellulosic biomass," Energy and Fuels, vol. 25, no. 4, pp. 1802-1810, 2011.

[73] J. G. Lynam, C. J. Coronella, W. Yan, M. T. Reza, and V. R. Vasquez, "Acetic acid and lithium chloride effects on hydrothermal carbonization of lignocellulosic biomass," Bioresour. Technol., vol. 102, no. 10, pp. 6192-6199, 2011.

[74] A. Toptas Tag, G. Duman, and J. Yanik, "Influences of feedstock type and process variables on hydrochar properties," Bioresour. Technol., vol. 250, 
pp. 337-344, 2018.

[75] M. Mäkelä, V. Benavente, and A. Fullana, "Hydrothermal carbonization of lignocellulosic biomass: Effect of process conditions on hydrochar properties," Appl. Energy, vol. 155, pp. 576-584, Oct. 2015.

[76] A. M. Borrero-López, V. Fierro, A. Jeder, A. Ouederni, E. Masson, and A. Celzard, "High added-value products from the hydrothermal carbonisation of olive stones," Environ. Sci. Pollut. Res., vol. 24, no. 11, pp. 9859-9869, Apr. 2017.

[77] B. M. Ghanim, W. Kwapinski, and J. J. Leahy, "Hydrothermal carbonisation of poultry litter: Effects of initial $\mathrm{pH}$ on yields and chemical properties of hydrochars," Bioresour. Technol., vol. 238, pp. 78-85, Aug. 2017.

[78] M. M. Titirici, A. Thomas, and M. Antonietti, "Back in the black: Hydrothermal carbonization of plant material as an efficient chemical process to treat the CO2problem?," New J. Chem., vol. 31, no. 6, pp. 787$789,2007$.

[79] British Petroleum, "BP Statistical Review of World Energy," London, UK, 2018.

[80] IPCC, "Mitigation of climate change: Contribution of working group III to the fourth assessment report of the Intergovernmental Panel on Climate Change," Cambridge University Press, 2007.

[81] S. Román et al., "Hydrothermal Carbonization: Modeling, Final 
Properties Design and Applications: A Review," Energies, vol. 11, no. 1, p. 216, 2018.

[82] M. T. Reza, J. G. Lynam, M. H. Uddin, and C. J. Coronella, "Hydrothermal carbonization: Fate of inorganics," Biomass and Bioenergy, vol. 49, pp. 86-94, Feb. 2013.

[83] B. Girisuta, L. P. B. M. Janssen, and H. J. Heeres, "Kinetic Study on the Acid-Catalyzed Hydrolysis of Cellulose to Levulinic Acid," Ind. Eng. Chem. Res., vol. 46, no. 6, pp. 1696-1708, Mar. 2007.

[84] J. F. Saeman, "Kinetics of Wood Saccharification - Hydrolysis of Cellulose and Decomposition of Sugars in Dilute Acid at High Temperature," Ind. Eng. Chem., vol. 37, no. 1, pp. 43-52, 1945.

[85] X. Lu, J. R. V Flora, and N. D. Berge, "Influence of process water quality on hydrothermal carbonization of cellulose," Bioresour. Technol., vol. 154, pp. 229-239, 2014.

[86] S. A. Channiwala and P. P. Parikh, "A unified correlation for estimating HHV of solid, liquid and gaseous fuels," Fuel, vol. 81, no. 8, pp. 10511063, 2002.

[87] S. K. Hoekman, A. Broch, C. Robbins, B. Zielinska, and L. Felix, "Hydrothermal carbonization (HTC) of selected woody and herbaceous biomass feedstocks," Biomass Convers. Biorefinery, vol. 3, no. 2, pp. 113$126,2013$.

[88] J. Cai, B. Li, C. Chen, J. Wang, M. Zhao, and K. Zhang, "Hydrothermal 
carbonization of tobacco stalk for fuel application," Bioresour. Technol., vol. 220, pp. 305-311, 2016.

[89] S. Naik, V. V. Goud, P. K. Rout, K. Jacobson, and A. K. Dalai, "Characterization of Canadian biomass for alternative renewable biofuel," Renew. Energy, vol. 35, no. 8, pp. 1624-1631, Aug. 2010.

[90] K. Nakason, B. Panyapinyopol, V. Kanokkantapong, N. Viriya-empikul, W. Kraithong, and P. Pavasant, "Characteristics of hydrochar and liquid fraction from hydrothermal carbonization of cassava rhizome," J. Energy Inst., vol. 91, no. 2, pp. 184-193, 2018.

[91] W. Stelte, J. K. Holm, A. R. Sanadi, S. Barsberg, J. Ahrenfeldt, and U. B. Henriksen, "Fuel pellets from biomass: The importance of the pelletizing pressure and its dependency on the processing conditions," Fuel, vol. 90, no. 11, pp. 3285-3290, 2011.

[92] L. Bertinetti, P. Fratzl, and T. Zemb, "Chemical, colloidal and mechanical contributions to the state of water in wood cell walls," New J. Phys., vol. 18, no. 8, pp. 1-15, 2016.

[93] A. A. Khan, W. de Jong, P. J. Jansens, and H. Spliethoff, "Biomass combustion in fluidized bed boilers: Potential problems and remedies," Fuel Process. Technol., vol. 90, no. 1, pp. 21-50, Jan. 2009.

[94] A. A. Peterson, F. Vogel, R. P. Lachance, M. Fröling, M. J. Antal, Jr., and J. W. Tester, "Thermochemical biofuel production in hydrothermal media: A review of sub- and supercritical water technologies," Energy 
Environ. Sci., vol. 1, no. 1, p. 32, 2008.

[95] D. W. Rackemann and W. O. Doherty, "The conversion of lignocellulosics to levulinic acid," Biofuels, Bioprod. Biorefining, vol. 5, no. 2, pp. 198214, Mar. 2011.

[96] A. Mukherjee, M. J. Dumont, and V. Raghavan, "Review: Sustainable production of hydroxymethylfurfural and levulinic acid: Challenges and opportunities," Biomass and Bioenergy, vol. 72, pp. 143-183, Jan. 2015.

[97] C. M. Cai, T. Zhang, R. Kumar, and C. E. Wyman, "Integrated furfural production as a renewable fuel and chemical platform from lignocellulosic biomass," J. Chem. Technol. Biotechnol., vol. 89, no. 1, pp. 2-10, Jan. 2014.

[98] M. Dashtban, A. Gilbert, and P. Fatehi, "Production of Furfural: Overview and Challenges Production of Furfural: Overview and Challenges," J. Sci. Technol. For. Prod. Process., vol. 2, no. 4, pp. 44-53, 2012.

[99] F. K. Kazi, A. D. Patel, J. C. Serrano-Ruiz, J. A. Dumesic, and R. P. Anex, "Techno-economic analysis of dimethylfuran (DMF) and hydroxymethylfurfural (HMF) production from pure fructose in catalytic processes," Chem. Eng. J., vol. 169, no. 1-3, pp. 329-338, 2011.

[100] M. Volpe, J. L. Goldfarb, and L. Fiori, "Hydrothermal carbonization of Opuntia ficus-indica cladodes: Role of process parameters on hydrochar 
properties," Bioresour. Technol., vol. 247, pp. 310-318, Jan. 2018.

[101] M. Sevilla and A. B. Fuertes, "The production of carbon materials by hydrothermal carbonization of cellulose," Carbon N. Y., vol. 47, no. 9, pp. 2281-2289, Aug. 2009.

[102] A. Sinağ, S. Gülbay, B. Uskan, and M. Güllü, "Comparative studies of intermediates produced from hydrothermal treatments of sawdust and cellulose," J. Supercrit. Fluids, vol. 50, no. 2, pp. 121-127, Sep. 2009.

[103] D. Steinbach, A. Kruse, and J. Sauer, "Pretreatment technologies of lignocellulosic biomass in water in view of furfural and 5hydroxymethylfurfural production- A review," Biomass Convers. Biorefinery, vol. 7, no. 2, pp. 247-274, 2017. 


\section{Appendices}

\section{Appendix A : Contribution of the Authors}

\section{Article 1: Catalysed Hydrothermal Carbonization with Process Liquid Recycling}

Author 1: Amin Ghaziaskar

- Designed and performed the experiments

- Collected the data

- Performed data analysis

- Wrote the paper

Author 2: Dr. Glenn McRae

- Contributed to the design of experiments and analysis of the data

- Contributed to drafting and editing of the paper

Author 3: Alexis Mackintosh

- Contributed to drafting the paper

Author 4: Dr. Onita Basu

- Contributed to the design of experiments and analysis of the data

- Contributed to drafting and editing of the paper 
Article 2: Production of Organic Compounds through Recycling the Process Liquid of Catalysed Hydrothermal Carbonization

Author 1: Amin Ghaziaskar

- Designed and performed the experiments

- Collected the data

- Performed data analysis

- Wrote the paper

Author 2: Dr. Glenn McRae

- Contributed to the design of experiments and analysis of the data

- Contributed to drafting and editing of the paper

Author 3: Alexis Mackintosh

- Contributed to drafting the paper

Author 4: Dr. Edward P.C. Lai

- Contributed to drafting the paper

Author 5: Dr. Onita Basu

- Contributed to the design of experiments and analysis of the data

- Contributed to drafting and editing of the paper 


\section{Appendix B : Hydrothermal Carbonization of Woody Biomass}

Hydrothermal carbonization (HTC) of woody biomass was done to determine its differences from the CHTC process. Four different L:B ratios, $3: 1,5: 1,10: 1$, and $12: 1$ were used. The processes were done similar to CHTC except using only deionized water instead of the catalyst. The hydrochar produced through HTC had lower HHV values compared with the hydrochar produced through CHTC; however, the differences were not significant. Table A-1 shows the differences in between the hydrochar made through CHTC and HTC.

Table B-1: Properties of the hydrochar made through CHTC and HTC processes.

\begin{tabular}{ccccccccc}
\hline & \multicolumn{7}{c}{ Liquid:Biomass ratio } \\
& \multicolumn{7}{c}{ CHTC } & \multicolumn{3}{c}{ HTC } & \\
\cline { 2 - 9 } & $3: 1$ & $5: 1$ & $10: 1$ & $12: 1$ & $3: 1$ & $5: 1$ & $10: 1$ & $12: 1$ \\
\hline HHV & 27.8 & 27.7 & 27.8 & 27.6 & 27.2 & 27.3 & 26.7 & 26.9 \\
(MJ/kg) & & & & & & & & \\
\hline EDR $^{1}$ & 1.42 & 1.42 & 1.43 & 1.41 & 1.40 & 1.40 & 1.37 & 1.36 \\
\hline EY $^{2}$ (\%) & $74.5 \%$ & $72.0 \%$ & $64.0 \%$ & $62.9 \%$ & 71.5 & $68.1 \%$ & $59.9 \%$ & $57.0 \%$ \\
& & & & & $\%$ & & & \\
\hline $\mathbf{V M}^{3}$ (\%) & $52.1 \pm$ & $50 \pm 0.3$ & $49.5 \pm$ & $50 \pm 0.1$ & 51.0 & $52.8 \pm$ & $54.7 \pm$ & $53.5 \pm$ \\
& 0.8 & & 0.5 & & \pm 0.1 & 0.1 & 0.2 & 0.3 \\
\hline FC $^{\mathbf{4}}$ (\%) & $47.3 \pm 1$ & $48.8 \pm$ & $49.6 \pm$ & $50.4 \pm$ & 49.0 & $47.2 \pm$ & $44.7 \pm$ & $47.9 \pm$ \\
& & 0.3 & 0.7 & 0.1 & \pm 0.1 & 0.2 & 0.2 & 0.3 \\
\hline Ash (\%) & $0.3 \pm$ & $0.6 \pm$ & $0.6 \pm$ & $0.0 \pm$ & $0.0 \pm$ & $0.0 \pm$ & $0.2 \pm$ & $0.0 \pm$ \\
& 0.2 & 0.0 & 0.1 & 0.3 & 0.1 & 0.1 & 0.0 & 0.8 \\
\hline 1 Energy Densification Ratio & & & & & & & \\
2 Energy Yield & & & & & & & & \\
3 Volatile Matter & & & & & & & & \\
4 Fixed Carbon & & & & & & &
\end{tabular}


The HTC process produced the Value-Added Compounds (VACs), which were found in the process liquid of CHTC process. Figure A-1 shows the concentration of these compounds in the process liquid as well as their production yields.
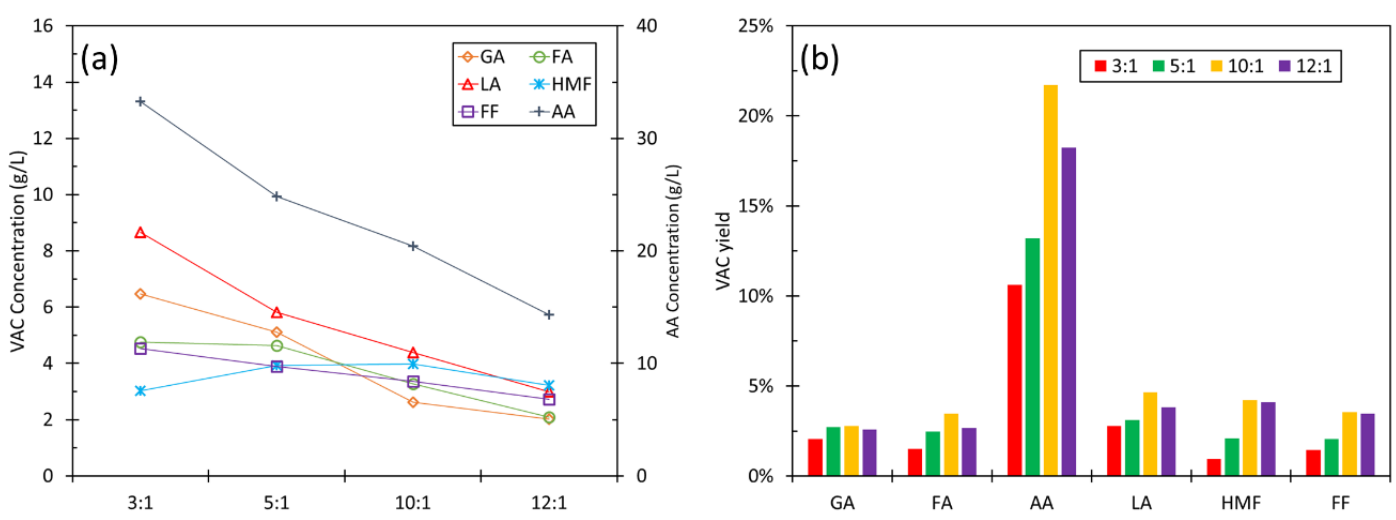

Figure B-1: (a) The concentration of VACs after changing L:B ratios for HTC processes and (b) the production yield of the VACs with respect to the biomass.

The properties of the hydrochar made through HTC was not significantly different from its counterpart CHTC. The concentrations of the VACs were similar, except the concentration of LA, compared with Figure 4-3. 


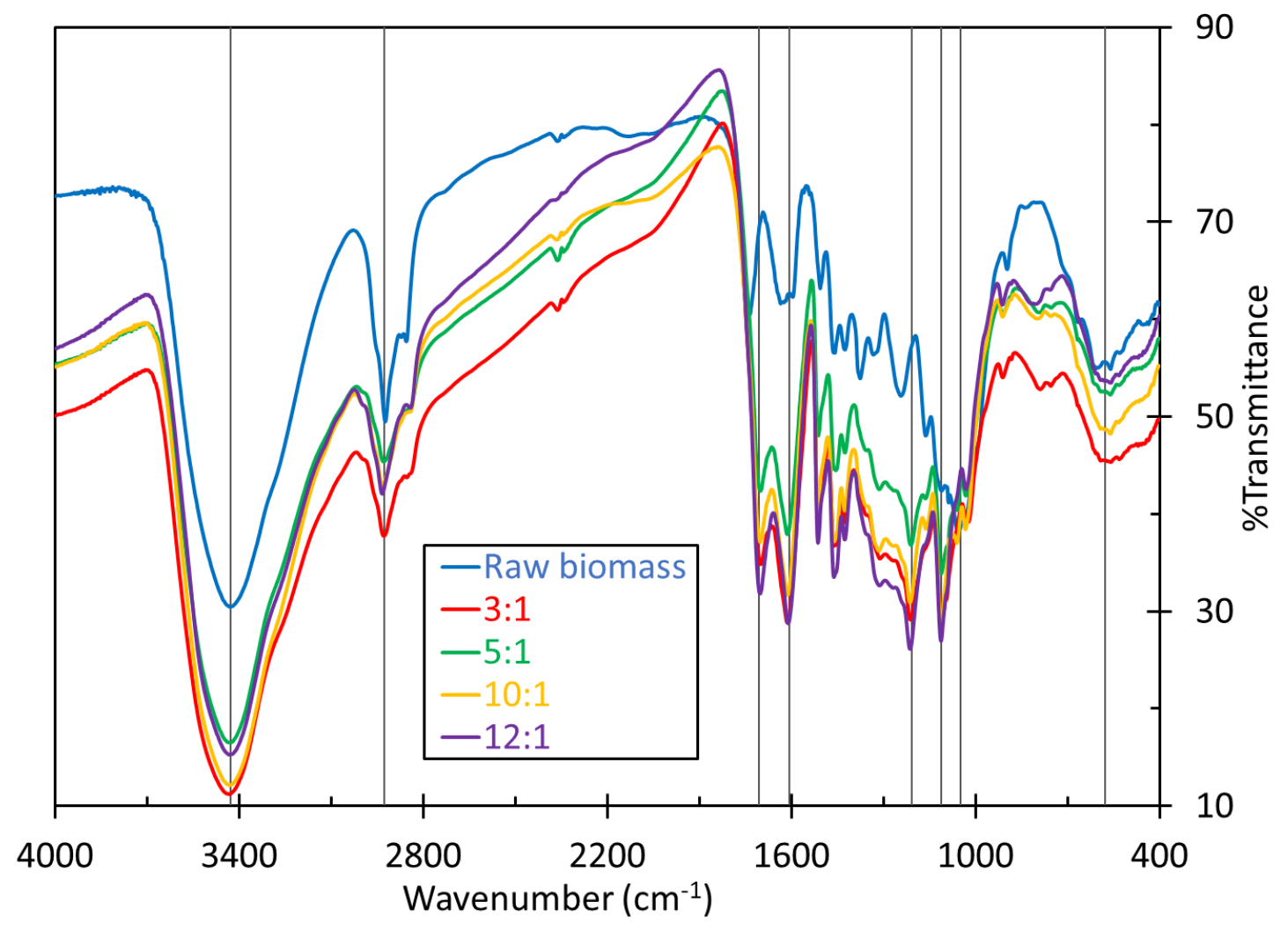

Figure B-2: IR spectra of the HTC hydrochar produced using different L:B ratios. The chemical bonds were found to be similar to CHTC hydrochar while the difference in $\%$ transmittance values of the CHTC hydrochar were slightly larger. 
Appendix C : Instrumentation

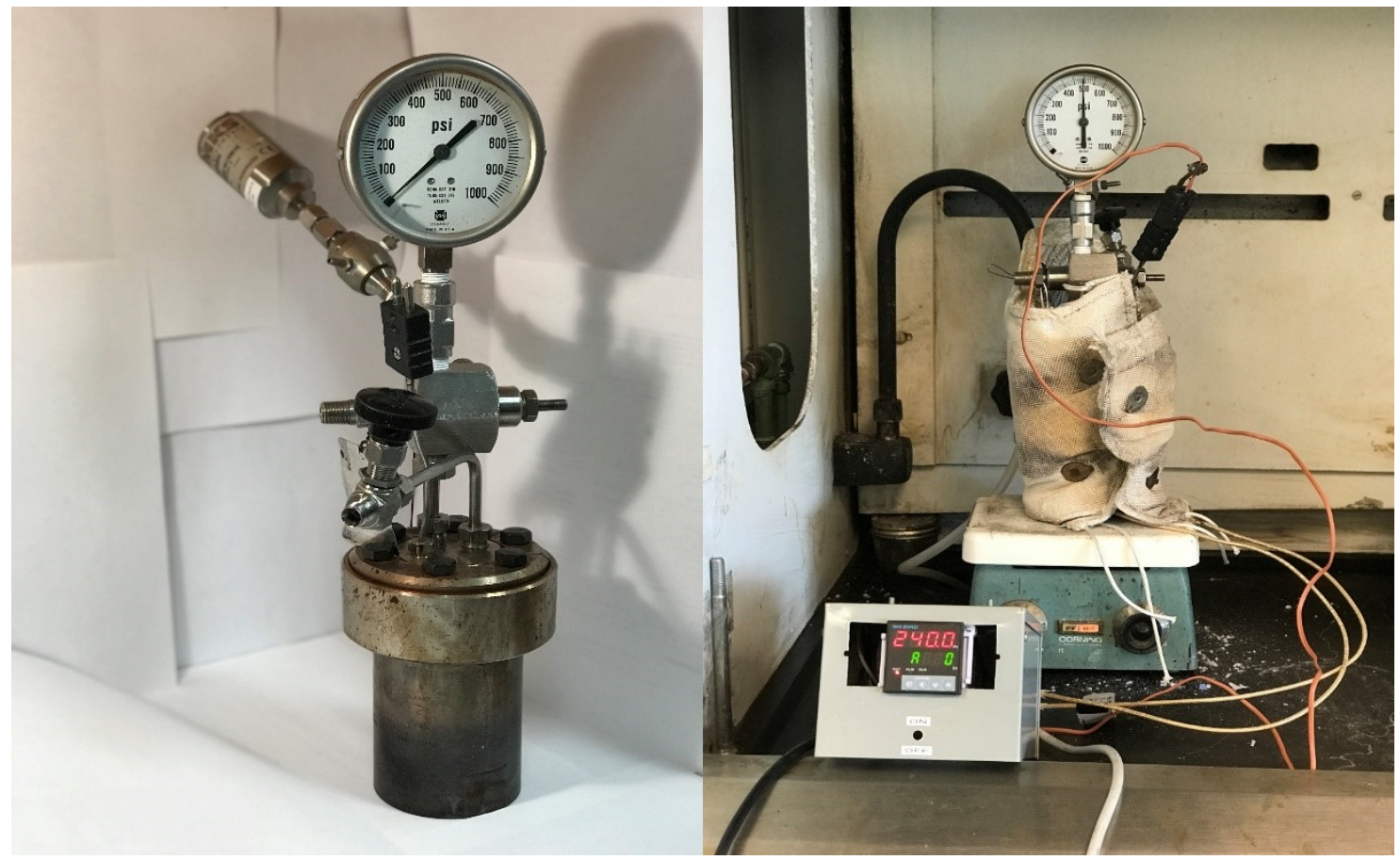

Figure C-1: CHTC reactor setup. The reactor is heated using a band heater and a hot plate. The temperature is monitored and controlled using the PID controller. The pressure is only monitored during the process. 


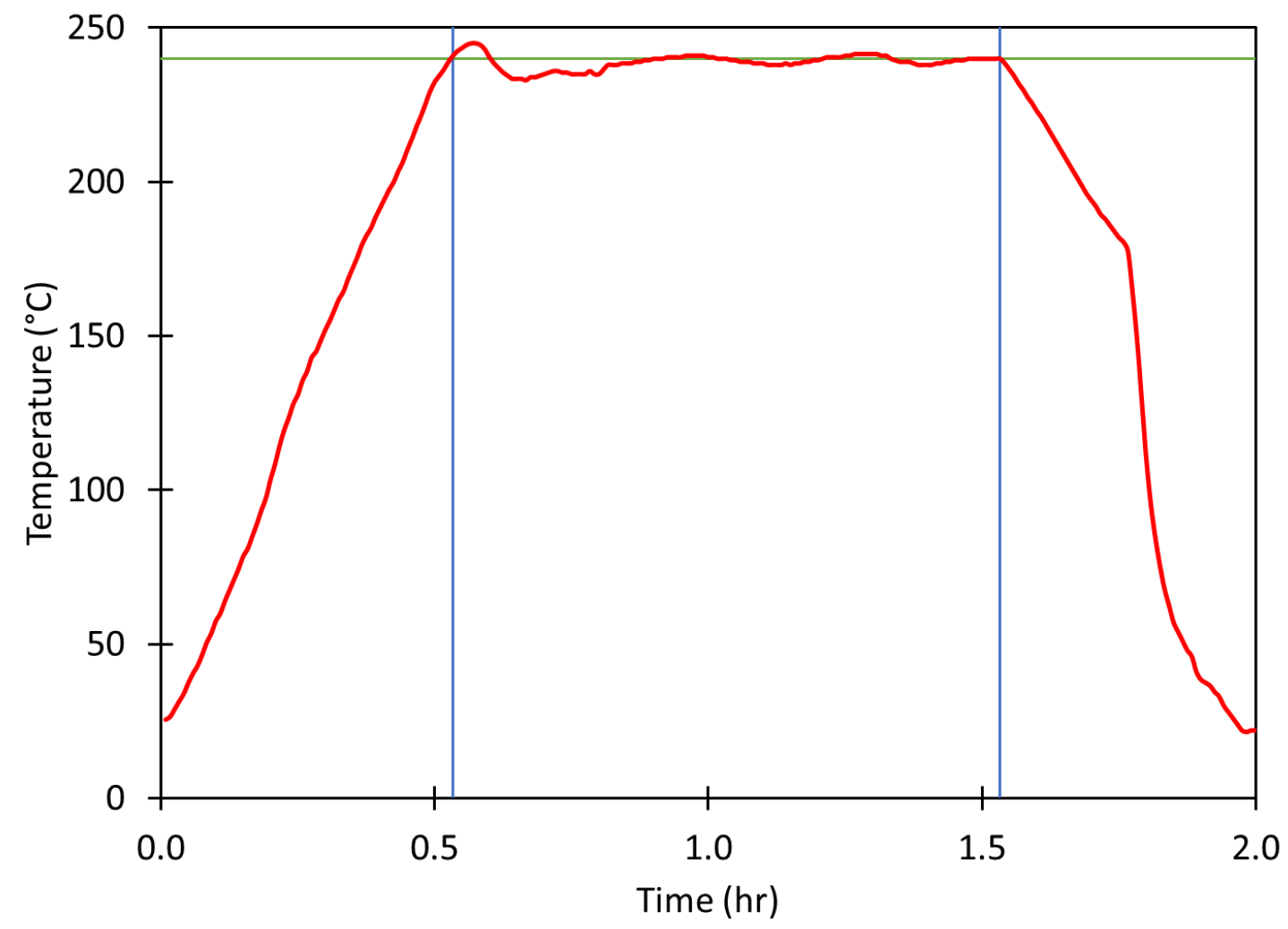

Figure C-2: A temperature profile sample of the CHTC process. 


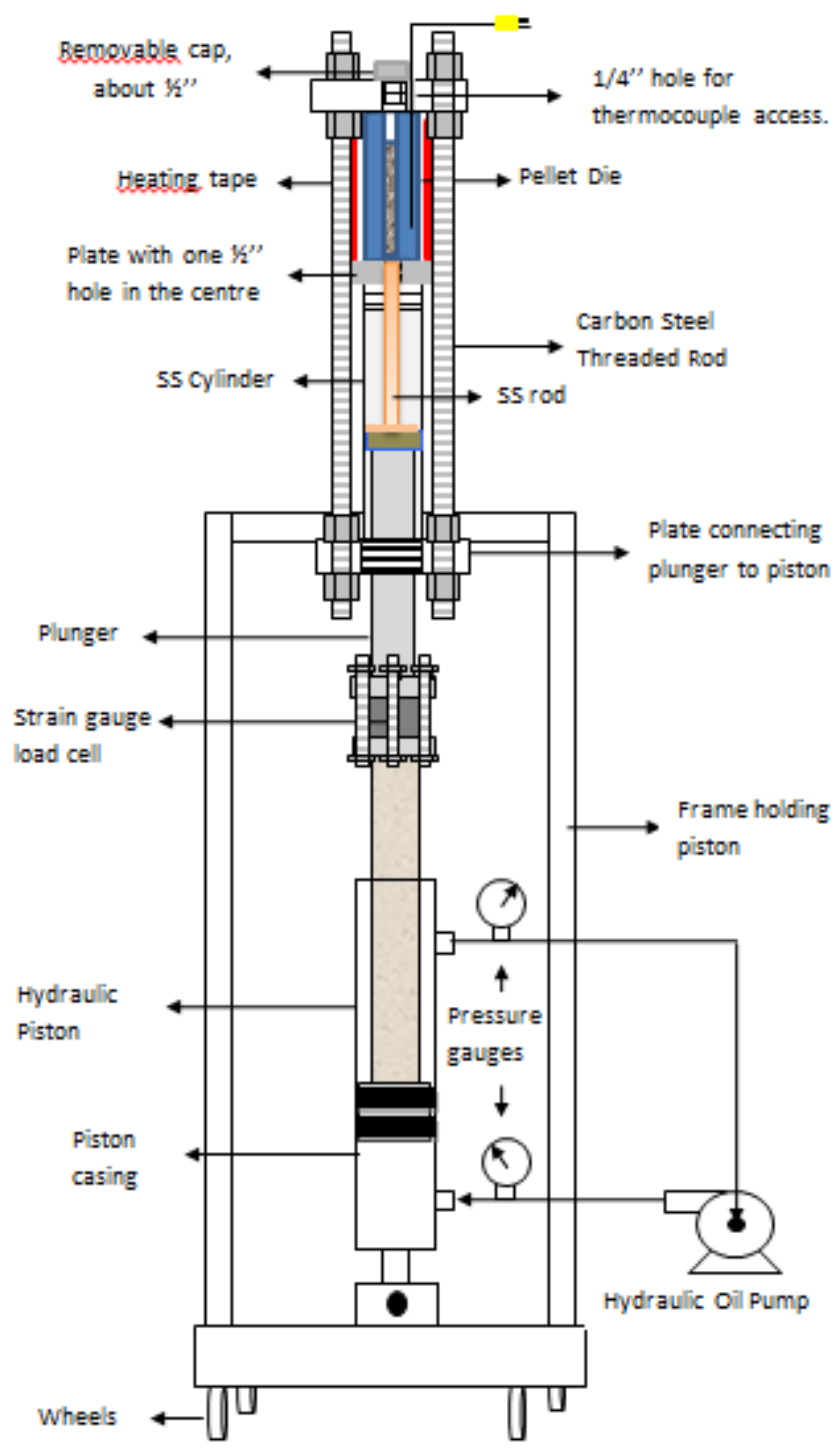

Figure C-3: Single-pellet press assembly. The schematic was provided by Guy Tourigny from Canmet Energy. 


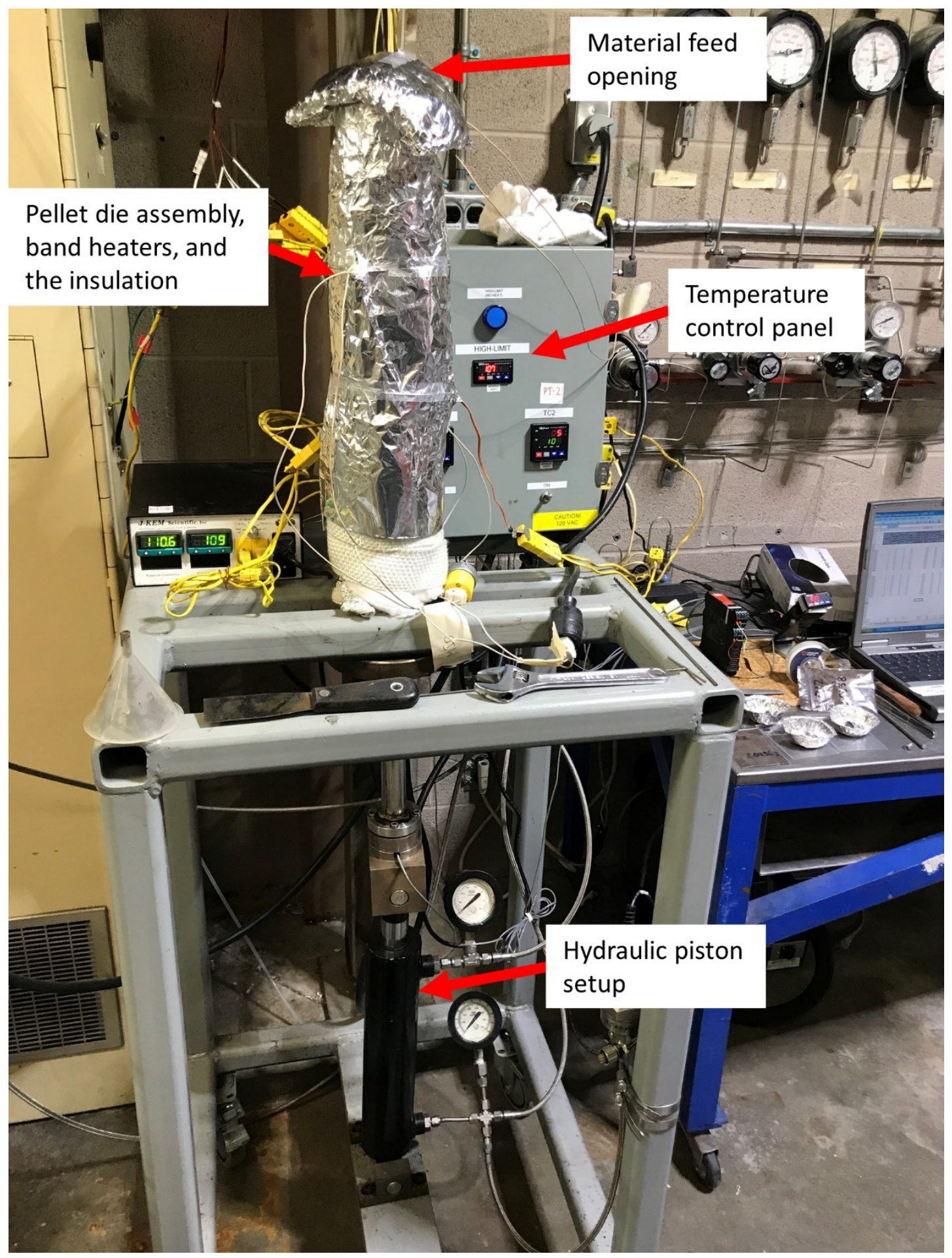

Figure C-4: Single-pellet press assembly. 


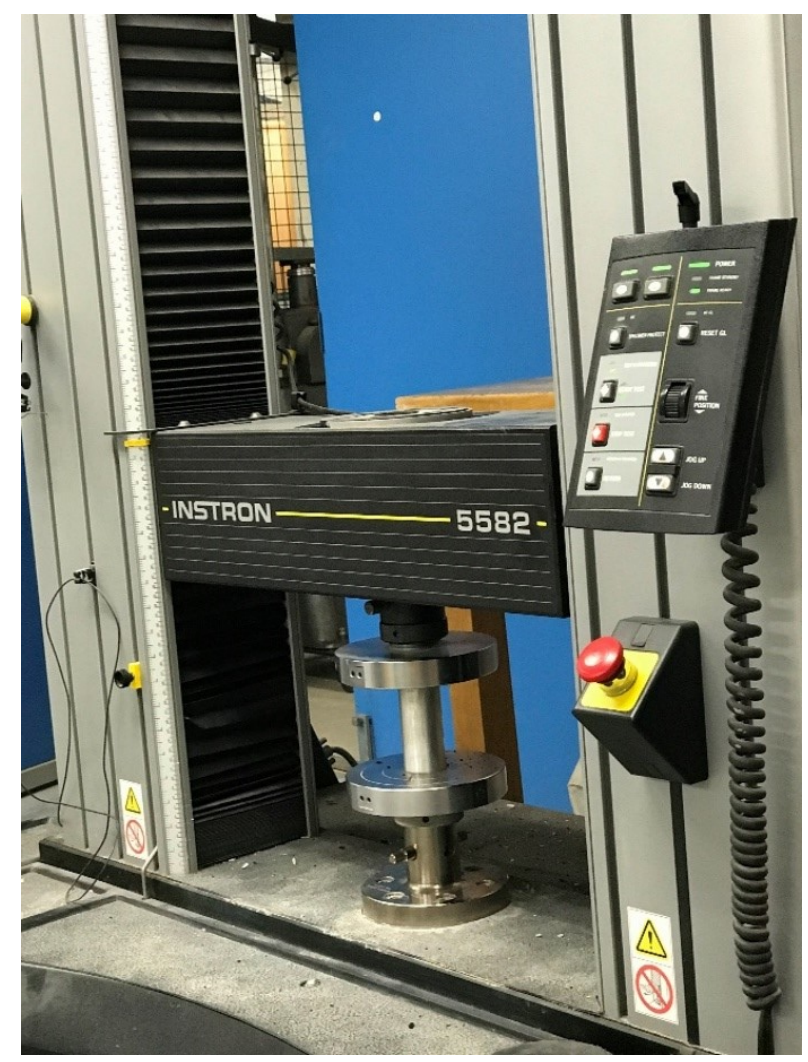

Figure C-5: The Instron 5582 testing machine used to measure compression strength of the hydrochar pellets.

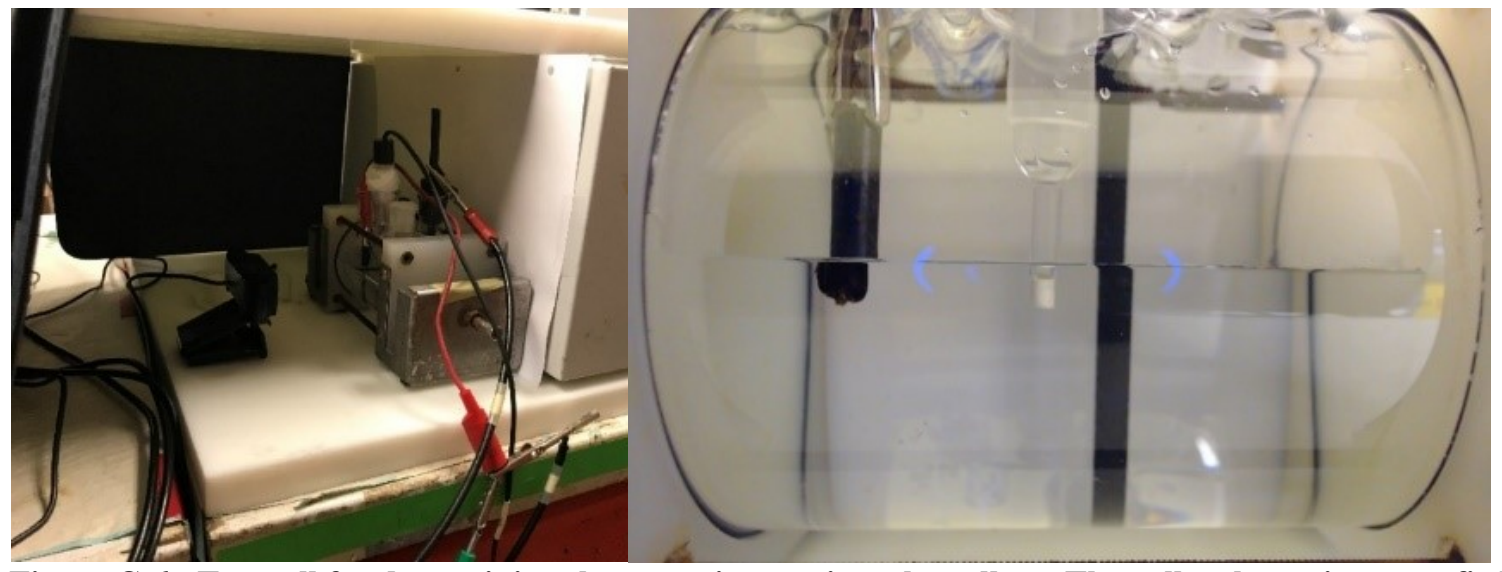

Figure C-6: Test cell for determining the water ingress into the pellets. The pellet shown is a torrefied wood pellet at $\mathbf{t}=\mathbf{0}$. 


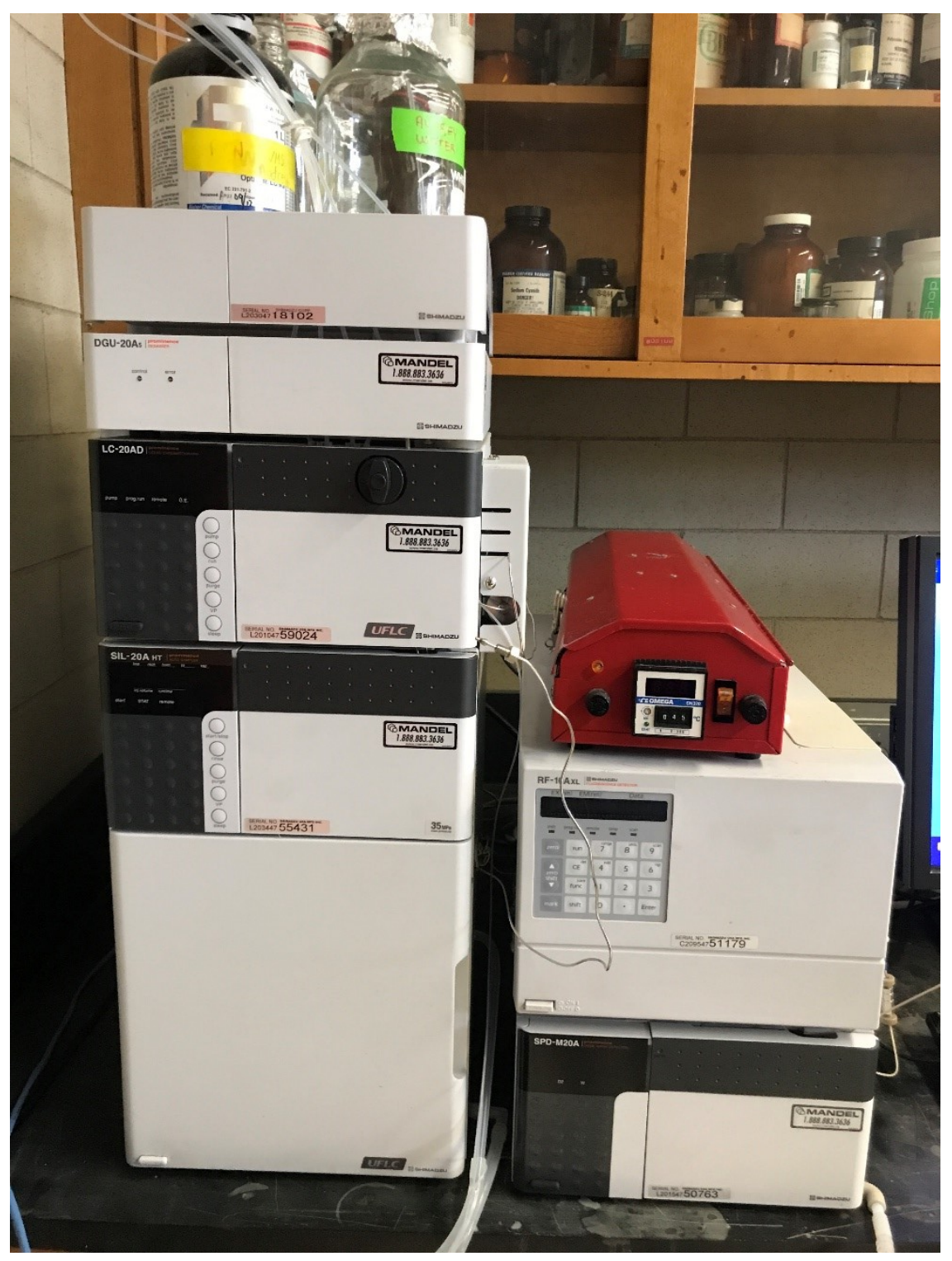

Figure C-7: Shimadzu UFLC setup 


\section{Appendix D : Supplemental Data to Chapter 4}

\section{D.1 IR Spectroscopy}

The following are the IR spectra of the hydrochar made through recycling the process liquid at the $\mathrm{L}: \mathrm{B}$ ratio of $5: 1$, Figure $\mathrm{C}-1$, and the IR spectra of hydrochar made through CHTC with different L:B ratios, Figure C-2.

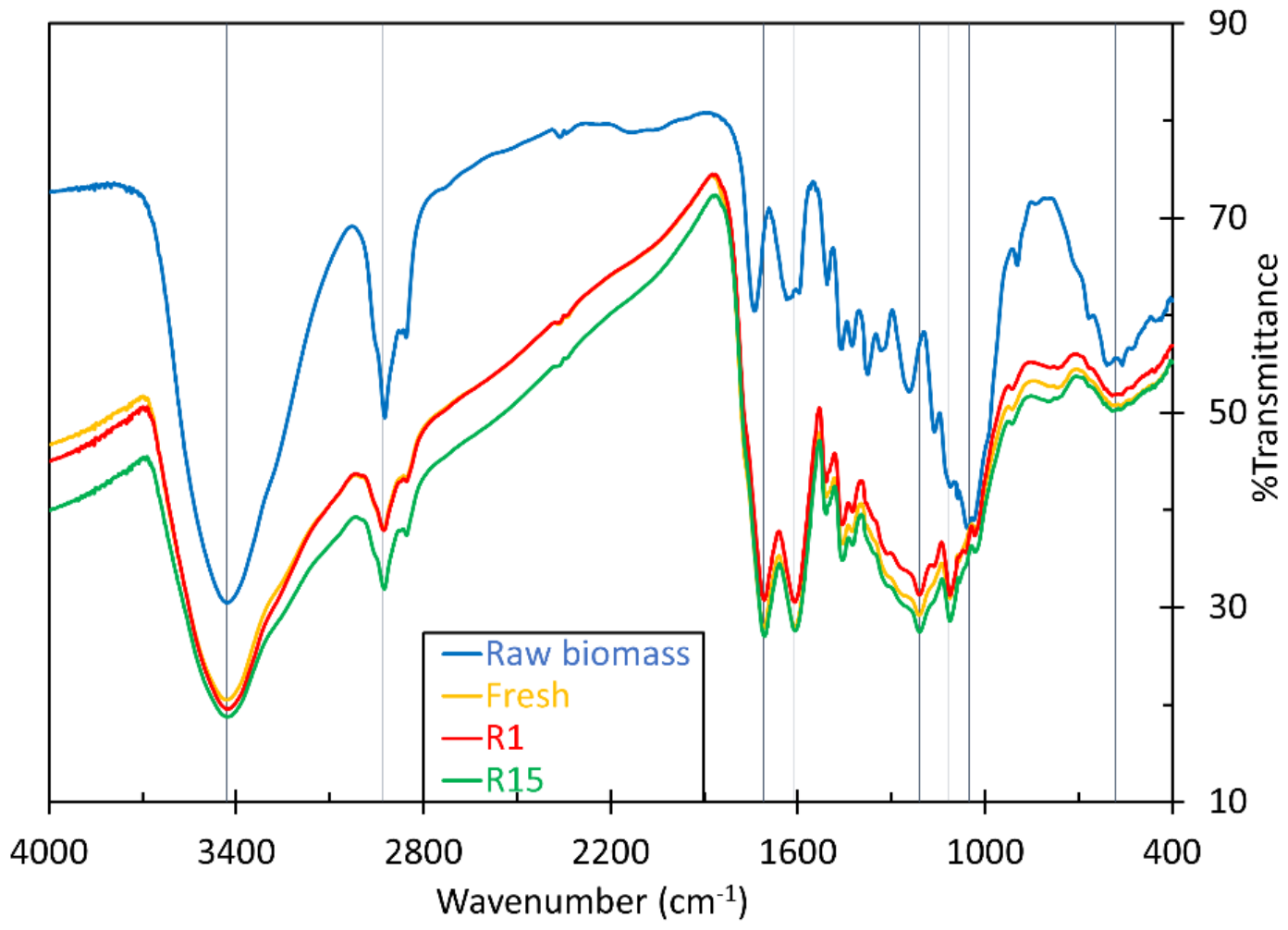

Figure D-1: IR spectra of raw biomass and hydrochar after recycling the process liquid. 


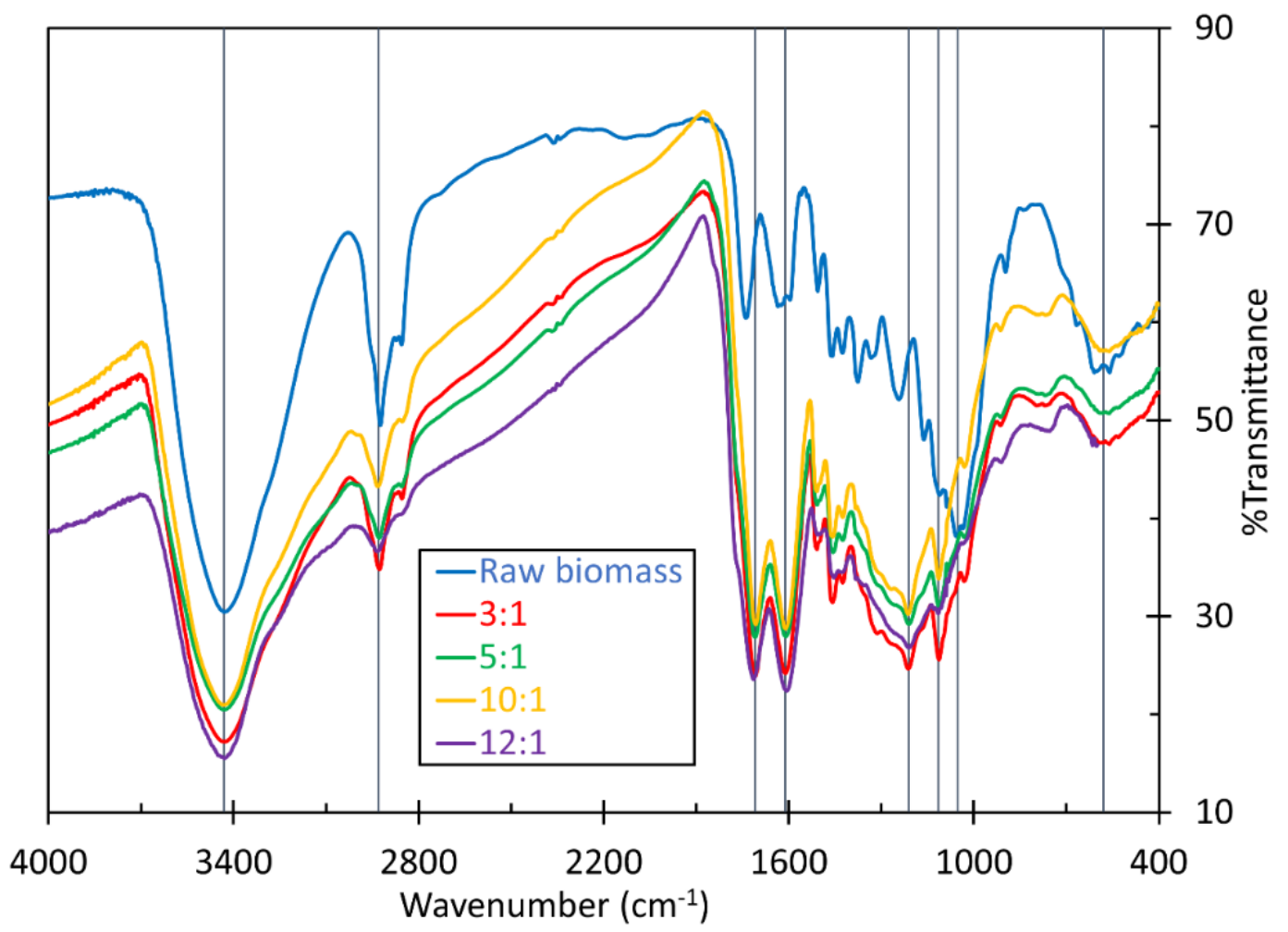

Figure D-2: IR spectra of biomass and the hydrochar made through CHTC using different L:B ratios. 


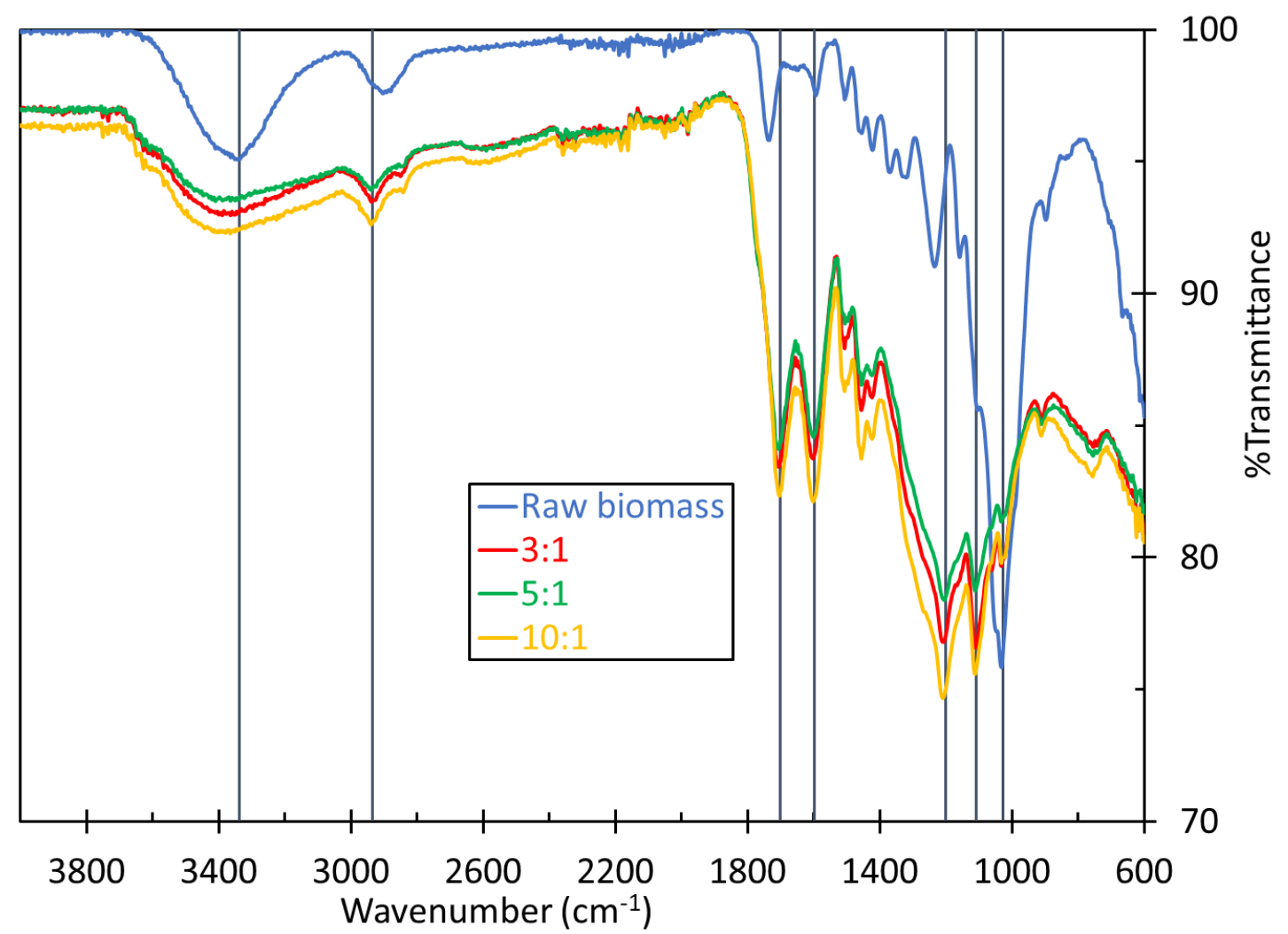

Figure D-3: ATR-IR spectra of hydrochar produced with different $L: B$ ratios. The peaks represent similar chemical bonds to the ones mentioned for FT-IR spectra. 


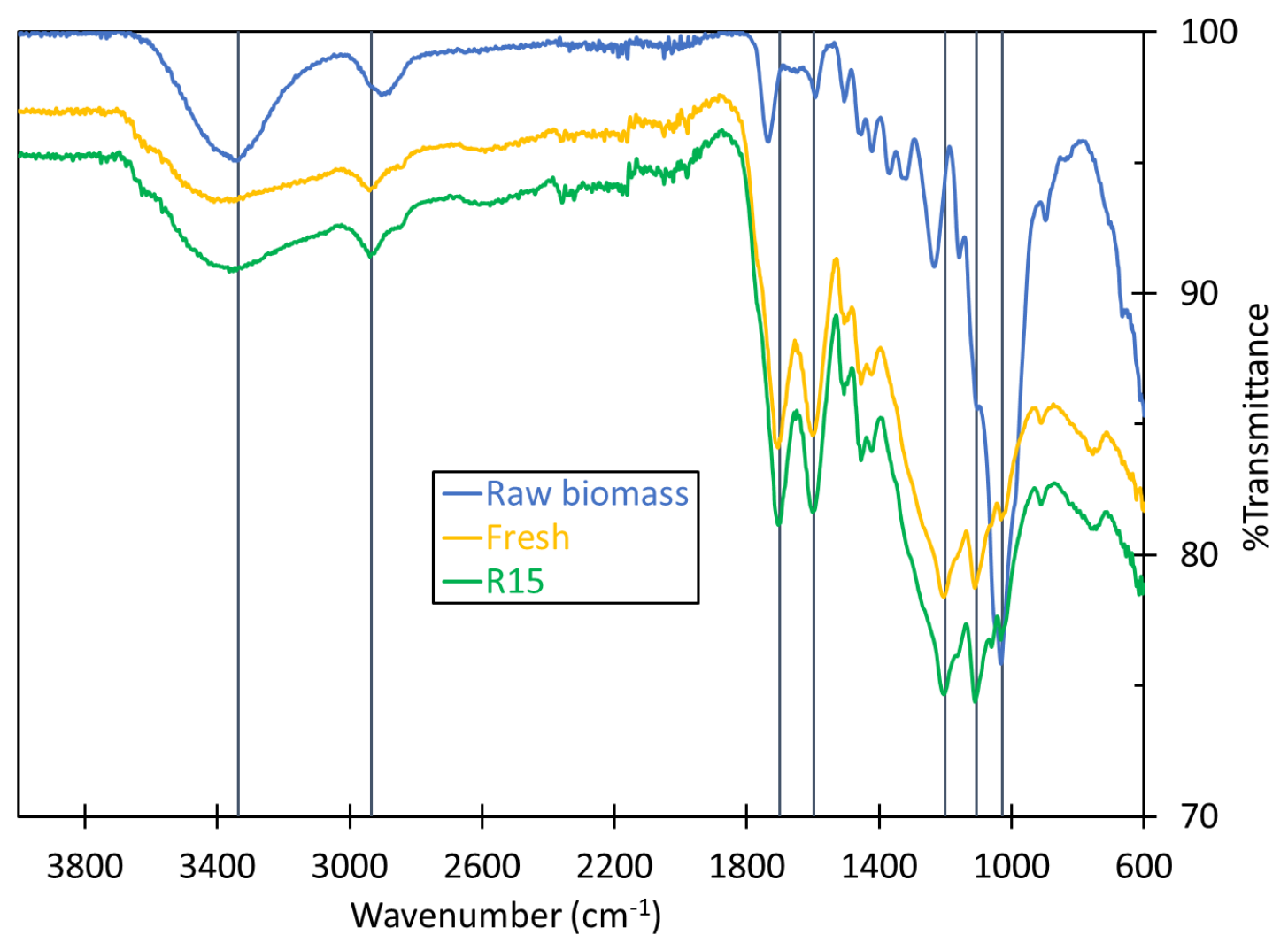

Figure D-3: ATR-IR spectra of the hydrochar after recycling the process liquid (R15), using pure catalyst (Fresh), compared with the Raw biomass.

The IR spectra of the hydrochar has a slope in the range 4000-2000 $\mathrm{cm}^{-1}$ compared with the ATR-IR spectra, mainly caused by Rayleigh principle, where the hydrochar particle sizes are on the order of the IR wavelengths. 


\section{D.2 SEM Images of the Hydrochar and the Biomass}
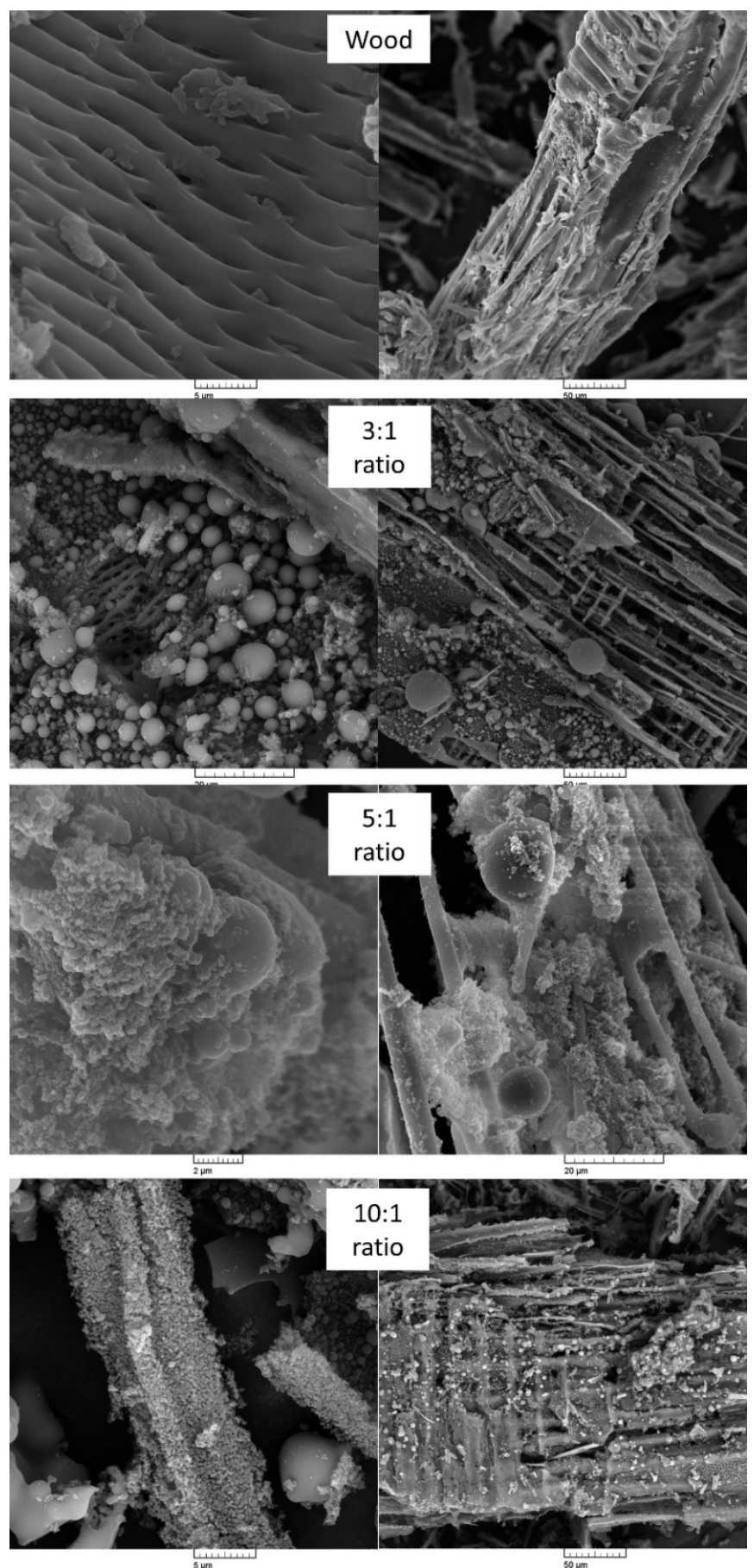

Figure D-4: SEM images taken from the biomass (wood) and the hydrochar for various L:B ratios.

The fibrous structure, mainly caused by lignin, was persistent while spherical hydrochar particles were formed. 

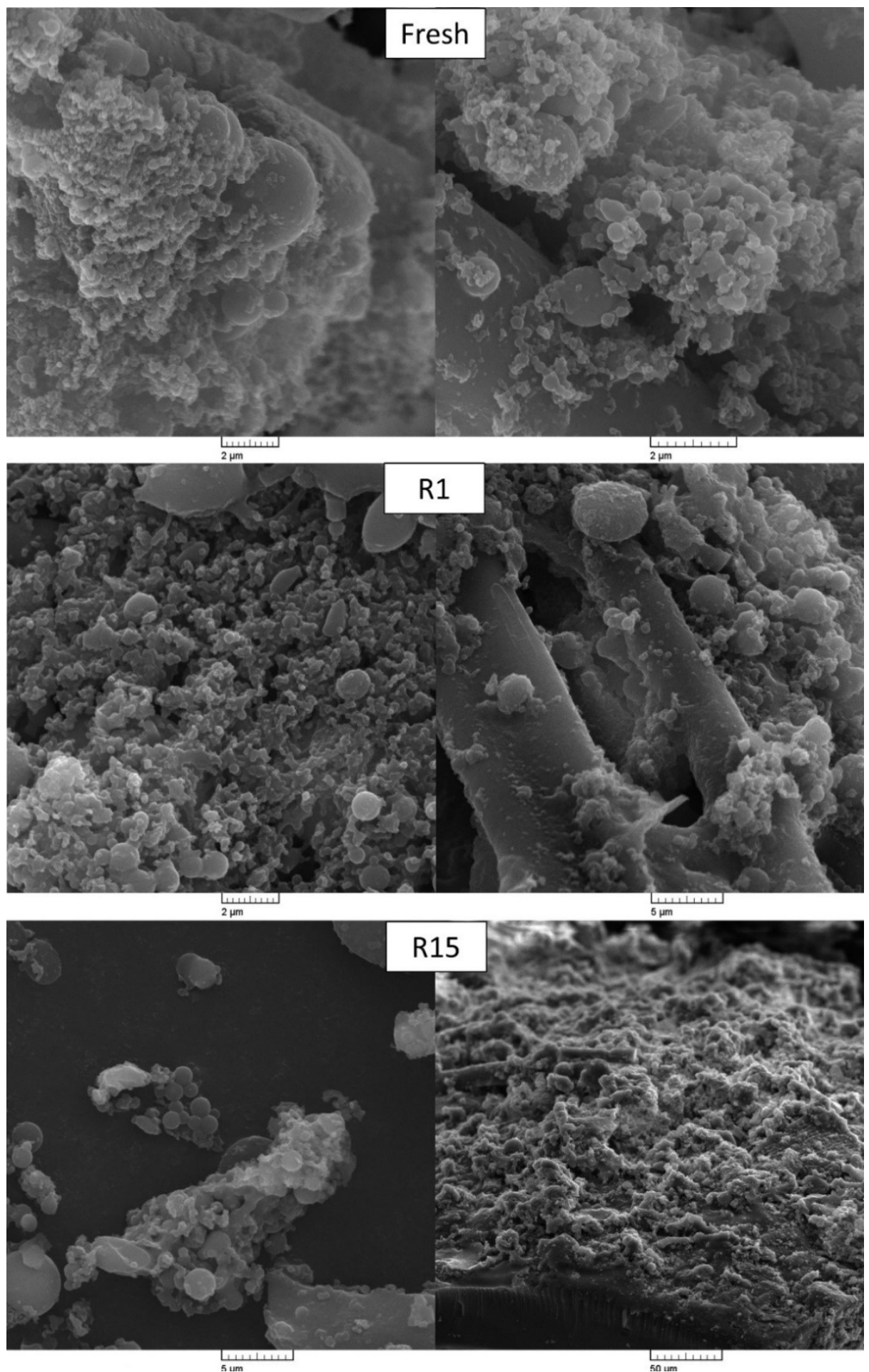

Figure D-5: SEM images of hydrochar produced with CHTC at 5:1 L:B ratio. The hydrochar made with fresh catalyst is Fresh and the hydrochar made after recycling the process liquid once and 15 times are called R1 and R15, respectively. The hydrochar was formed using the recycled process liquid. 
Figure $\mathrm{C}-5$ shows the correlation in between the mass yield and the energy yield, and lack of it in between the HHV and the energy yield, though both HHV and mass yield are used to calculate the energy yield of the hydrochar. Therefore, recycling the process liquid can improve the energy yield of the hydrochar by increasing its mass yield.
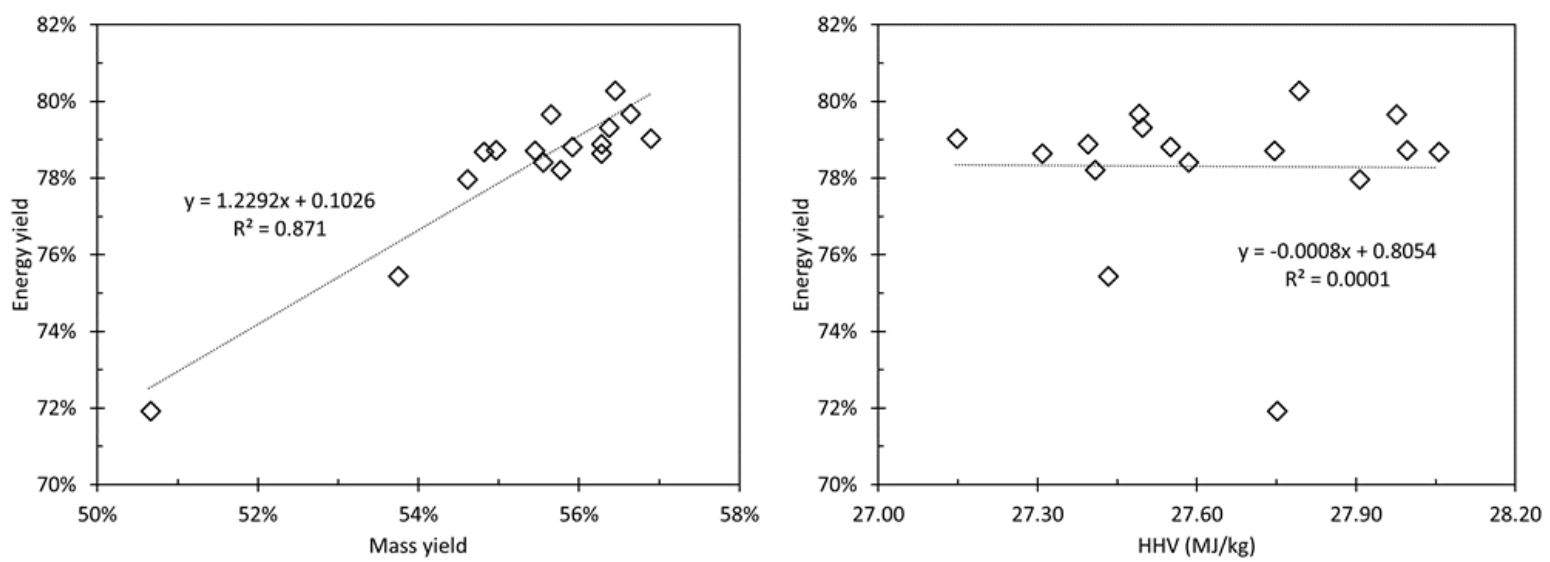

Figure D-6: Energy yield vs mass yield (left) and HHV (right). Energy yield has a higher dependency on the mass yield compared with the HHV. The energy yield of the CHTC process with 5:1 (L:B) ratio was found to be independent of the HHV of the hydrochar and correlated with the mass yield with a Pearson correlation coefficient of $(0.93)$ with $p=4.05 E-08$. 


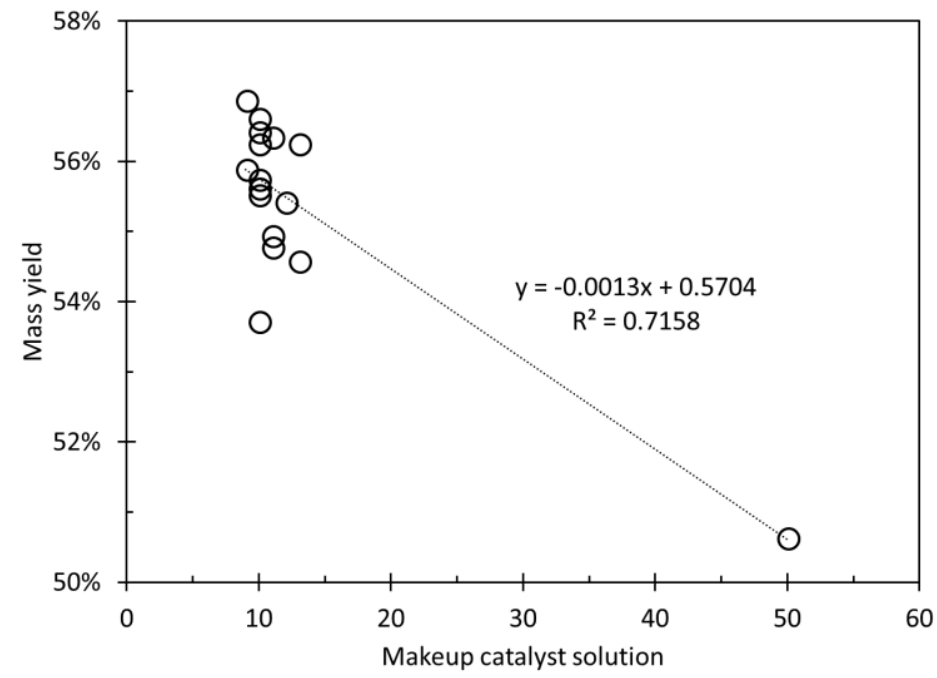

Figure D-7: Using more process liquid resulted in an increase in the mass yield. Lower volumes of makeup catalyst resulted in higher mass yield percentages, which suggested further polymerization of leftover chemical compounds in the process liquid.

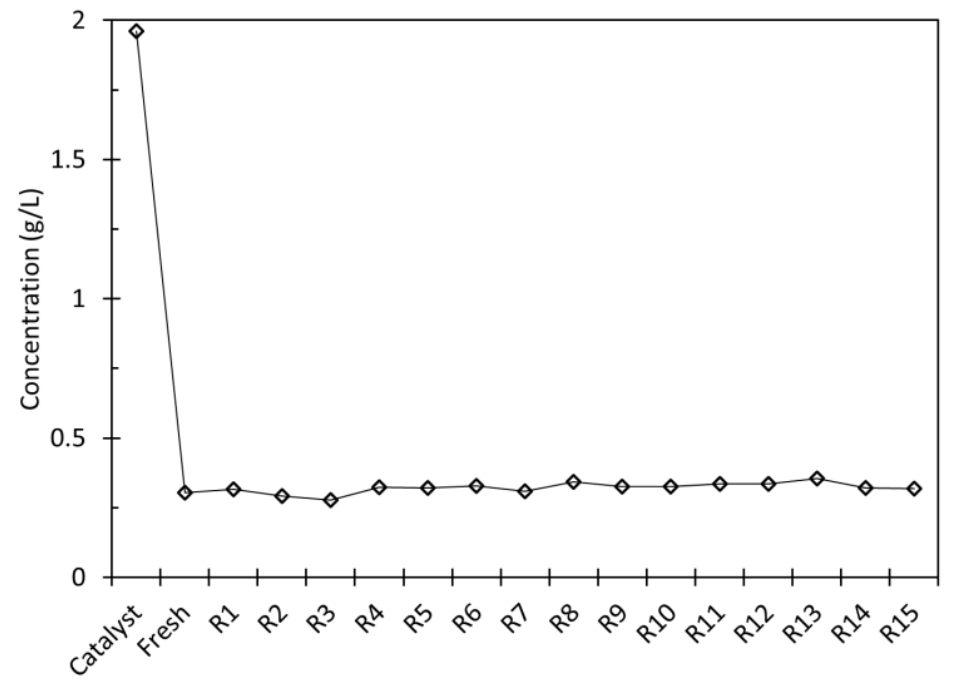

Figure D-8: The initial concentration of the catalyst (catalyst) used as the process liquid (Fresh) and after recycling the process liquid (R1-R15). The concentration of the catalyst decreased to $\approx 0.3 \mathrm{~g} / \mathrm{L}$ in the process liquid. The constant concentration of the catalyst after recycling can suggest the possibility of reducing its concentration. 


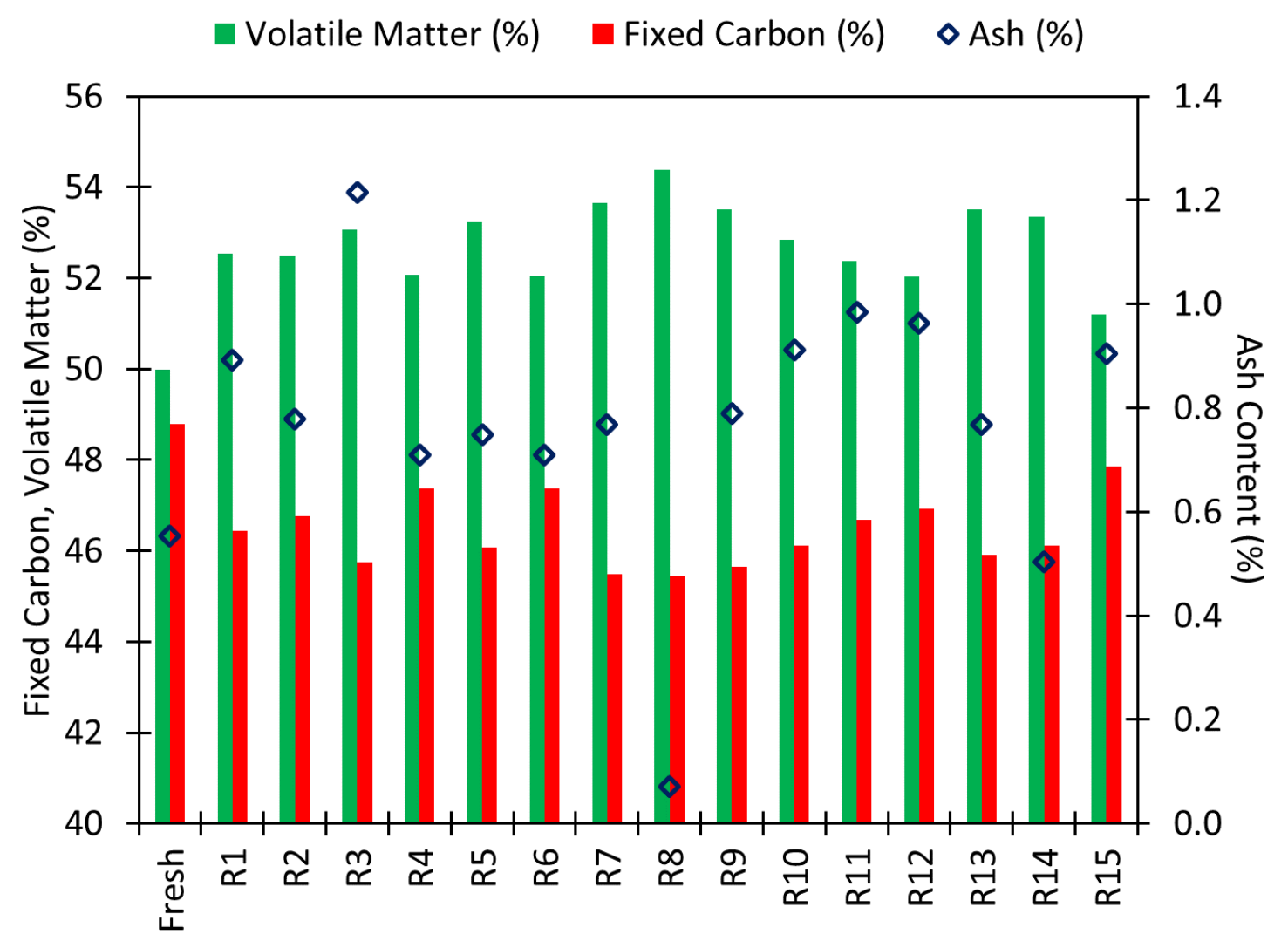

Figure D-9: Volatile matter, fixed carbon content, and ash content of the hydrochar made through CHTC with L:B ratio of 5:1. 


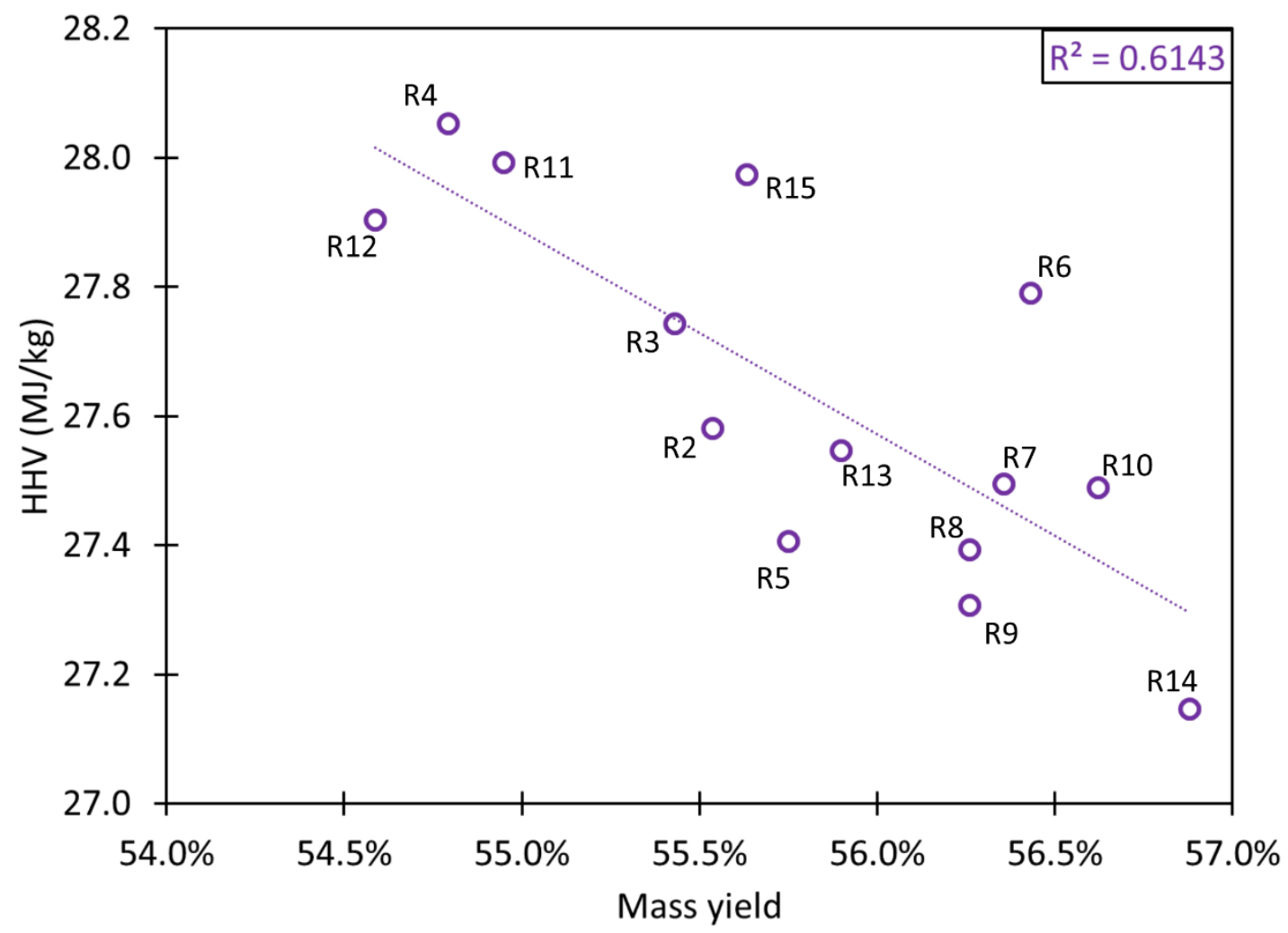

Figure D-10: The negative correlation in between the $\mathrm{HHV}$ and mass yield of the hydrochar from recycle range $\mathrm{R} 2-\mathrm{R} 15$. The hydrochar was made through $\mathrm{CHTC}$ with $\mathrm{L}: \mathrm{B}$ ratio of 5:1. 


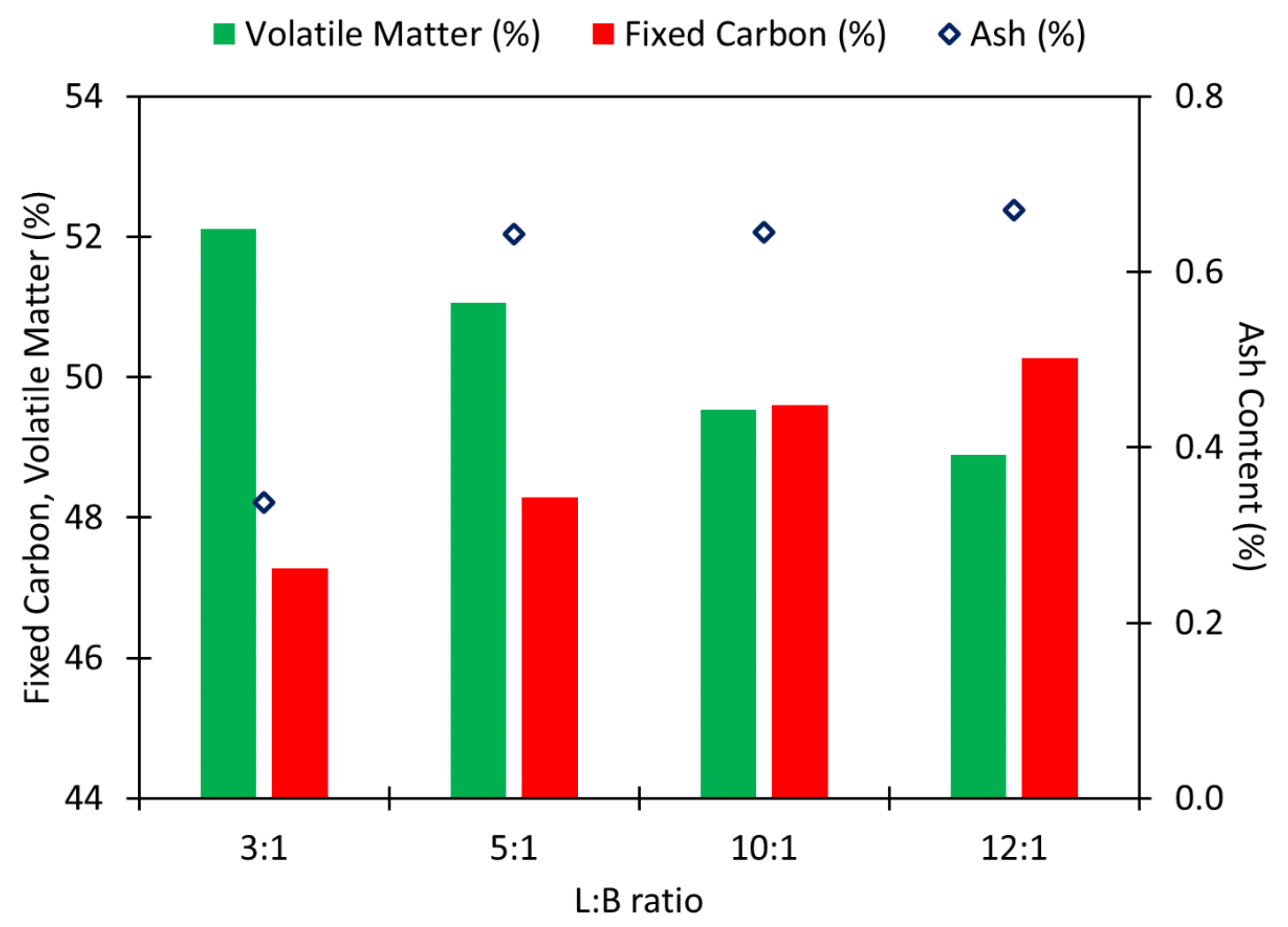

Figure D-11: Changes made to fixed carbon content and volatile matter of the hydrochar after changing the $L: B$ ratio 


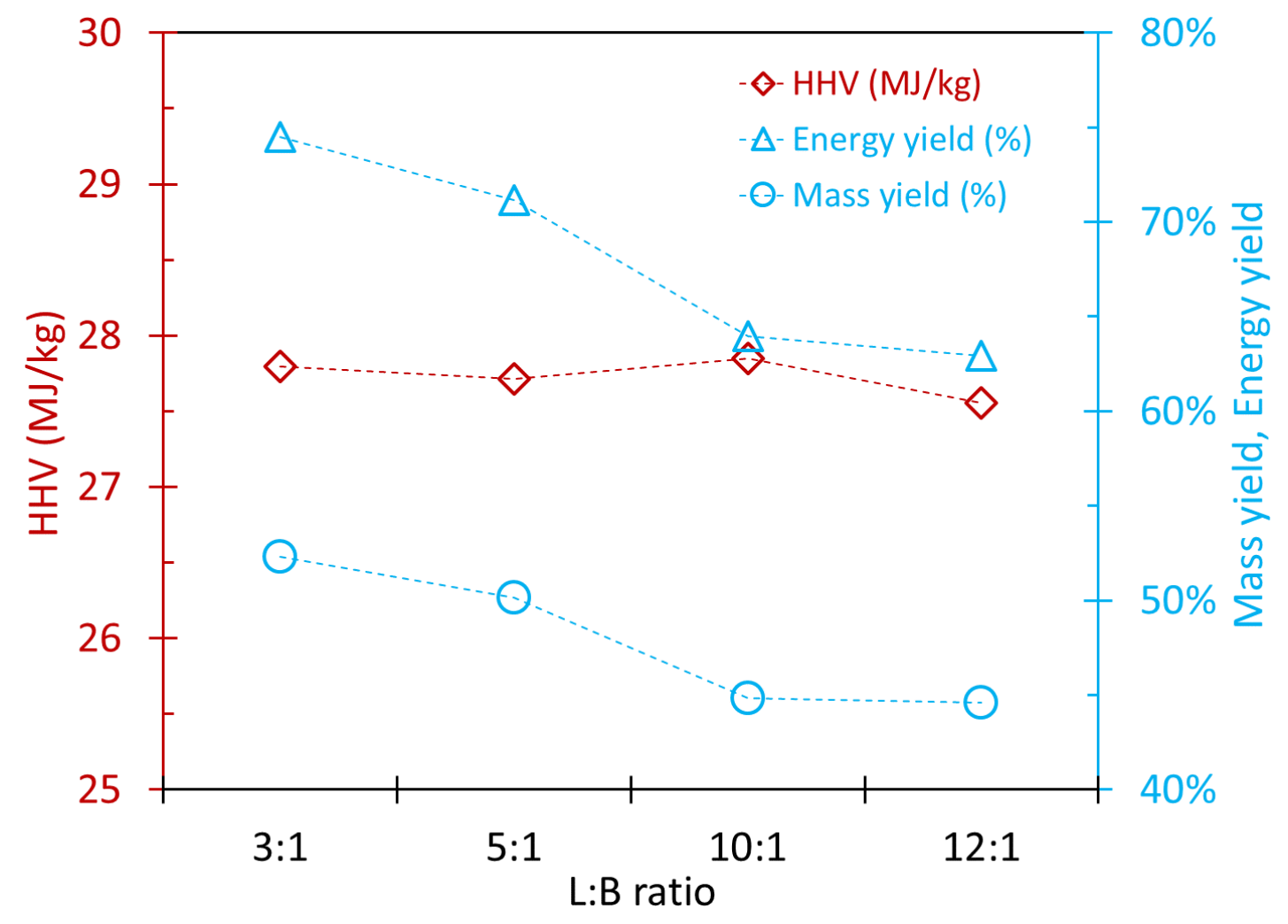

Figure D-12: HHV, mass yield, and energy yield of the hydrochar made through CHTC with different L:B ratios. 


\section{Appendix E : UFLC Calibration Curves}

The calibration curves used for UFLC analysis are provided in this section, Figures D-1 to D-6.

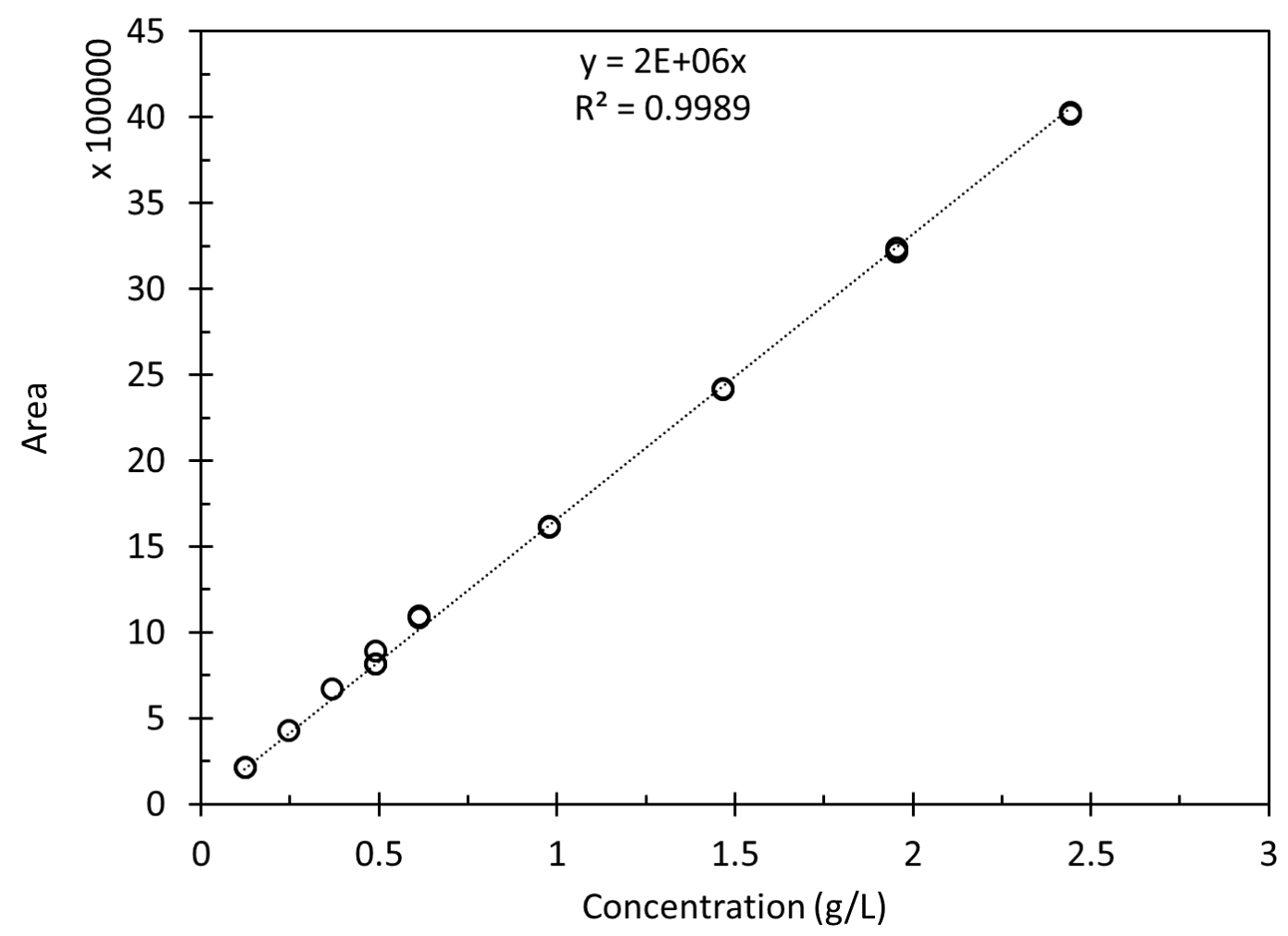

Figure E-1: Calibration curve of formic acid.

The process liquid samples run with UFLC were 20 times diluted prior to the test and were each run at least in duplicates. A standard was also injected along with the unknown to validate the calibration curves. The concentrations represented for the compounds were averaged from the 
injection trials (at least two) of one process liquid sample. Integration of the peaks in the spectra were all done by software, LC Shimadzu. Slope of the baseline was autodetected for each spectrum.

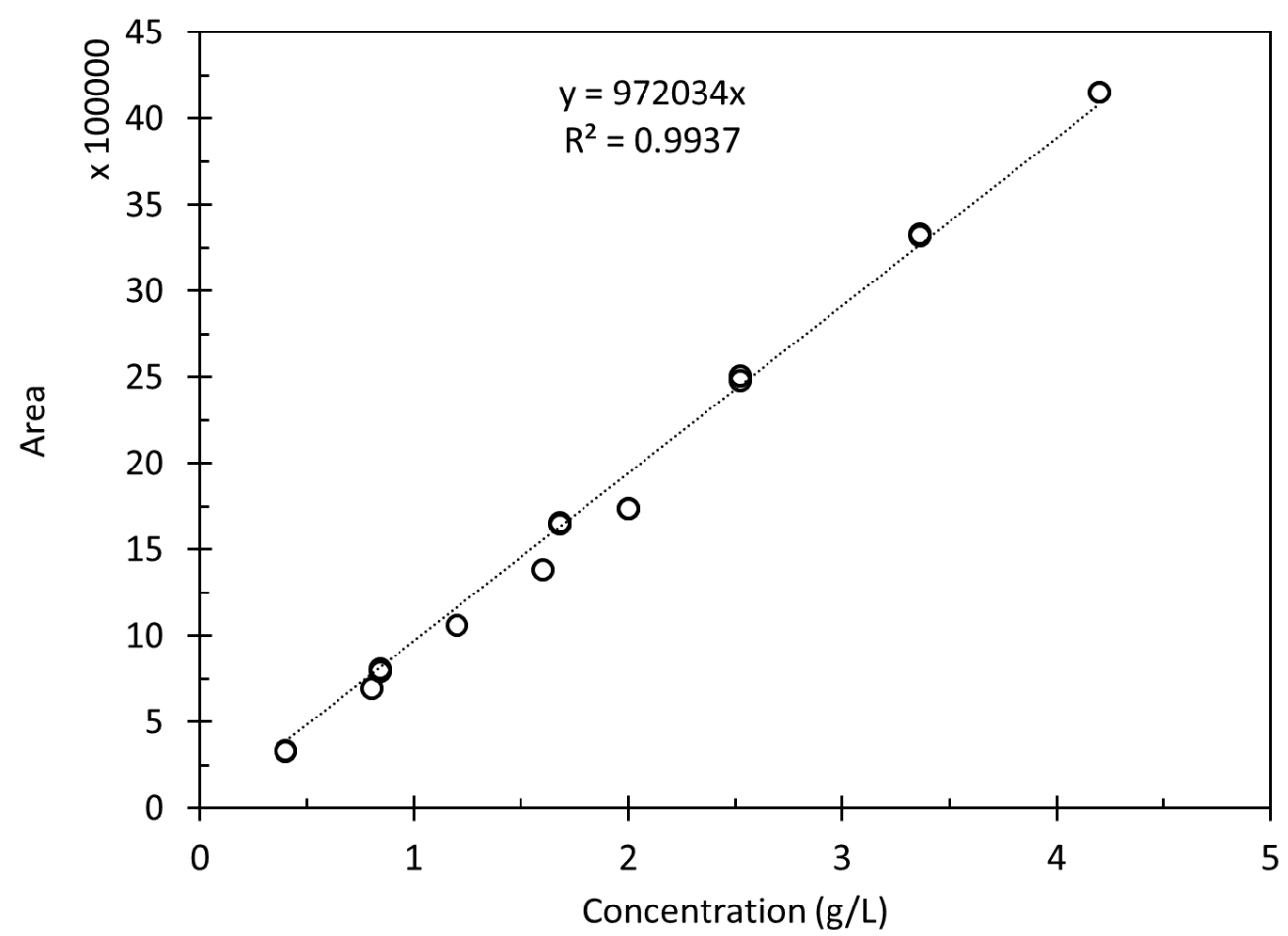

Figure E-2: Calibration curve of acetic acid. 


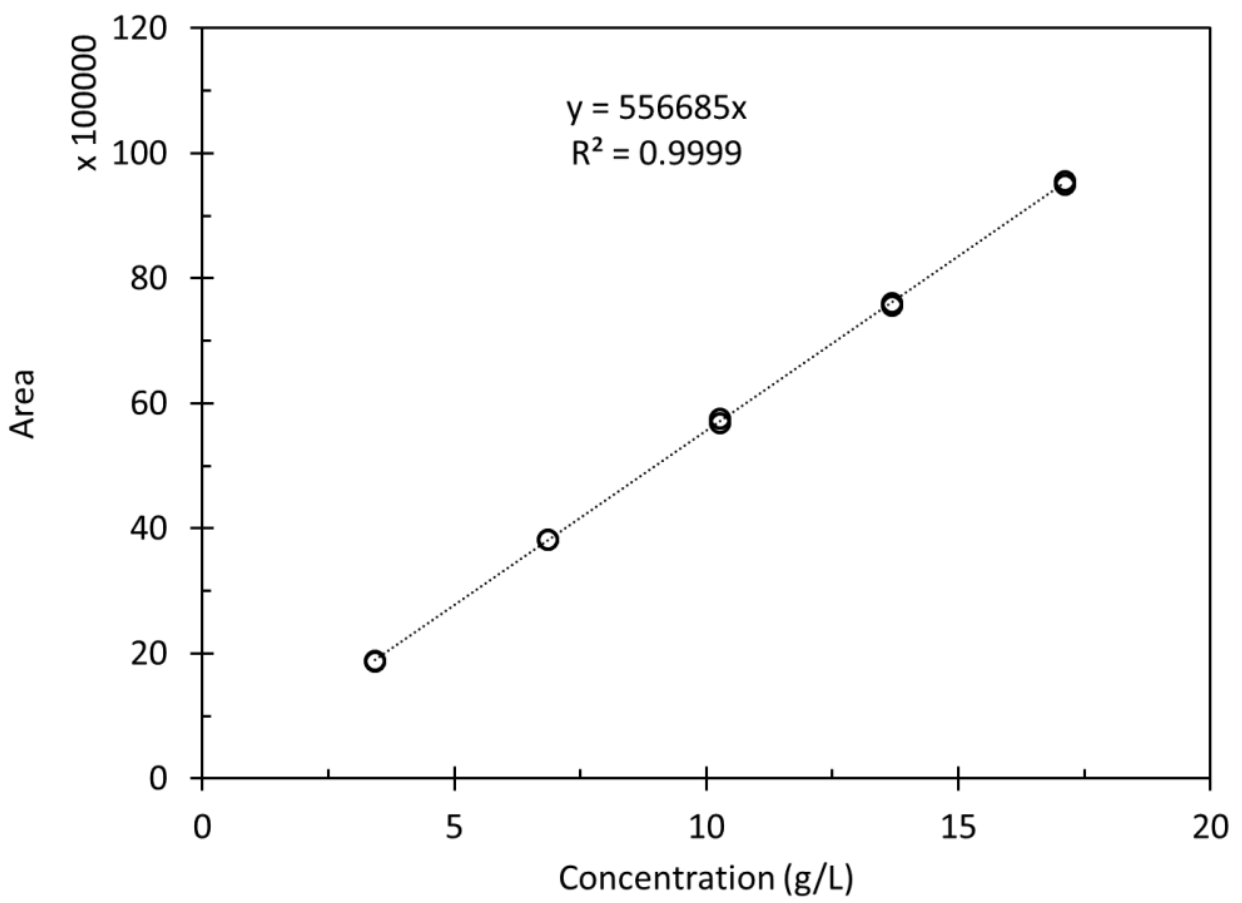

Figure E-3: Calibration curve for levulinic acid.

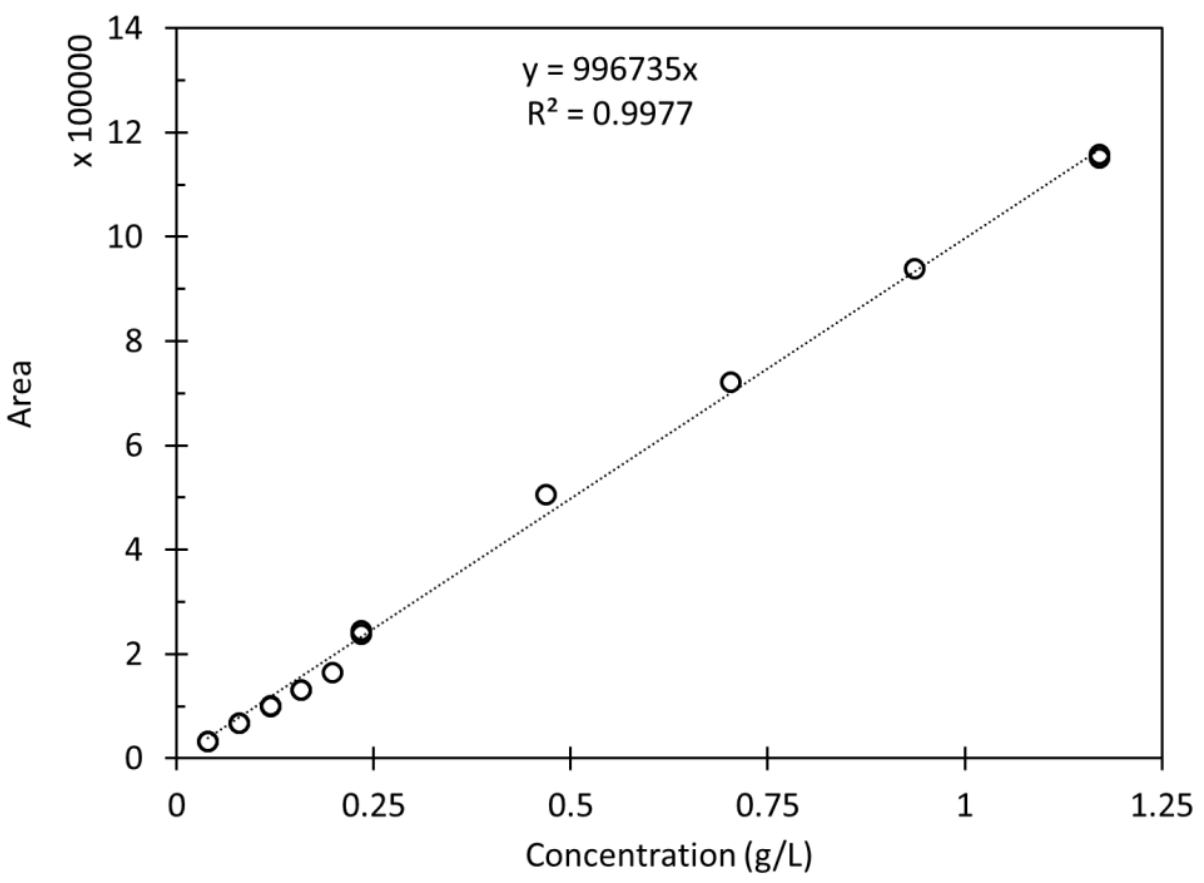

Figure E-4: Calibration curve used for glycolic acid. 


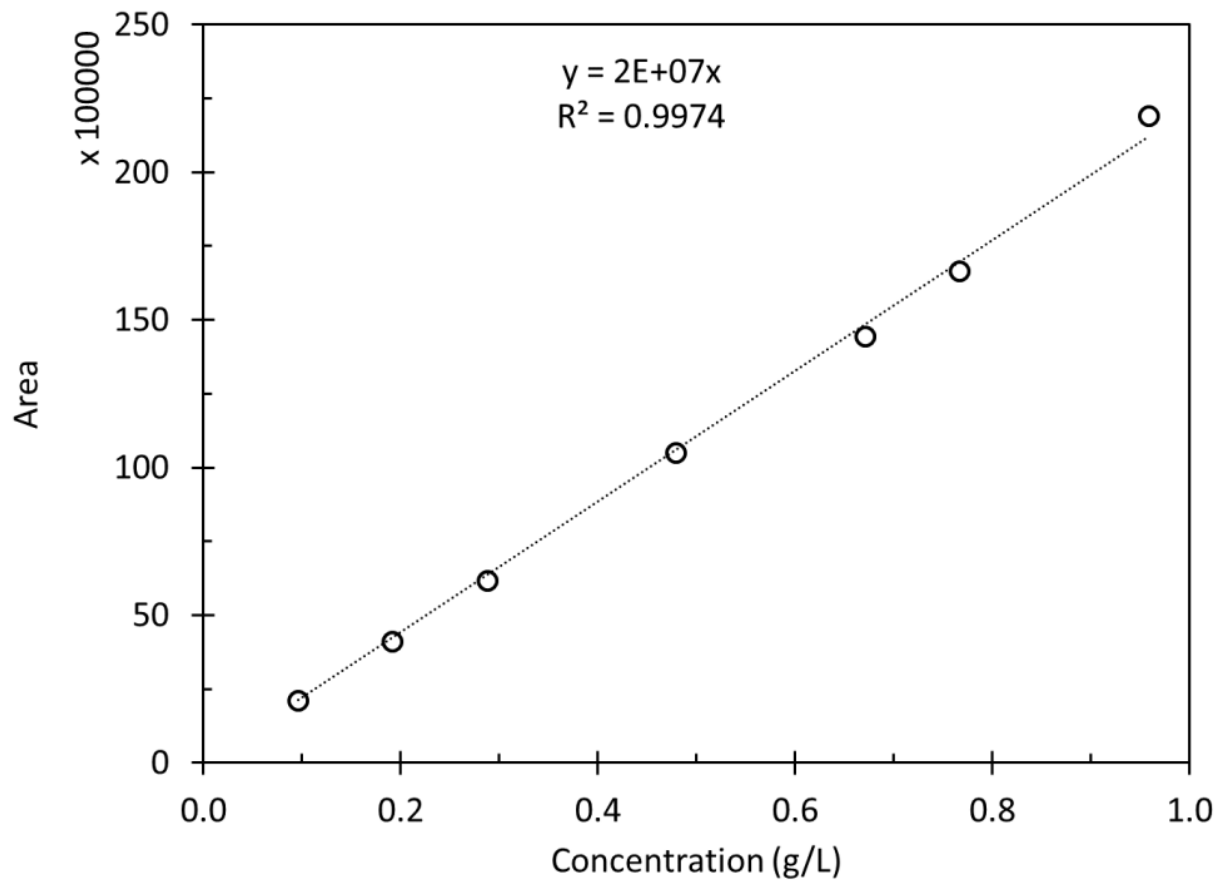

Figure E-5: Calibration curve for HMF.

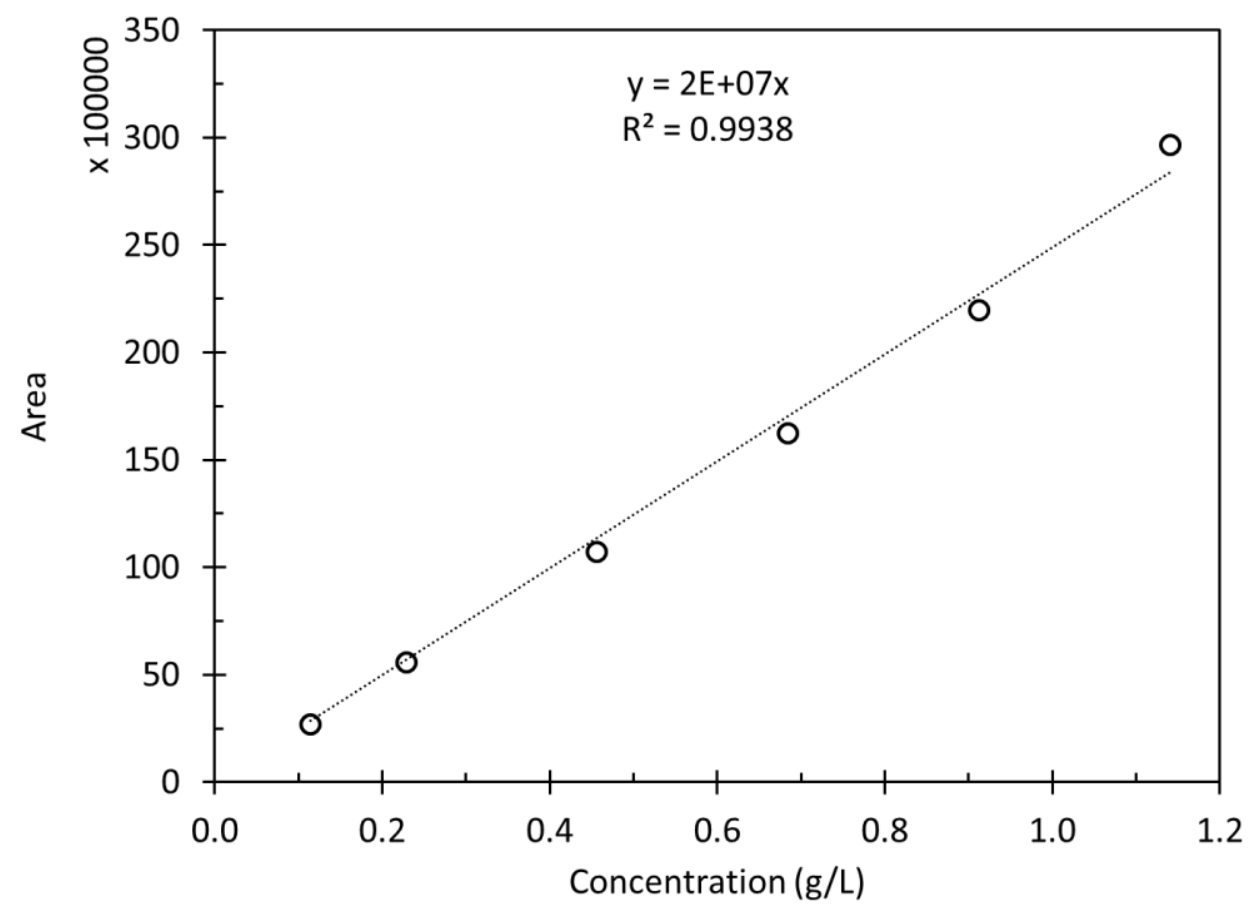

Figure E-6: Calibration curve for Furfural 